DANIEL SILVA COSTA

\title{
Variação do nível médio do mar - técnicas para a avaliação
}




\title{
DANIEL SILVA COSTA
}

\section{Variação do nível médio do mar - técnicas para a avaliação}

\author{
Dissertação apresentada à Coordena- \\ ção de Pós-Graduação em Engenharia \\ de Transportes da Escola Politénica da \\ Universidade de São Paulo para a ob- \\ tenção do título de Mestre em Enge- \\ nharia de Transportes. \\ Área de Concentração: \\ Engenharia de Transportes \\ Ênfase: \\ Informações Espaciais \\ Orientador: \\ Prof. Dr. Denizar Blitzkow
}

São Paulo 
Aos meus filhos Ana Clara e Daniel Tadeu. 


\section{Agradecimentos}

Agradeço a Deus pela sabedoria e por ensinar-me a cada dia por onde devo seguir;

à minha esposa Renata por todo amor e dedicação sempre presentes, à minha mãe e às minhas tias pelo apoio contante;

ao Prof. Dr. Denizar Blitzkow que foi mais do que um orientador durante todo o período desta pesquisa e sim, um verdadeiro amigo;

aos Profs. Nicola Pacileo Netto e Edvaldo Simões da Fonseca Jr. pelos conselhos e consideração;

aos funcionários do Laboratório de Topografia e Geodésia Adalberto e Arildo pelas inúmeras viagens a Cananéia;

aos professores Dr. Sílvio Rogério Correia de Freitas, Dr. Wladimir Schukowski, Dr. Afrânio Rubens de Mesquita, Dr. Jorge Luis Alves Trabanco e ao Dr. Carlos Augusto Sampaio França pelas colaborações;

ao Conselho Nacional de Desenvolvimento Científico e Tecnológico (CNPq) pela concessão de bolsa durante parte do meu curso;

à coordenação do curso de pós-graduação em Engenharia de Transportes e ao Instituto Oceanográfico pela ajuda financeira durante o meu estágio no Observatório Real da Bélgica, assim também como à empresa Alezi Teodolini pela concessão das passagens aéreas;

ao Prof. Dr. Bernard Ducarme e à Leslie Vandercoilden pela atenção com a qual me receberam e me trataram em Bruxelas e por tudo que me ensinaram na área das marés terrestres;

e, finalmente, aos amigos de curso Ana Cristina, Claudomiro Santos, Flávio Vaz, Ilce Campos, Maria Cristina Lobianco e Mário Alexandre de Abreu pelo apoio, pelos conselhos, pela companhia e pela troca de ensinamentos. 


\section{Resumo}

A variação do Nível Médio do Mar (NMM) é um assunto de grande importância para a sociedade, pois a sua elevação, que é verificada em diversas estações de monitoramento no mundo, pode trazer diversos prejuízos para o homem. Aponta-se como razão principal deste fenômeno a elevação da temperatura média do planeta causada pelo aumento da concentração dos Gases de Efeito Estufa (GEE). Em Cananéia, litoral sul do estado de São Paulo, o nível do mar vem sendo monitorado há mais de 50 anos através de um marégrafo. A estação também conta, desde o ano de 2002, com um receptor do Global Positioning System (GPS) cuja antena está instalada em um pilar adequado, engastado na rocha. Além disso, um gravímetro geodinâmico foi instalado junto à estação para, associado ao marégrafo e ao receptor GPS, contribuir para a determinação da variação absoluta do NMM, que representa a diferença entre os movimentos do nível do mar e da crosta. Com os dados maregráficos durante o período de 1954 a 2004 foi possível determinar um aumento relativo do NMM de 4,2 mm/ano, com a determinação de um modelo global de marés oceânicas que melhor se adaptou à região. A análise das observações gravimétricas permitiram a determinação de um modelo de maré terrestre para a estação, porém a deriva instrumental impediu a detecção de alguma tendência para a crosta. Já os resultados obtidos através do processamento das observações GPS entre os anos de 2004 e 2006 através do método Precise Point Positioning (PPP) determinaram um rebaixamento da crosta de $1,59 \mathrm{~mm} /$ ano. No entanto, este curto período de observações processadas impede que se conclua algo de definitivo sobre o movimento da crosta. 


\section{Abstract}

The Mean Sea Level (MSL) variation is very important for the society because its elevation, verified in many monitoring stations around the world, causes several damages for the humanity. It's pointed how principal reason of this phenomena the elevation of the world mean temperature due to greenhouse gases concentration increasing. At Cananéia, south coast of São Paulo, the sea level has been monitored for more than 50 years by a tide gauge. The station has since 2002 a GPS receiver whose antenna is installed in a stable pillar fixed in the bed rock. Moreover a geodynamic gravitymeter installed at the site of the station, out of the tide gauge and the GPS receiver, contributes for the determination of absolute variation of the MSL that represents the difference between the movement of the sea level and the crust. With tide gauge observations from 1954 to 2004 it was possible to find a relative increasing of MSL of $4.2 \mathrm{~mm} /$ year with the determination of the ocean tide model that best fit in the region. The analysis of gravimetric observations allowed the determination of an earth tide model but the instrumental drift hindered the detection of some crust tendency. However the results obtained by processing GPS observations between 2004 and 2006 by Precise Point Positioning showed a decrease of the crust of $1.59 \mathrm{~mm} /$ year. However, any definite conclusion on the crust movement need a longe period of observations with GPS. 


\section{Lista de Figuras}

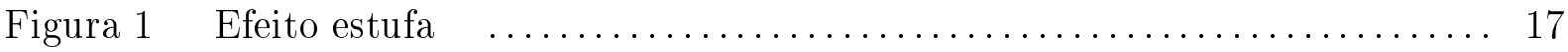

Figura 2 Variações da temperatura para a superfície da Terra $\ldots \ldots \ldots \ldots \ldots \ldots .17$

Figura 3 Série cronológica dos níveis relativos do mar durante os 300 últimos anos

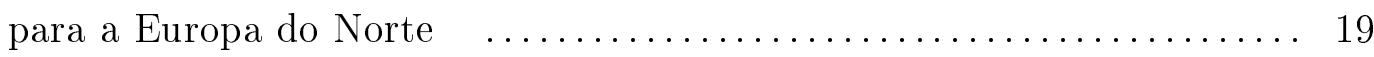

Figura 4 O comportamento do nível relativo do mar em Cananéia $\ldots . . \ldots \ldots . .20$

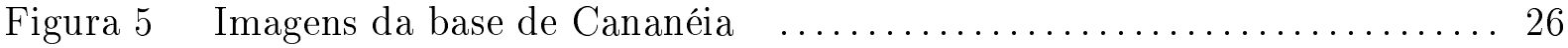

Figura 6 Imagens do abrigo de instalação do gravímetro $\quad \ldots \ldots \ldots \ldots \ldots \ldots \ldots \ldots$

Figura 7 Imagens do gravímetro e seu sistema de aquisição de dados $\ldots \ldots \ldots .27$

Figura 8 Posições da Terra e da Lua em movimento em torno do centro de massa do sistema durante o período de um mês lunar $\quad \ldots \ldots \ldots \ldots \ldots \ldots \ldots . \ldots 32$

Figura 9 Decomposição da rotação de um corpo rígido (a), rotação Kepleriana (b), rotação da Terra em torno de seu próprio eixo (c), caso do sistema TerraSol

Figura 10 Relação direta da força de maré (linha cheia) com a força gravitacional (linha pontilhada) e a força centrífuga (linha tracejada) $\ldots \ldots \ldots \ldots . \ldots 35$

Figura 11 Campo de força de maré $\quad \ldots \ldots \ldots \ldots \ldots \ldots \ldots \ldots \ldots \ldots \ldots \ldots \ldots \ldots \ldots \ldots \ldots \ldots \ldots$

Figura 12 Ponto $P$ em um sistema onde $\zeta$ é a distância zenital ao corpo celeste $M \quad 39$

Figura 13 Triângulo esférico para transformação de coordenadas de um sistema ter-

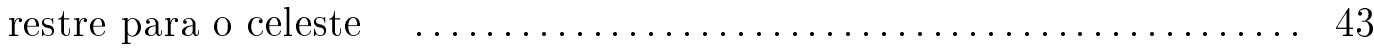

Figura 14 Interpretação geométrica das três famílias de ondas de maré $\ldots \ldots \ldots .44$

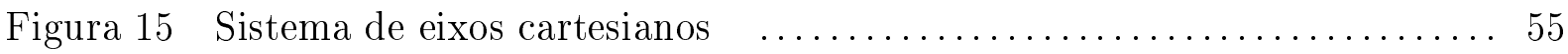

Figura 16 Resposta da Terra sólida e elática à força de maré $\quad \ldots \ldots \ldots \ldots \ldots \ldots \ldots$

Figura 17 Nível do mar registrado no marégrafo de Cananéia durante o ano de $1976 \quad 63$

Figura 18 Resíduos das ondas diurnas principais, em metros, durante o ano de $1976 \quad 64$

Figura 19 Resíduos das ondas semi-diurnas principais, em metros, durante o ano de 
Figura 20 Resíduos das ondas diurnas principais durante o ano de 1976, após a remoção de alguns intervalos

Figura 21 Resíduos das ondas semi-diurnas principais durante o ano de 1976, após a remoção de alguns intervalos

Figura 22 Comparação das amplitudes das ondas diurnas e semi-diurnas entre os dados de Cananéia e alguns modelos de maré oceânica

Figura 23 Comparação das fases das ondas diurnas e semi-diurnas entre os dados de Cananéia e alguns modelos de maré oceânica

Figura 24 Desvio médio quadrático, obtido a partir da diferença entre o vetor calcu-

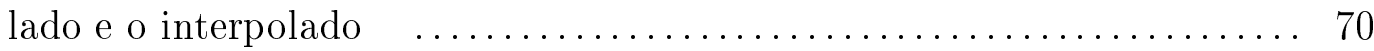

Figura 25 Ascenção do NMM ao longo dos 50 anos de coleta em Cananéia $\quad . . . .72$

Figura 26 Geometria de um gravímetro astatizado $\quad \ldots \ldots \ldots \ldots \ldots \ldots \ldots \ldots \ldots \ldots$

Figura 27 Características de torque para um sistema linear e para um sistema astatizado

Figura 28 Exemplo de um nível em um gravímetro e das posições usadas para de-

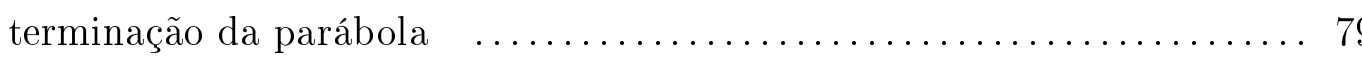

Figura 29 Registros gravimétricos brutos $\ldots \ldots \ldots \ldots \ldots \ldots \ldots \ldots \ldots \ldots \ldots \ldots \ldots \ldots \ldots \ldots \ldots \ldots$

Figura 30 Registros gravimétricos após correções $\quad \ldots \ldots \ldots \ldots \ldots \ldots \ldots \ldots \ldots \ldots \ldots$

Figura 31 Calibração aplicada ao instrumentro num período de quadratura $\ldots . .82$

Figura 32 Quatros pontos notáveis para o cálculo da calibração $\ldots \ldots \ldots \ldots \ldots . . .63$

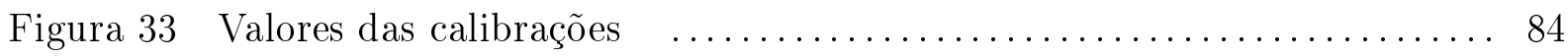

Figura 34 Dados gravimétricos após a conversão de Hertz em $\mu g a l \quad \ldots \ldots \ldots \ldots . .86$

Figura 35 Registros encontrados após a remoção do novo modelo definido $\ldots \ldots 88$

Figura 36 Registros antes e após a remoção do efeito de carga oceânica utilizando dados do modelo FES95

Figura 37 Registros antes e após a remoção do efeito de carga oceânica utilizando as observações da própria estação

Figura 38 Espectro para os resíduos e carga oceânica calculada a partir do modelo FES95 na região de freqüência semi-diurna $\ldots \ldots \ldots \ldots \ldots \ldots \ldots \ldots$ 
Figura 39 Espectro para os resíduos e carga oceânica calculada a partir do modelo FES95 na região de freqüência diurna $\ldots \ldots \ldots \ldots \ldots \ldots \ldots \ldots \ldots \ldots \ldots$

Figura 40 Espectro para os resíduos e carga oceânica calculada a partir das observações maregráficas na região de freqüência semi-diurna $\ldots \ldots \ldots \ldots . . \ldots 92$

Figura 41 Espectro para os resíduos e carga oceânica calculada a partir das observações maregráficas na região de freqüência diurna $\ldots \ldots \ldots \ldots \ldots \ldots 92$

Figura 42 Altitude geométrica da estação Cananéia para $2004 \quad$. . . . . . . . . . . . 94

Figura 43 Altitude geométrica da estação Cananéia para $2005 \quad \ldots \ldots \ldots \ldots \ldots \ldots . \ldots 4$

Figura 44 Altitude geométrica da estação Cananéia para $2006 \quad \ldots \ldots \ldots \ldots \ldots \ldots$...... 95

Figura 45 Comportamento da altitude geométrica em Cananéia entre os anos de

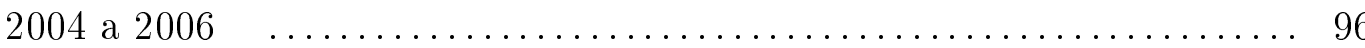




\section{Lista de Tabelas}

Tabela 1 Estimativas de volume dos parâmetros do balanço hidrológico mundial 22

Tabela 2 Exemplos de determinação do número de Doodson $\ldots \ldots \ldots \ldots \ldots \ldots . .52$

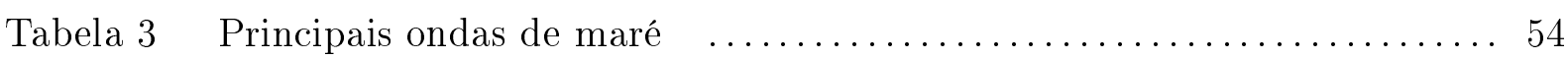

Tabela 4 Argumentos trigonométricos das três famílias de maré $\ldots \ldots \ldots \ldots \ldots .55$

Tabela 5 Amplitudes máximas para uma Terra rígida. $\quad \ldots \ldots \ldots \ldots \ldots \ldots \ldots \ldots . \quad 57$

Tabela 6 Amplitudes máxima para uma Terra elástica $\quad \ldots \ldots \ldots \ldots \ldots \ldots \ldots \ldots$. 61

Tabela 7 Modelos de maré oceânica utilizados neste trabalho, suas respectivas re-

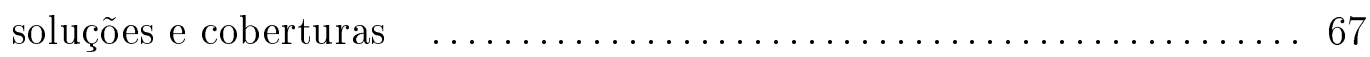

Tabela 8 Componentes calculadas de maré oceânica para a estação de Cananéia $\quad 67$

Tabela 9 Comparativo para as componentes principais de maré oceânica para a estação de Cananéia entre os valores calculados e os obtidos a partir de

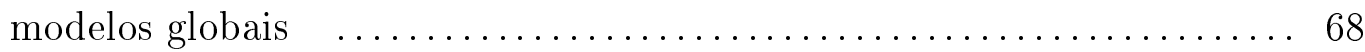

Tabela 10 Valores de diferença RMS entre os modelos de maré oceânica e o valor

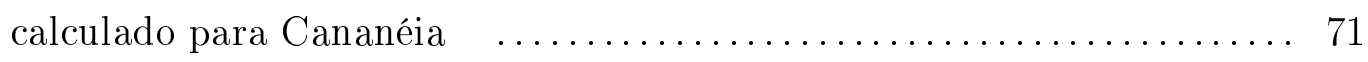

Tabela 11 Valores calculados para as calibrações efetuadas na estação de Cananéia 85

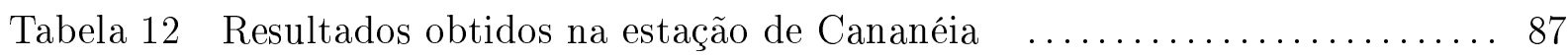

Tabela 13 Valores de carga oceânica obtidas a partir do modelo FES95 ….... 88

Tabela 14 Valores de carga oceânica obtidas a partir das observações maregráficas 89 


\section{Lista de Siglas}

$\begin{array}{ll}\text { NMM } & \text { Nível Médio do Mar } \\ \text { GEE } & \text { Gases de Efeito Estufa } \\ \text { GPS } & \text { Global Positioning System } \\ \text { PPP } & \text { Precise Point Positioning } \\ \text { IPCC } & \text { International Panel of Climate Change } \\ \text { IOUSP } & \text { Instituto Oceanográfico da Universidade de São Paulo } \\ \text { CSRS } & \text { Canadian Spatial Reference System } \\ \text { IOUSP } & \text { Instituto Oceanográfico da Universidade de São Paulo } \\ \text { GLOSS } & \text { The Global Sea Level Observing System } \\ \text { IBGE } & \text { Instituto Brasileiro de Geografia e Estatística } \\ \text { RBMC } & \text { Rede Brasileira de Monitoramento Contínuo } \\ \text { AIC } & \text { Akaike Information Criterion } \\ \text { RMS } & \text { Root Mean Square } \\ \text { FFT } & \text { Fast Fourier Transformer } \\ \text { ITRF } & \text { International Terrestrial Reference Frame } \\ \text { IGS } & \text { International GNSS Service }\end{array}$




\section{Sumário}

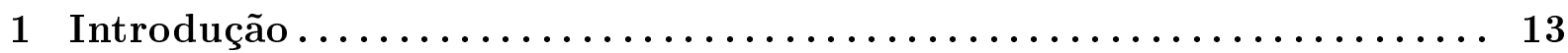

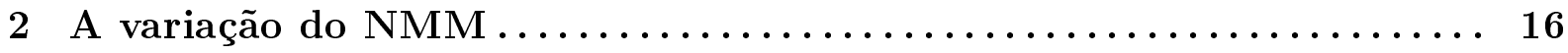

2.1 O aumento da temperatura média global . . . . . . . . . . . . . . . 16

2.2 O aumento recente do $\mathrm{NMM} \ldots \ldots \ldots \ldots \ldots \ldots$

2.3 As causas da variação do nível do mar . . . . . . . . . . . . . . . . . . 21

2.4 Conseqüências do aumento do NMM . . . . . . . . . . . . . . . . 23

2.5 A base "Dr. João Paiva de Carvalho" do IOUSP . . . . . . . . . . . . . . . . 25

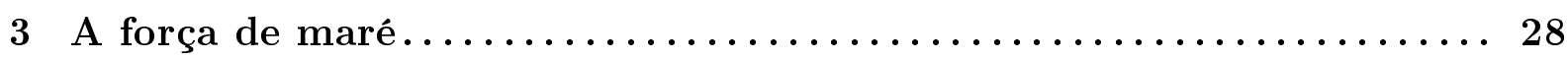

3.1 Introdução . . . . . . . . . . . . . . . . . . . 28

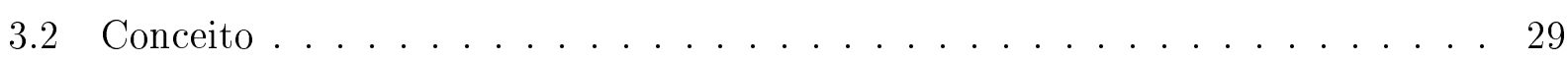

3.3 Avaliação numérica . . . . . . . . . . . . . . . . . . . . 37

3.4 Potencial de maré . . . . . . . . . . . . . . . . . . . . . . . 39

3.5 Representação do potencial de maré . . . . . . . . . . . . . . . . . . 42

3.5.1 O desenvolvimento de Laplace . . . . . . . . . . . . . . . . . . . 42

3.5.2 O desenvolvimento harmônico . . . . . . . . . . . . . . 45

3.5.3 As ondas semi-diurnas . . . . . . . . . . . . . . . 47

3.5.4 As ondas diurnas . . . . . . . . . . . . . . . . . . . 49

3.5.5 As ondas de longo período . . . . . . . . . . . . . . 51

3.5.6 Sistema de classificação para as ondas de maré . . . . . . . . . . . 51

3.6 Cálculo da magnitude do fenômeno de maré . . . . . . . . . . . . . 53 
3.7 Deformações elásticas da Terra devido aos efeitos da força de maré . . . . . . 57

4 Processamento e análise dos dados de nível do mar........... 62

4.1 Introdução . . . . . . . . . . . . . . . . . . . . . 62

4.2 Pré-processamento das observações . . . . . . . . . . . . . . . . . . . . . 63

4.3 Comparação entre modelos de maré oceânica . . . . . . . . . . . . . . . . . . 65

4.4 Variação relativa do NMM . . . . . . . . . . . . . . . . . . 71

5 Resultados derivados na estação Cananéia $\ldots \ldots \ldots \ldots \ldots \ldots \ldots \ldots \ldots$

5.1 O gravímetro astatizado e o seu comportamento instrumental . . . . . . . 73

5.2 Pré-processamento dos dados gravimétricos . . . . . . . . . . . . . . . . 80

5.3 Processamento das observações gravimétricas . . . . . . . . . . . . . 86

5.4 Resultados obtidos com o uso do GPS . . . . . . . . . . . . . . . . . 93

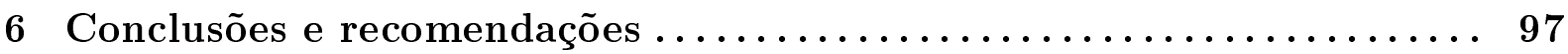

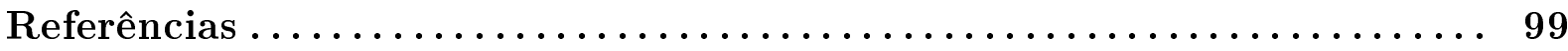




\section{Introdução}

O comportamento do nível do mar chama cada vez mais a atenção de toda a sociedade uma vez que a sua elevação pode causar sérios danos em todo o planeta. Alguns efeitos já estão surgindo e geram preocupação.

A elevação da temperatura média do planeta tem conseqüência direta e indireta no aumento do NMM. Diretamente, devido à expansão térmica nas camadas superficiais dos oceanos; indiretamente, como fruto do derretimento das geleiras continentais que aumentam a massa de água. A elevação da temperatura média do planeta, verificada desde o início da revolução industrial (séc. XIX), está correlacionada com o aumento da concentração dos GEE (IPCC, 2001). Atualmente, as possíveis conseqüências do aumento do NMM já são visíveis. Os prejuízos abrangem a ocupação territorial costeira com a inundação de cidades e vilas, a fauna marinha com a extinção de espécies que vivem nos manguezais e o clima com a presença cada vez mais freqüente de fenômenos devastadores, como os furacões e tempestades tropicais. Estes são apenas alguns exemplos que demonstram a importância multidisciplinar deste tema.

O relatório do International Panel of Climate Change (IPCC) (IPCC, 2001) trouxe previsões alarmantes a este respeito. Prevê-se, no mínimo, uma elevação média do NMM de 48 centímetros até o fim deste século. Esta previsão é de uma elevação relativa, ou seja, é desconsiderado o movimento da crosta. Ela está baseada em dados maregráficos e de altímetros instalados em satélites, como foi a missão espacial TOPEX/POSEIDON e atualmente o JASON. O IPCC publicou recentemente novos relatórios que confirmam as previsões feitas anteriormente. 
O Capítulo 2 desta dissertação retrata a importância do estudo da variação do NMM e suas conseqüencias. Neste trabalho foram utilizados os dados maregráficos, gravimétricos e de receptores GPS referentes à base "Dr. João Paiva de Carvalho" localizada em Cananéia, litoral sul do estado de São Paulo, integrante do Instituto Oceanográfico da Universidade de São Paulo (IOUSP).

Toda a massa que compõe a Terra está sujeita à ação de forças gravitacionais exercidas por outros corpos celestes que mudam continuamente o campo de gravidade terrestre. Dentre elas, a força de maré é a principal e causa deformações verticais, horizontais e declinacionais à crosta. A sua relação com o tema deste trabalho exige uma explanação sobre o assunto. Desta forma, o estudo da teoria das marés, ou seja, um breve histórico, a definição das principais ondas e o cálculo teórico da deformação resultante sobre a crosta são encontrados no Capítulo 3.

A elevação relativa do NMM foi encontrada a partir das observações maregráficas na base de Cananéia. Os maregráfos registram continuamente a posição do nível do mar em relação a uma determinada referência. Para obter um valor que indique a tendência relativa do NMM foi necessário preparar, processar e analisar estas observações. A partir da análise destes dados definiu-se os componentes, amplitude e fase, das principais ondas, além do valor de tendência de elevação. Com a comparação entre estes valores encontrados e os modelos teóricos de maré oceânica, foi possível determinar qual dentre deles melhor se adaptou à região. Este é o assunto do Capítulo 4.

O estudo das observações contínuas de um gravímetro em uma estação pode contribuir e completar as análises do capítulo anterior. Da mesma forma que nas observações maregráficas, é necessário preparar, processar e analisar os dados coletados. Num primeiro instante, obteve-se a amplitude e a fase para as principais ondas, o que resultou em um novo conjunto de valores que determinam o efeito gravimétrico de maré terrestre para a região. Removendo este efeito dos dados brutos, encontrou-se um sinal que contém, dentre outros, os resíduos meteorológicos. A partir deste sinal determinou-se o efeito de 
carga oceânica baseando-se tanto em valores calculados a partir do modelo de maré que melhor se adaptou à região, encontrado no capítulo anterior, quanto nos valores calculados a partir dos dados maregráficos. Novos resíduos foram encontrados a partir da remoção do efeito gravimétricos de carga oceânica. No entanto, eles não permitiram avaliar uma tendência de movimentação da crosta. Uma outra forma de avaliar este movimento é o processamento das observações de receptores GPS instalados próximos aos marégrafos. Esta análise foi realizada para o receptor instalado na base de Cananéia. Utilizou-se para tal, o processamento automático fornecido pela agência canadense Canadian Spatial Reference System (CSRS) através da internet. Os resultados forneceram um valor que confirmou a tendência da crosta durante o período de observações coletadas. Este é o assunto do Capítulo 5.

De posse de todos os resultados obtidos a partir de elementos diferentes, concluiuse a respeito da variação absoluta do NMM e das contribuições que estes trouxeram para a pesquisa, além de algumas recomendações para o seu prosseguimento (Capítulo 6). 


\section{A variação do NMM}

\subsection{O aumento da temperatura média global}

De acordo com o relatório do IPCC (IPCC, 2001), a temperatura média global está aumentando em conseqüência, principalmente, da elevação da concentração dos GEE e dos aerosóis ${ }^{1}$ na atmosfera. Entre o período de 1990 a 2100, está prevista uma elevação na temperatura média global de $1,4^{\circ} \mathrm{C}$ a $5,8^{\circ} \mathrm{C}$.

Os GEE podem ser naturais ou não. Eles estão situados ao longo de toda a atmosfera e são fundamentais para que haja um equilíbrio térmico sobre o planeta. Eles atuam, principalmente, sobre os raios infravermelhos. Quando a radiação solar incide sobre a camada composta pelos GEE, parte dela é refletida para o espaço. Da fração que incide sobre a Terra, parte é absorvida e a outra refletida. Esta parcela de energia refletida incide sobre a camada dos GEE novamente que faz o mesmo papel quando da incidência da radiação solar, reflete uma parte para a Terra e libera a outra para o espaço. Um aumento na concentração dos GEE causa uma maior reflexão da energia irradiada da Terra, a qual retorna à superfície. A Figura 1 ilustra este efeito para uma determinada parcela desta camada. Dentre estes gases, pode-se citar como principais o vapor d'água $\left(\mathrm{H}_{2} \mathrm{O}\right)$, o dióxido de carbono $\left(\mathrm{CO}_{2}\right)$, o óxido nitroso $\left(\mathrm{N}_{2} \mathrm{O}\right)$, o metano $\left(\mathrm{CH}_{4}\right)$ e o ozônio $\left(O_{3}\right)$.

Desde o início da revolução industrial houve um aumento constante na queima de combustíveis fósseis elevando conseqüentemente a concentração de gás carbônico na

\footnotetext{
${ }^{1}$ Conjunto de partículas sólidas e líquidas em suspensão no ar cuja dimensão encontra-se entre 0,01 e $10 \mu \mathrm{m}$.
} 


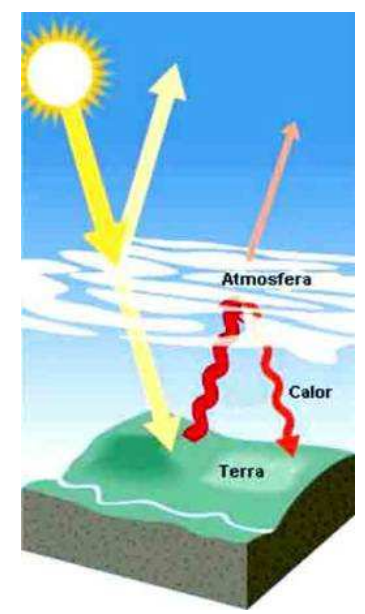

Figura 1: Efeito estufa (Fonte:

http://www.cp.ufmg.br/Clube_de_Ciencias/o_efeito_estufa_e_as_geleiras.htm)

atmosfera. Além disso, já no último século, o aumento do uso de aerosóis e de CFC's (clorofluorcarbonetos) em equipamentos de refrigeração tem contribuído para um aumento da concentração dos GEE. Segundo IPCC (2001), entre os anos de 1861 e 2000, a temperatura da superfície da Terra elevou-se em $0,6^{\circ} \mathrm{C} \pm 0,2^{\circ} \mathrm{C}$ (Figura 2).

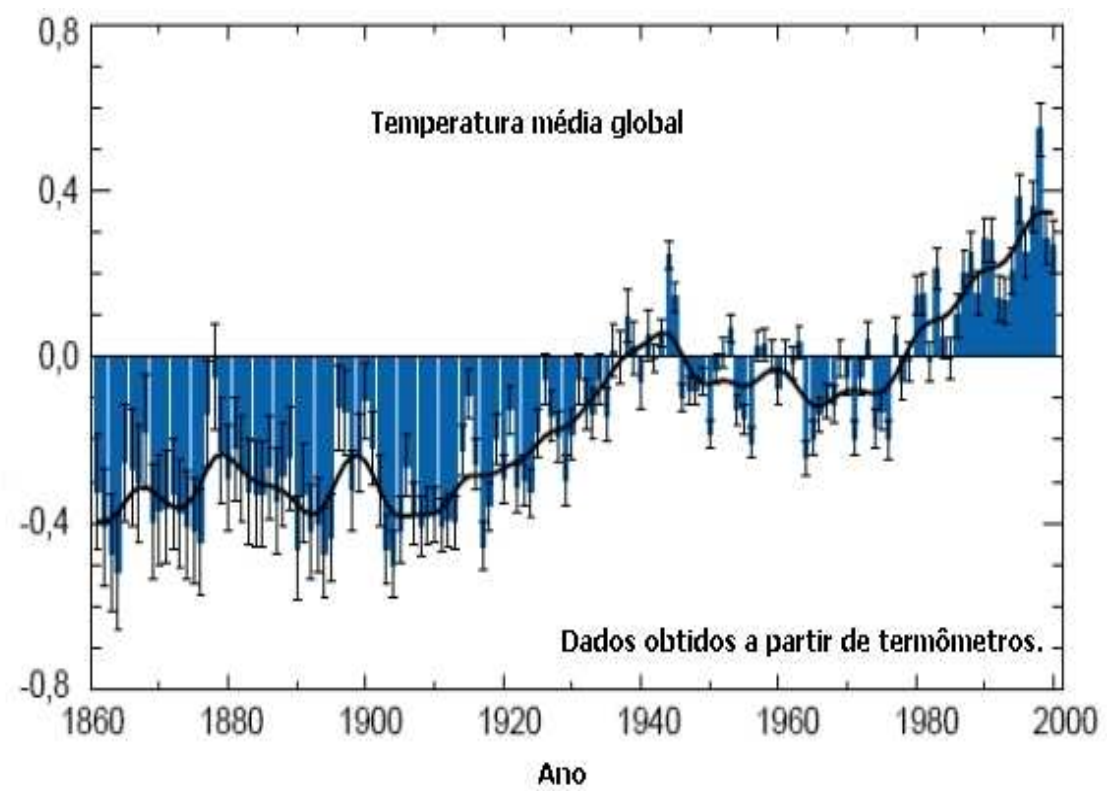

Figura 2: Variações da temperatura para a superfície da Terra (Fonte: IPCC (2001))

A importância deste assunto, aliada à evolução tecnológica que vem permitindo um número crescente de observações diretas e mais precisas das grandezas envolvidas nesta questão, faz com que novas pesquisas sejam realizadas trazendo melhores resultados e previsões. Como exemplo, as medições de temperatura da superfície terrestre e dos 
oceanos vêm sendo realizadas e ajustadas separadamente. Os resultados, em ambos os casos, mostram um aquecimento bem acentuado em dois períodos: 1910 a 1945 e 1976 aos dias de hoje. Em outra situação, as medições realizadas através de balões meteorológicos indicam que a temperatura na troposfera vem aumentando desde 1958, sendo que, em 1979, este aumento tornou-se mais relevante, e os dados obtidos a partir de missões orbitais confirmam esta tendência.

Outro fator observado é a diminuição da amplitude térmica² nas regiões continentais, que coincide com um aumento da temperatura média nestas regiões. Este fenômeno traz como conseqüência um aumento de nebulosidade, de pluviosidade e de concentração do vapor d'água na atmosfera, o que gera uma incidência maior de fenômenos meteorológicos como as tempestades tropicais, que causam destruição e inundações (PIRAZZOLI, 1996).

Um indício do aumento da temperatura média é a diminuição das áreas ocupadas pelas geleiras e pelo gelo sazonal que se forma nos pólos, denominado nesta dissertação como calota polar, que vem sendo constatada em diversas regiões do planeta. O derretimento das geleiras pode, além das outras tendências mencionadas, justificar o aumento do NMM relativo que vem ocorrendo constantemente em boa parte das estações onde é realizado o seu monitoramento.

Nos últimos anos, a sociedade tem dado uma importância maior ao aumento da temperatura média do planeta uma vez que suas conseqüências são prejudiciais a toda humanidade. Porém, independente do que vem sendo feito para minimizar o aquecimento global, muitas de suas conseqüências são consideradas irreversíveis.

\section{$2.2 \quad \mathrm{O}$ aumento recente do NMM}

Desde a última era glacial há cerca de 20.000 anos, o nível do mar elevou-se mais de 120 metros em conseqüência do aumento do volume da massa de água nos oceanos,

\footnotetext{
${ }^{2}$ Diferença entre a temperatura mínima e a máxima durante um determinado período de tempo.
} 
além de outros fatores como a variação crustal e a variação térmica dos oceanos. Em função desta redistribuição de massas ainda hoje constatam-se movimentos verticais da crosta terrestre. A ascensão mais rápida do nível do mar numa escala global ocorreu entre 15.000 e 6.000 anos antes de nossa era, na taxa média aproximada de $10 \mathrm{~mm} /$ ano. De acordo com dados geológicos, a ascensão eustática do nível de mar (que corresponde a uma variação do volume dos oceanos) ocorreu nos intervalos médios de 0,1 a $0,2 \mathrm{~mm} / \mathrm{ano}$ durante os últimos 3.000 anos. Esta taxa é aproximadamente 10 vezes mais baixa do que aquela observada no século XX. Durante os últimos 3.000 a 5.000 anos, as oscilações do NMM provavelmente não excederam 0,3 a 0,5 metros (PIRAZZOLI, 1996).

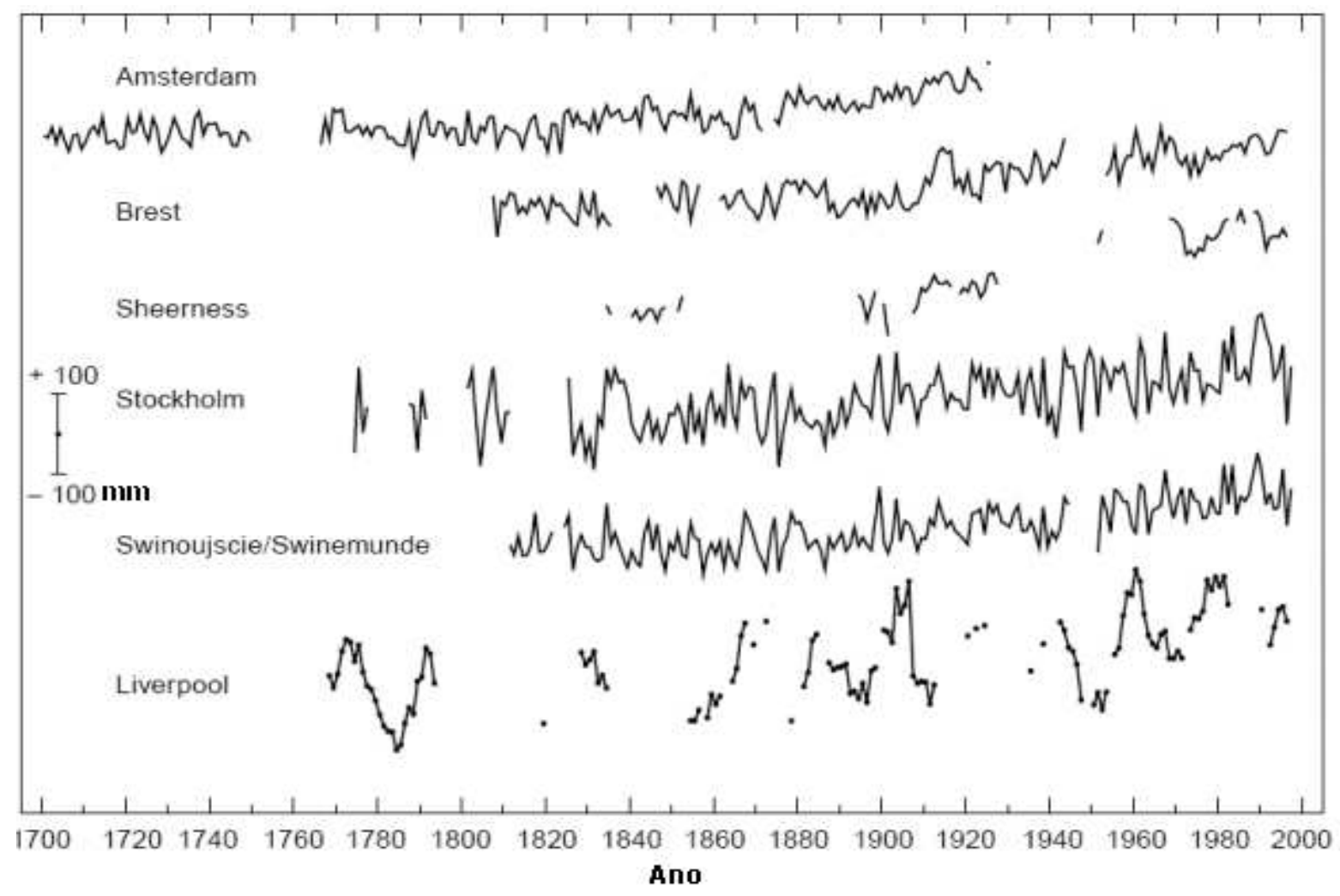

Figura 3: Série cronológica dos níveis relativos do mar durante os 300 últimos anos para a Europa do Norte (Fonte: IPCC (2001))

Durante o século XX, de acordo com os dados maregráficos, o NMM elevou-se de 1,0 a 2, $0 \mathrm{~mm} /$ ano, sendo o valor médio estabelecido de 1,5 mm/ano (IPCC, 2001). De acordo com estes dados, a taxa de ascensão no nível de mar foi mais elevada no século XX do que no século XIX. A Figura 3 ilustra o comportamento dos níveis relativos do mar para algumas estações do norte europeu. Já a Figura 4 retrata o comportamento na 
estação de Cananéia.

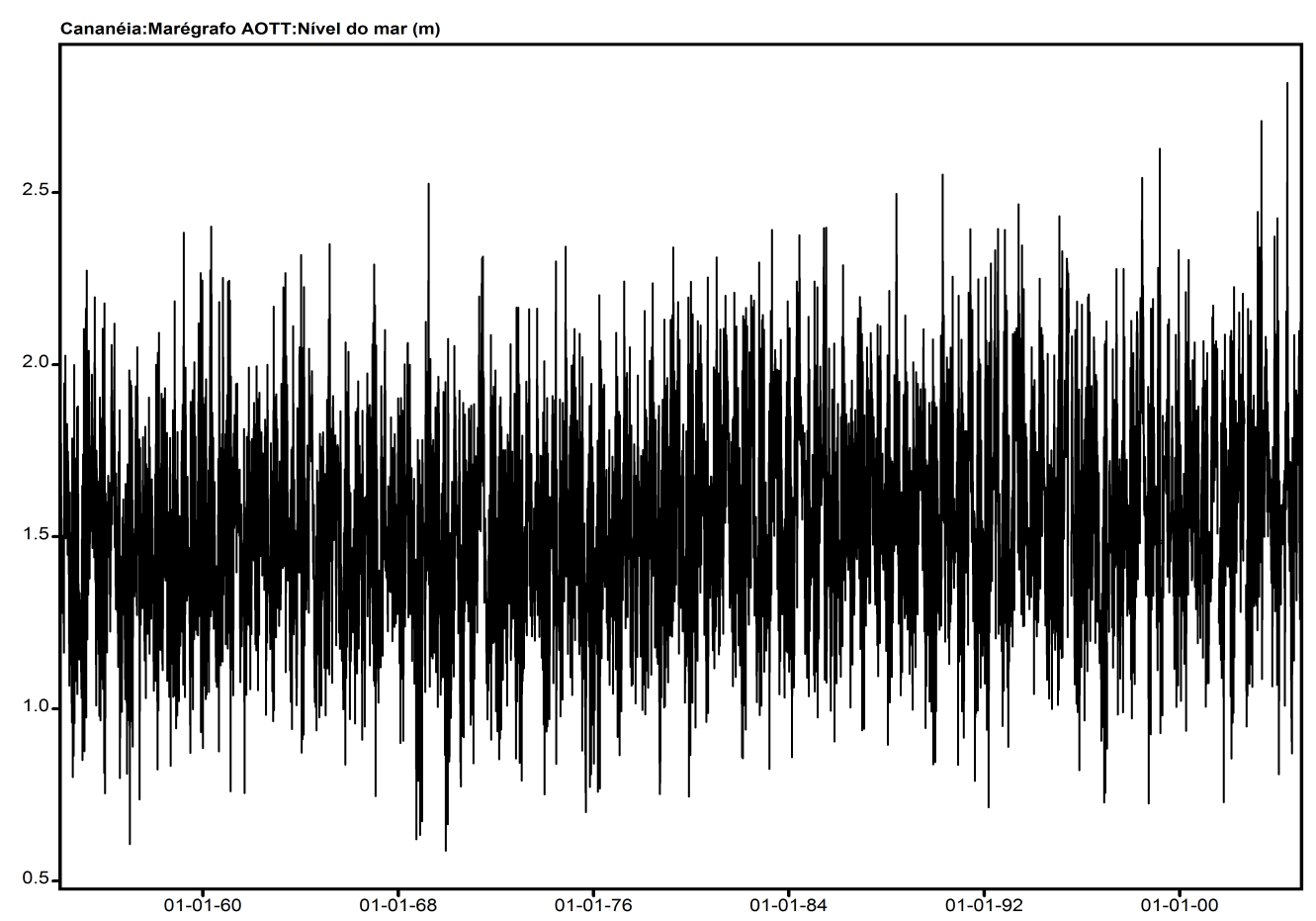

Figura 4: O comportamento do nível relativo do mar em Cananéia

As projeções médias para a elevação do nível do mar entre 1990 e 2100 estão entre 0,11 e 0,77 metros e os principais fatores que contribuem para esta ascenção são (IPCC, 2001):

- a expansão térmica dos mares que pode variar de 0,11 a 0,43 metros e tende a aumentar no presente século;

- a contribuição devido ao derretimento das geleiras continentais que pode vir a representar uma variação de 0,01 à 0,23 metros;

- a contribuição devido ao derretimento das calotas polares da Groelândia que pode chegar a 0,09 metros;

- a contribuição devido ao derretimento das calotas polares da Antártica que pode atingir 0,02 metros. 
As incertezas nas contribuições citadas refletem que ainda não há precisão nos modelos utilizados que simulam tais projeções, mas todos indicam um aumento do NMM numa escala global. Além do mais, os movimentos da crosta terrestre, de origem isostática ou tectônica, ocorrerão neste século, independente das mudanças climáticas que farão com que a massa oceânica aumente.

\subsection{As causas da variação do nível do mar}

O nível do mar encontra-se em constante variação e a determinação do seu valor médio envolve diversos fatores de conjuntura global que agem em escalas de tempo diferentes, desde algumas horas como as marés (terrestres, oceânicas e atmosféricas), até alguns milhares ou milhões de anos como a modificação de uma bacia oceânica sob ação de movimentos tectônicos e de sedimentação. Certamente, em uma escala de tempo menor, os principais fatores que influenciam estão ligados às variações climáticas. Porém, quando, durante um determinado período de tempo, movimentos aleatórios e periódicos são removidos, um valor estável é obtido: o NMM.

A água que compõe o oceâno possui propriedades físicas e químicas importantes para o estudo em questão como a densidade, a salinidade, a temperatura e a pressão. Tais variáveis, ao sofrerem alterações, modificam o volume de massa oceânica, em razão da relação que existe entre elas; a densidade d'água do mar depende da salinidade, da temperatura e da pressão. Ela diminui quando a temperatura aumenta, e aumenta com a elevação da salinidade e da pressão. Esta, por sua vez, aumenta com a profundidade. Quanto menor a densidade d'água, maior será o volume por ela ocupado. Logo, um decréscimo em sua densidade causa um aumento do nível do mar. Se a temperatura d'água tivesse um aumento médio de $1^{\circ} \mathrm{C}$ sobre uma camada de 4000 metros, produziria um aumento no nível de $60 \mathrm{~cm}$. Da mesma forma, uma variação de $0,4 \%$ na salinidade faria este mesmo efeito.

Segundo IPCC (2001), a expansão térmica aparece como uma das principais cau- 
sas das variações históricas do nível do mar e deverá representar um papel primordial na sua elevação no decorrer deste século. Este efeito se dará mais rapidamente nas camadas superficiais dos oceanos. Nas camadas mais profundas, onde a temperatura varia muito lentamente, a expansão térmica ocorrerá ao longo de vários séculos em função da transferência de calor.

Além dos fatores citados anteriormente, a circulação oceânica e o regime de ventos também contribuem para a variação do nível do mar. Desta forma, como cada região possui características próprias, haverá uma divisão geográfica daquele nível. As variações regionais possuirão amplitudes superiores e inferiores em relação à elevação média do NMM numa escala global. Haverá regiões onde o NMM aumentará e outras onde ele diminuirá.

O nível do mar também varia a partir de alterações na quantidade da água oceânica, que é representada através do seu balanço hidrológico. A equação que define este balanço mundial é expressa por $A+O+L+R+M+B+U+I=K$, onde $K$ é um valor constante e representa toda a água existente no planeta. A Tabela 1 apresenta o significado de cada componente da equação e seus valores estimados.

\begin{tabular}{llll}
\hline \hline & Parâmetro & Volume $\left(\mathrm{km}^{3}\right)$ & $\begin{array}{l}\text { Espessura de água equiva- } \\
\text { lente }\end{array}$ \\
\hline \hline A & Água atmosférica & 13.000 & $36 \mathrm{~mm}$ \\
O & Oceanos e mares & $1.375 \times 10^{6}$ & $3,8 \mathrm{~km}$ \\
$\mathbf{L}$ & Lagos e reservatórios & 125.000 & $35 \mathrm{~cm}$ \\
$\mathbf{R}$ & Rios e canais & 1.700 & $5 \mathrm{~mm}$ \\
$\mathbf{S}$ & Pântanos & 3.600 & $10 \mathrm{~mm}$ \\
$\mathbf{B}$ & Água biológica & 700 & $2 \mathrm{~mm}$ \\
$\mathbf{M}$ & Mistura em solos e zo- & 65.000 & $18 \mathrm{~cm}$ \\
& nas insaturadas & & \\
U & Água subterrânea & $4 \times 10^{6}-60 \times 10^{6}$ & $11-166 \mathrm{~m}$ \\
$\mathbf{I}$ & Água congelada & $32,5 \times 10^{6}$ & $90 \mathrm{~m}$ \\
\hline \hline
\end{tabular}

Tabela 1: Estimativas de volumes dos parâmetros do balanço hidrológico mundial (Fonte: Pirazzoli (1996))

\footnotetext{
${ }^{a}$ Usando uma área de superfície oceânica de $361,3 \times 10^{6} \mathrm{~km}^{2}$
}

A principal reserva de água continental é constituída pelas geleiras e pelas calotas 
polares. Estas reservas se devem à última era glacial $^{3}$, época na qual o nível do mar sofreu um decréscimo da ordem de uma a duas centenas de metros. Podia-se esperar que o derretimento deste material fosse a principal razão de uma elevação do nível do mar. Porém, boa parte deste estoque d'água encontra-se na Antártica e na Groelândia, regiões muito frias, e que possuem um baixo ritmo de derretimento durante as glaciações. Portanto, prevê-se que esta contribuição será pequena no decorrer deste século, justificando uma maior contribuição por parte da expansão térmica da massa oceânica.

A questão do aumento do NMM precisa ser abordada considerando também o movimento da crosta terretre. Por este ponto de vista, o valor encontrado é denominado relativo, uma vez que é tomado em relação a um marégrafo que está fixo à crosta. No entanto, se o comportamento da crosta terrestre for estudado e o seu resultado removido do valor das observações maregráficas, durante um período de tempo coincidente em ambas determinações, uma variação residual é encontrada. Nesta dissertação ela é denominada de variação absoluta.

O comportamento da crosta terrestre é distinto em relação ao da massa oceânica. Enquanto a resposta da crosta, em função das redistribuições de massa e qualquer outra ação, é lenta, devido a sua densidade e rigidez, para a água a resposta é imediata. Como conseqüência, há um intervalo de tempo resultante e uma diferença escalar vertical entre estas variações que causam mudanças do NMM em escalas regionais ou, até mesmo, continentais ao longo do tempo. Daí a importância de serem estudados como dois movimentos independentes que se complementam gerando um único resultado.

\subsection{Conseqüências do aumento do NMM}

As regiões litorâneas têm uma importância fundamental para a humanidade, seja nos transportes, na indústria ou na economia. Além disto, o ecossistema que se aloja nestas regiões é muito rico. São inúmeras as espécies de animais e os tipos de vegetação

\footnotetext{
${ }^{3}$ Período em que a água reteve-se em grande volume na forma de gelo devido a um resfriamento do planeta.
} 
que aí se encontram.

Segundo Pirazzoli (1996), estima-se que mais de 1/3 da população mundial more em regiões litorâneas ou até uma distância de $100 \mathrm{~km}$ da costa. Diversos países possuem os seus grandes centros urbanos nestas regiões. Além disso, grande parte do turismo em todo o mundo é realizado em cidades litorâneas.

Um aumento do nível do mar provocará a sua progradação, causando grandes perdas em diversas áreas. A extensão da invasão dependerá da topografia da região, mas, nos últimos anos, já há diversos registros de praias desaparecidas e de áreas com grandes ocorrências de erosão. Em Israel, no início dos anos 90, uma cidade teve a sua principal fonte de água potável contaminada pela intrusão de sal. Casos como este já ocorreram em outras regiões do Oriente Médio. Nos últimos anos, houve um aumento dos diversos tipos de fenômenos meteorológicos devastadores, como as enchentes e os furacões, entre outros, que derivam principalmente do aumento da massa oceânica e da elevação de sua temperatura superficial. Tudo isto aponta para uma severa deterioração de parte do meio ambiente.

De acordo com Pirazzoli (1996), classificam-se os efeitos físicos do aumento do NMM em cinco categorias. São elas:

- erosão das praias;

- aumento de enchentes e tempestades e suas consequências;

- progradação do nível do mar;

- intrusão de sal em aquíferos e fontes subterrâneas;

- aumento dos valores das tábuas de maré ${ }^{4}$.

A perda financeira que virá a ocorrer se torna incalculável. Inúmeros portos terão de se adaptar para efetuar suas operações de carga e descarga. Diversos imóveis

\footnotetext{
${ }^{4}$ Tabela com horários e as correspondentes alturas do nível do mar para um determinado ponto.
} 
serão invadidos pela água do mar, perdendo assim o seu valor imobiliário. Inúmeras outras conseqüências poderão vir a ocorrer, uma vez que as previsões indicam mudanças irreversíveis.

São inúmeras as pesquisas que abordam atualmente este tema e constantemente o termo "aumento do nível do mar" é usado. Parte destes estudos derivam suas informações a partir dos altímetros instalados em satélites, o que vêm permitindo obter bons resultados sobre a variação absoluta do nível do mar. No entanto, os mesmos não são precisos junto à costa pois o sinal não incide somente sobre a lâmina d'água nestas regiões. Com isso, é importante que a variação seja estimada junto aos marégrafos, ressaltando, mais uma vez, que existem dois movimentos em questão, o da crosta terrestre e o do nível do mar. Após a obtenção do NMM absoluto e de sua tendência será possível associar tal resultado aos altímetros.

Neste trabalho, o objetivo é desenvolver atividades que possam contribuir para os estudos da variação absoluta do nível do mar na estação de Cananéia, situada no litoral sul do estado de São Paulo. O Instituto Oceanográfico da Universidade de São Paulo (IOUSP) é que mantém esta base em operação. Lá são desenvolvidas diversas pesquisas, não somente na área de Oceanografia como em outras áreas afins.

\subsection{A base "Dr. João Paiva de Carvalho" do IOUSP}

A base "Dr. João Paiva de Carvalho", localizada em Cananéia, litoral sul de São Paulo, opera desde 1954 e integra a rede de estações do programa The Global Sea Level Observing System (GLOSS) desde 1993 sob o número 194. Os dados maregráficos são registrados graficamente a partir de uma marégrafo de bóia AOTT, Figuras 5(a) e 5(b). Posteriormente, os dados são digitalizados e disponibilzados pelo IOUSP. Além de um sensor de pressão subsuperficial que foi instalado em 1999 e opera desde então, um terceiro aparelho, um marégrafo de radar, foi instalado em 2006 com o objetivo de registrar e disponibilizar em tempo real os dados do nível do mar. Este último é um 
equipamento mais preciso. A base ainda conta com um receptor GPS de marca Trimble, modelo 4600, de dupla freqüência, em operação desde 2002, cuja antena está instalada num pilar especialmente construído, Figura 5(c). Suas coordenadas foram homologadas pelo Instituto Brasileiro de Geografia e Estatística(IBGE). Desde o início de 2006, esta estação integra a Rede Brasileira de Monitoramento Contínuo (RBMC).

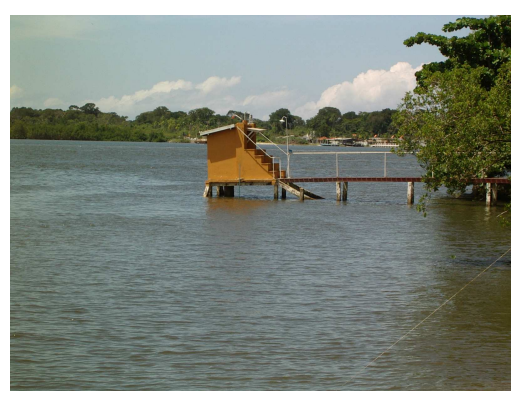

(a) Abrigo do marégrafo

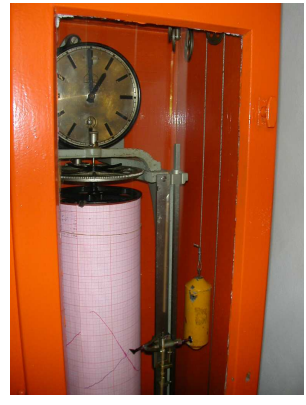

(b) Marégrafo de bóia AOTT

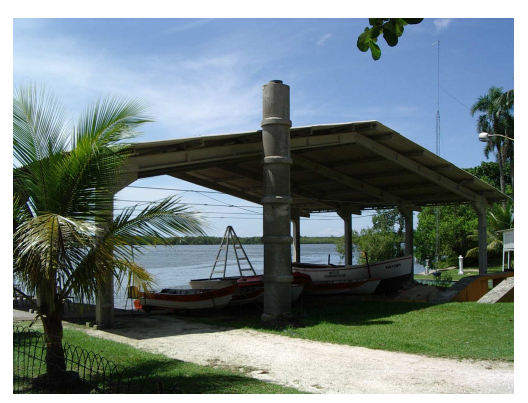

(c) Pilar para suporte da antena GPS

Figura 5: Imagens da base de Cananéia

Existe uma estação meteorológica na base que registra a temperatura, a pressão atmosférica, os períodos e quantidades de chuva, entre outras variáveis.

A base conta com um abrigo para instalação de gravímetros a fim de se registrar continuamente a variação relativa da gravidade. Este abrigo, Figura 6(a), foi construído a fim de minimizar os efeitos de variação térmica e da umidade relativa do ar. Dentro dele existe um outro compartimento onde está localizado o pilar de instalação do gravímetro. Desta forma, o local de instalação do equipamento está isolado do sistema de aquisição de dados conforme ilustra a Figura 6(b). Com isso, é possível que o operador entre no abrigo e faça a manutenção do aparelho sem entrar no compartimento que o isola, Figura 7(a). Ou ainda, quando for necessário verificar o próprio gravímetro, o operador pode entrar no compartimento tendo sempre o cuidado de fechar as portas do abrigo e do compartimento a fim de minimizar a entrada do ar externo, evitando assim uma possível mudança de temperatura no ambiente. 


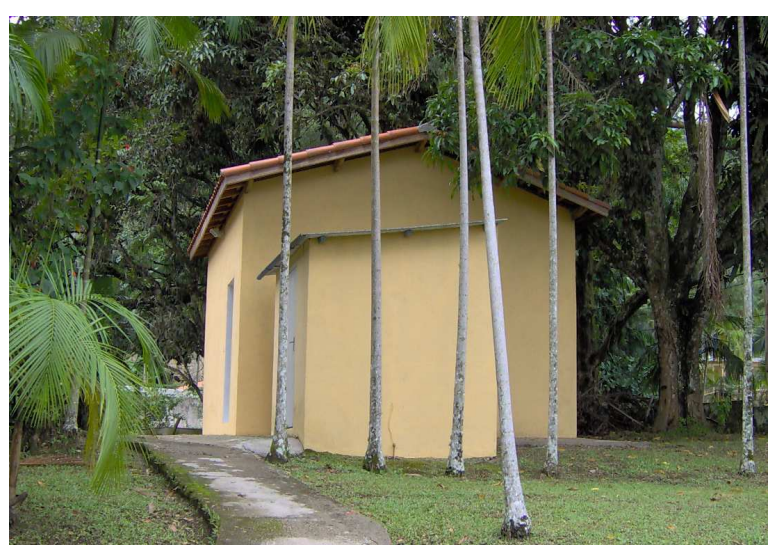

(a) A frente, o antigo abrigo do gravímetro, ao fundo, o construído mais recentemente

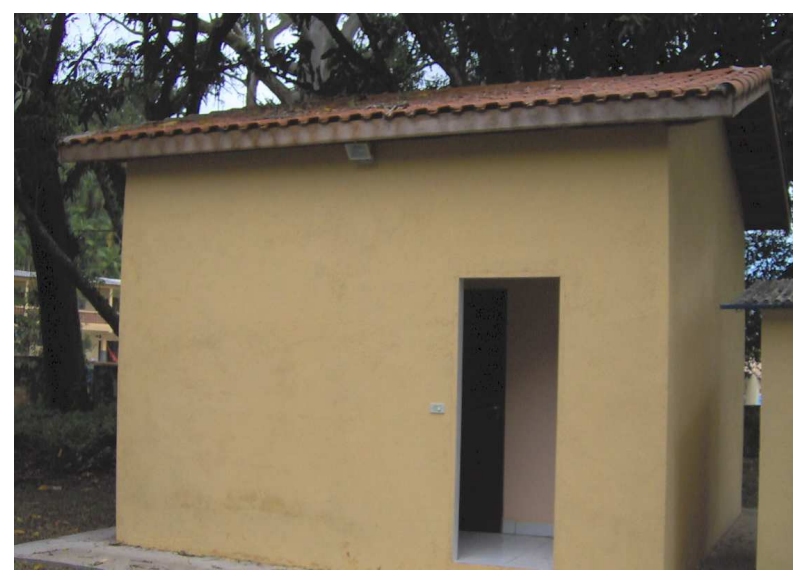

(b) Dentro do novo abrigo, um cômodo isola o pilar de instalação do gravímetro

Figura 6: Imagens do abrigo de instalação do gravímetro

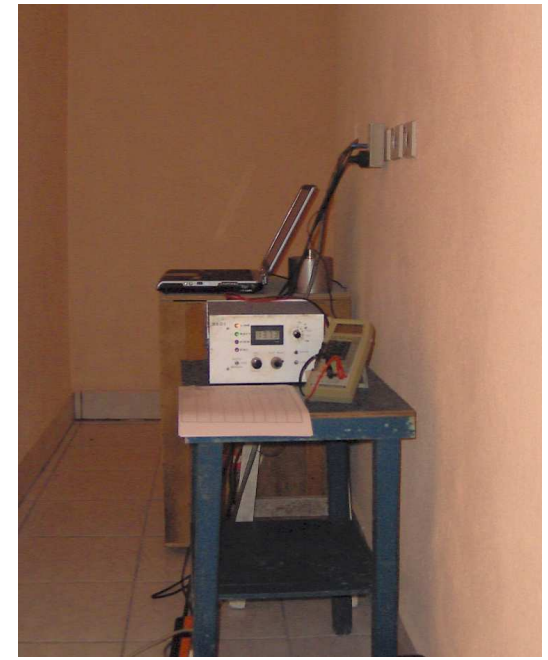

(a) Sistema de aquisição de dados localizado externamente ao cômodo do pilar

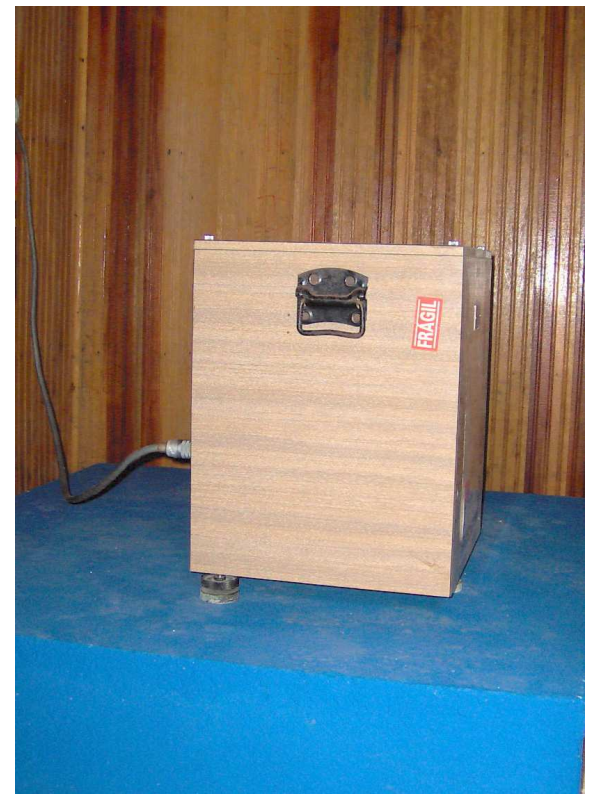

(b) Pilar dentro do cômodo com o gravímetro instalado

Figura 7: Imagens do gravímetro e seu sistema de aquisição de dados 


\section{A força de maré}

\subsection{Introdução}

Desde a antigüidade o fenômeno das marés oceânicas já era reconhecido por sua amplitude e periodicidade. Em 550 a.C. Aristóteles correlacionou este evento com as fases lunares e, no início da era cristã, Plinio as associou à amplitude de maré. Uma boa compreensão deste efeito veio depois que Newton apresentou a Lei da Gravitação Universal, e Laplace, no fim do século $X V I I I$, deu um tratamento matemático às marés. No entanto, foi somente um século depois com Thomson que a análise harmônica na predição de marés foi introduzida e, a partir daí, o aperfeiçoamento desta teoria continuou com outros cientistas dentre eles Darwin, Doodson e Cartwright.

O fenômeno das marés terrestres só foi reconhecido neste mesmo período, segunda metade do século XIX, com o próprio Thomson que introduziu a idéia de que a Terra não é um corpo totalmente rígido e está sujeita às deformações visco-elásticas em conseqüência da atração luni-solar, a exemplo do que ocorre com os oceanos, porém com amplitudes reduzidas. Tais deformações na crosta terrestre variam em função das características reológicas da região.

Toda massa unitátia $m$, localizada em um determinado ponto sobre a superfície terrestre, está sujeita à força gravitacional, exercida por toda a massa que compõe a Terra, e à força centrífuga devido ao movimento de rotação do planeta em torno de seu próprio eixo. O vetor resultante, cuja direção é a vertical do ponto considerado e cuja orientação é para o interior da Terra, exprime a intensidade da força de gravidade neste ponto através 
do módulo.

Por outro lado, todo corpo celeste exerce sobre aquela mesma massa $m$ uma outra força gravitacional variável com o tempo devido às posições relativas do astro e do ponto considerado. Finalmente, a rotação da Terra em torno do centro de massa do sistema considerado, composto pela própria Terra e pelo corpo celeste em questão, gera uma força centrífuga que age juntamente com a força gravitacional. Esta resultante, das forças gravitacional e centrífuga, é denominada força de maré. A ação desta força causa variações na direção e na intensidade do vetor gravidade.

Torge (2001) define de forma semelhante a força de maré como sendo causada pela superposição da gravitação lunisolar (e em menor extensão à gravitação planetária) e acelerações orbitais devido ao movimento da Terra ao redor do baricentro do respectivo sistema dos dois corpos (Terra-Lua, Terra-Sol, etc.).

\subsection{Conceito}

Considere-se um ponto de massa $m$ em repouso sobre a superfície da Terra e os sistemas de referência, não inerciais, celeste $\check{R}^{\prime}\left(O^{\prime}, x^{\prime}, y^{\prime}, z^{\prime}\right)$ e terrestre $\check{R}(O, x, y, z)$. Define-se:

- $\gamma$ - aceleração absoluta;

- $\gamma_{r}$ - aceleração relativa;

- $\gamma_{e}$ - aceleração devido ao movimento do sistema $\check{R}$ em relação ao $\check{R}^{\prime}$.

Em qualquer ponto $P$ da superfície da Terra tem-se:

$$
\gamma=\gamma_{r}+\gamma_{e}+2 \omega \wedge v_{r}
$$

sendo $v_{r}$, a velocidade de $P$ em relação ao sistema $\check{R}$ e $\omega$ a velocidade de rotação angular de $\check{R}$ em relação a $\check{R}$ '. As forças aplicadas em $\mathrm{P}$ são: 
- $m \vec{A}$ - força de atração gravitacional exercida pela Terra;

- $m \vec{a}$ - força de atração gravitacional exercida pelos corpos celestes;

- $\vec{f}$ - forças locais.

A aceleração absoluta $\gamma$ se relaciona às demais forças pela relação:

$$
m \gamma=m \vec{A}+m \vec{a}+\vec{f}
$$

Considerando um ponto $P$ fixo em relação ao referencial terrestre, ou seja, aceleração relativa e velocidade do ponto nulas, $\gamma_{r}=0$ e $v_{r}=0$, é necessário que a força $\vec{f}$ esteja em equilíbrio com a força de gravidade $m \vec{g}$. Logo:

$$
\vec{f}+m \vec{g}=0
$$

Substituindo (3.3) em (3.2) tem-se:

$$
m \gamma_{e}=m \vec{A}+m \vec{a}-m \vec{g}
$$

A aceleração $\gamma_{e}$ é composta por dois termos: a aceleração do centro de massa $\gamma_{0}$, e a aceleração centrífuga $\omega^{2} r \vec{x}$. A força centrífuga $\vec{f}_{c}$ vale:

$$
\overrightarrow{f_{c}}=m \vec{v} \wedge \omega
$$

Tem-se ainda, que a velocidade $\vec{v}$ é expressa por:

$$
\vec{v}=(\omega r) \vec{y}
$$

e a rotação angular $\vec{\omega}$ : 


$$
\vec{\omega}=\omega \vec{z}
$$

Substituindo (3.6) e (3.7) em (3.5), tem-se::

$$
\overrightarrow{f_{c}}=m \omega^{2} r \vec{x}
$$

Finalmente, substituindo (3.8) em (3.4), obtem-se:

$$
m \vec{g}=\underbrace{m \vec{A}}_{\text {f gravitacional }}+\underbrace{m\left(\vec{a}-\gamma_{0}\right)}_{f \text { de maré }}-\underbrace{m\left(\omega^{2} r\right) \vec{x}}_{f \text { centrifuga }}
$$

Vê-se que a força de maré é um efeito diferencial entre a atração gravitacional dos corpos celestes em um ponto $P$ e a força centrífuga neste mesmo ponto gerada a partir da aceleração do centro de massa da Terra em torno do centro de massa do sistema.

Considere a Figura 9. O centro de massa do sistema Terra-Sol, devido à razão entre suas massas, é muito próximo do centro de massa do Sol. Desta forma, pode-se considerar, em uma primeira aproximação, que a Terra segue uma órbita circular com uma velocidade em torno do ponto $S$, que representa o centro de massa do sistema.

No entanto, esta aproximação é impossível para a Lua, pois o centro de massa do sistema Terra - Lua não coincide com o centro de massa do corpo principal. Dada a razão $\mu=\frac{1}{81,3}$, entre a massa da Lua e a massa da Terra, o centro de massa do sistema está localizado a uma distância $\rho=\frac{R}{1+\mu^{-1}}$. Para uma distância média Terra - Lua, $R=384.000 \mathrm{~km}$, o centro de massa está a uma distância $\rho=4.665,9 \mathrm{~km}$ do centro de massa da Terra, ou seja, está localizado no interior do planeta. Este sistema resulta em uma rotação da Terra em torno deste centro de massa comum em um período de 27, 3 dias lunares ${ }^{1}$. Neste caso, o movimento do sistema Terra - Lua em torno do Sol pode ser visto na Figura 8.

\footnotetext{
${ }^{1} \mathrm{O}$ dia lunar possui $24 h 48 \mathrm{~min}$, e compreende o período de tempo em que a Lua passa pelo mesmo meridiano terrestre que é 48 minutos mais tarde em relação ao dia anterior.
} 
CT - Centro da Terra

$\mathrm{CM}$ - Centro de massa

do sistema Terra - Lua

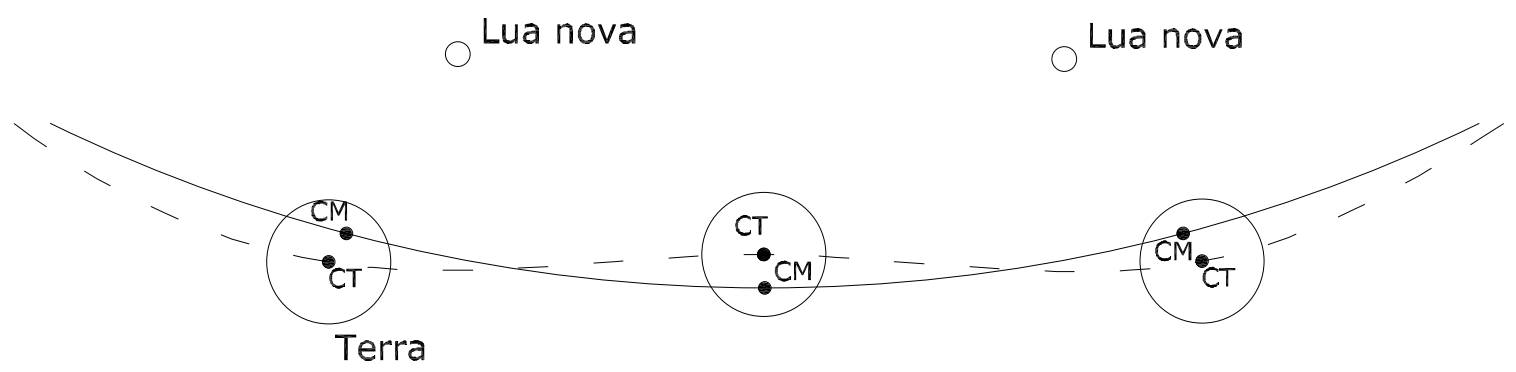

Lua cheia

Figura 8: Posições da Terra e da Lua em movimento em torno do centro de massa do sistema durante o período de um mês lunar (Fonte: Mesquita e França (1996))

Em Melchior (1983), assim como em Ducarme (2005), o conceito de rotação kepleriana é introduzido para discriminar o efeito da ação da força de maré entre os movimentos de rotação e translação da Terra. Neste conceito, cada ponto do planeta gira em torno de um centro de rotação diferente e instantâneo e possue a mesma aceleração centrífuga.

O campo da força centrífuga devido à rotação de um corpo rígido em torno do centro de massa do sistema pode ser considerado como a soma de um campo constante e de um campo radial. No caso do Sol, o campo constante vale $\omega^{2} R$, onde $\omega$ representa a aceleração centrífuga e $R$ a distância entre os centros de massa do Sol e da Terra. Este campo é paralelo à linha que une os centros dos corpos. Já o campo radial vale $\omega^{2} r$, onde $r$ é o raio da Terra, e representa a força centrífuga devido à rotação do planeta em torno de si mesmo, considerado um corpo rígido, durante o seu movimento em torno do centro de massa do sistema. Segundo Ducarme (2005) esta componente radial está adicionada à rotação própria do planeta da qual não pode ser distingüida e somente o campo alinhado com os corpos está incluído na força de maré. 
(a)

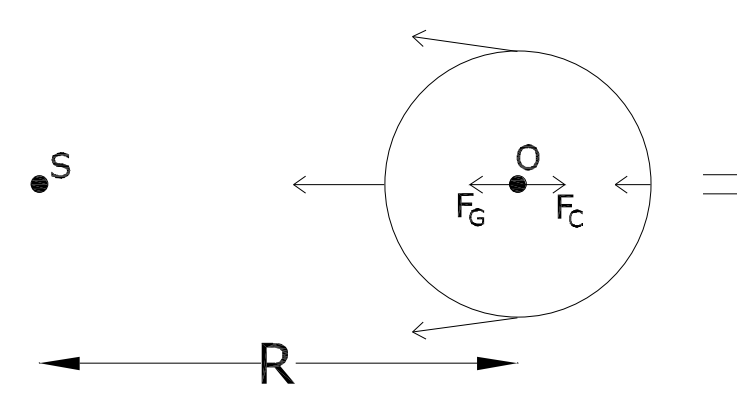

(b)

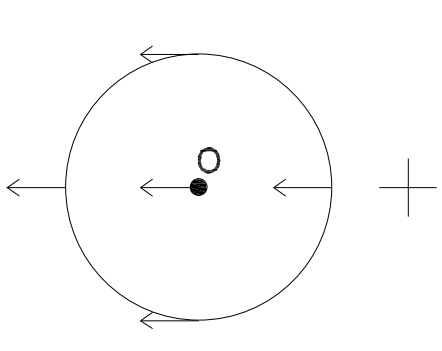

(c)

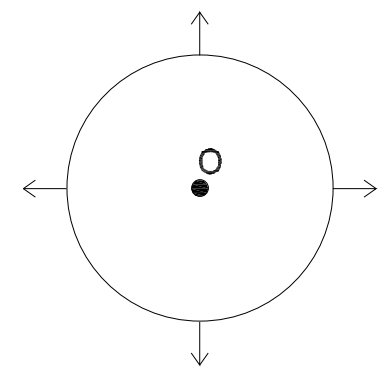

Figura 9: Decomposição da rotação de um corpo rígido (a), rotação Kepleriana (b), rotação da Terra em torno de seu próprio eixo (c), caso do sistema Terra-Sol

Assim, para conseguir uma configuração estável é necessário que a integral, para todo o volume da Terra, da atração gravitacional do Sol esteja balanceada exatamente com a integral da força centrífuga ligada à translação da Terra, a qual, neste caso, tem contribuições constantes com o tempo. Como conseqüência, tem-se que, no centro $O$ da Terra esférica, as forças centrífuga e gravitacional são iguais, porém opostas.

Considerando ainda a Figura 9, sendo $R$ a distância Terra - Sol, $G$ a constante gravitacional, e $M$ a massa do Sol, a força gravitacional em $O$ exercida pelo Sol, $(S)$ é:

$$
F_{G}(O)=\frac{G M}{R^{2}}
$$

e a força devida à aceleração centrífuga $\omega$ : 


$$
F_{C}(O)=\omega^{2} R
$$

orientada segundo a direção de $F_{G}$, porém oposta.

Como em $O$ as forças estão em equilíbrio tem-se:

$$
F_{G}(O)=F_{C}(O)
$$

Substituindo em (3.10) os valores das massas do Sol e da Lua e suas distâncias médias à Terra, tem-se que o Sol exerce sobre a Terra uma aceleração média de 0,59 gal, enquanto a Lua, 3,32 mgal. Utilizando a representação vetorial, a força resultante em $O$ (Figura 9), $\overrightarrow{F_{T}}$, vale:

$$
\vec{F}_{T}(O)=\vec{F}_{G}(O)+\vec{F}_{C}(O)=\overrightarrow{0} \text { por estar em equilíbrio... }
$$

O equilíbrio, entretanto, somente se verifica no centro de massa da Terra. Em qualquer outro ponto, esta resultante é denominada força de maré. Aplicando (3.13) para um ponto qualquer $P$, tem-se a relação:

$$
\begin{aligned}
\vec{F}_{T}(P) & =\overrightarrow{F_{G}}(P)+\vec{F}_{C}(P) \\
& =\left(\overrightarrow{F_{G}}(P)-\vec{F}_{G}(O)\right)+\left(\overrightarrow{F_{C}}(P)-\vec{F}_{C}(O)\right) \\
& =\overrightarrow{F_{G}}(P)-\vec{F}_{G}(O)
\end{aligned}
$$

Na equação acima, a relação $\left.F_{C} \overrightarrow{(P}\right)$ e $F_{C} \overrightarrow{(O)}$ se anula uma vez que foi utilizada a condição de rotação kepleriana e, desta forma, seus valores são iguais em toda a Terra.

Esta equação define a força de maré como a diferença entre a atração gravitacional exercida pelo corpo perturbador em um ponto e o valor da atração gravitacional no centro da Terra. 
Esta definição é usada em Gemael (1986) que diz que a força de maré (tidal force) em um ponto $P$ do modelo esférico sólido e rígido é a diferença entre a força de atração exercida pelo Sol e pela Lua sobre a unidade de massa colocada nesse ponto e no centro do modelo.

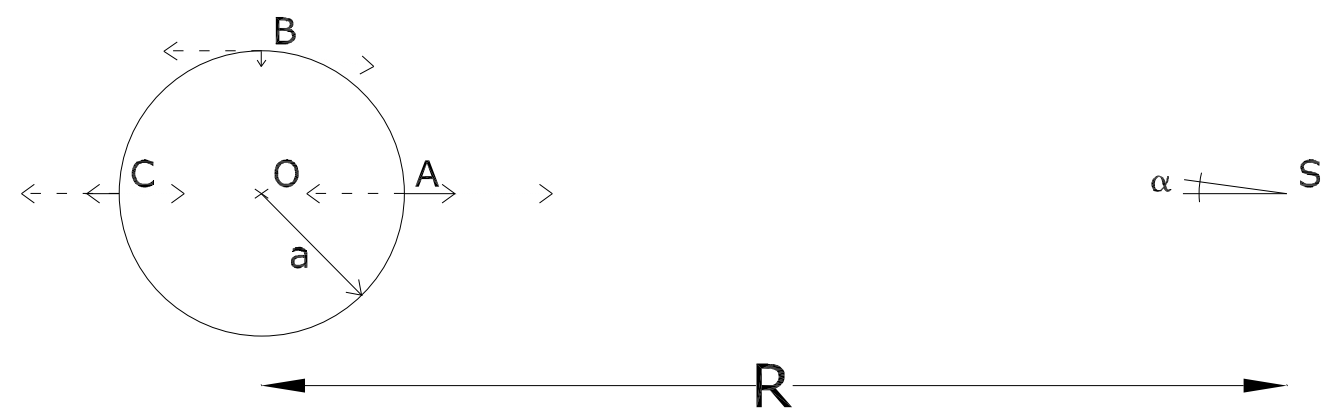

Figura 10: Relação direta da força de maré (linha cheia) com a força gravitacional (linha pontilhada) e a força centrífuga (linha tracejada)

No ponto $A$ da Figura 10, sendo $S$ o Sol, $a$ o raio da Terra, e $R$ a distância entre os centros de massa do Sol e da Terra, tem-se:

$$
F_{G}(A)=\frac{G M}{(R-a)^{2}}
$$

Substituindo (3.10) na equação acima, considerando $x=\frac{a}{R}$ um número muito pequeno, e $F_{G}(O)=F$, tem-se:

$$
F_{G}(A)=F_{G}(O) \frac{R^{2}}{(R-a)^{2}}=\frac{F}{(1-x)^{2}}=F(1+2 x)
$$


A força de maré $F_{T}$ tem o seu sentido dirigido para o corpo celeste, ou seja, para $S$. Logo, no ponto $A$, a força de maré é a diferença entre a força gravitacional exercida pelo astro $\left(F_{G}(A)\right)$ e a força centrífuga no centro da Terra, ponto $O, F_{C}(O)$. Como demonstrou-se em 3.12, a força centrífuga no centro da Terra nada mais é do que a força gravitacional exercida pelo mesmo astro neste ponto.

$$
F_{T}(A)=F_{G}(A)-F_{G}(O)=F(1+2 x)-F=2 x F
$$

De modo similar no ponto $C$ :

$$
F_{G}(C)=\frac{G M}{(R+a)^{2}}=F(1-2 x)
$$

e,

$$
F_{T}(C)=F_{G}(C)-F_{G}(O)=F(1-2 x)-F=-2 x F
$$

No ponto $B$, a força gravitacional $F_{G}$, ao longo do eixo $S B$, é dada por:

$$
F_{G}(B)=\frac{G M}{R^{2}+a^{2}}=F_{G}(O) \frac{R^{2}}{R^{2}+a^{2}}=\frac{F}{1+x^{2}}
$$

Como no triângulo $S O B, r=R \tan \alpha$, a projeção radial da força sobre $O B$ é:

$$
F_{r}(B)=F_{G}(B) \sin \alpha=\frac{-F x}{\left(1+x^{2}\right)}=-F x
$$

e a projeção tangencial:

$$
F_{t}(B)=F_{G}(B) \cos \alpha \cong F \frac{\left(1-\frac{x^{2}}{2}\right)}{\left(1+x^{2}\right)} \cong F
$$

Desta forma são anuladas as forças centrífugas $F_{C}(B)=F_{C}(O)$, paralelas e opostas. Assim, a força de maré em $B$ é radial e orientada na direção do centro da Terra, 
$F_{T}(B)=F_{G}(B)-F_{G}(O)$, e vale:

$$
F_{T}(B)=F_{r}(B)=-F x
$$

A partir dos resultados acima, vê-se que a amplitude máxima de maré, ou seja, a diferença entre o maior e o menor valor obtido vale $3 F x$. Esta força varia em função da posição dos astros envolvidos. A Figura 11 representa o campo de forças de maré em uma seção do planeta em um determinado intante.

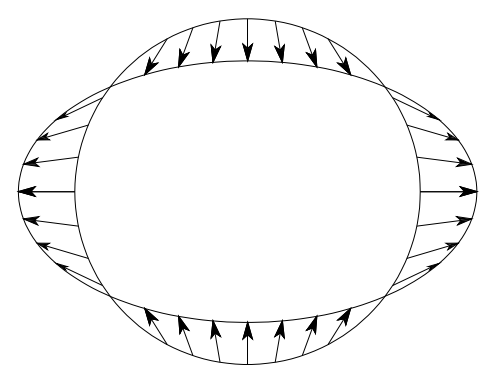

Figura 11: Campo de força de maré

\subsection{Avaliação numérica}

A fim de avaliar a amplitude de maré, as seguintes constantes são adotadas, e aplicadas nas fórmulas citadas anteriormente:

1. Para a Terra:

$a=6.371 \mathrm{~km}$ - raio aproximado;

$\rho=4.670,7 \mathrm{~km}$ - distância entre o seu centro e o baricentro do sistema Terra - Lua.

2. Para o Sol:

$R_{S}=149.597 .871 \mathrm{~km}$ - distância aproximada à Terra;

$T_{S}=365,25$ dias - período de revolução da Terra em torno do sistema Terra-Sol.

3. Para a Lua:

$R_{L}=384.400 \mathrm{~km}$ - distância aproximada à Terra; 
$T_{L}=27,3216$ dias - período de revolução sideral.

Para o Sol, substituindo a constante $T_{S}$ em Hertz, e $R_{S}$ em centímetros, encontrase a aceleração centrífuga da Terra em sua rotação no sistema Terra-Sol:

$$
F=\omega^{2} R=0,59303 \mathrm{~cm} / \mathrm{s}^{2}
$$

Nesta situação, o valor de $x$, que é a razão entre o raio da Terra e a distância entre os centros de massa da Terra e do Sol, vale:

$$
x=\frac{a}{R}=4,25875 \times 10^{-5}
$$

Substituindo os valores em (3.17), no momento em que o Sol cruza o meridiano o módulo da amplitude vale $2 F x=50,5 \mu$ gal. Usando os mesmos valores em (3.21) tem-se o módulo da amplitude quando o Sol está no horizonte $F x=25,3 \mu$ gal. Somando os dois valores encontrados tem-se o módulo da amplitude máxima que é de $\rightarrow 3 F x=75,8 \mu$ gal.

Ao aplicar o mesmo procedimento para a Lua, a amplitude quando a mesma cruza o meridiano é de $2 F x=109,7 \mu$ gal; quando ela está no horizonte vale $F x=54,8 \mu$ gal; e a amplitude máxima, $3 F x=164,5 \mu$ gal.

Os valores acima mostram que a componente solar representa menos da metade do efeito lunar. Isto se deve à proximidade da Lua ao nosso planeta. O Sol, apesar da distância em relação à Terra, ainda exerce uma força expressiva devido à sua massa. A amplitude total da aceleração de gravidade gerada pela força de maré luni-solar alcança um valor próximo a $240 \mu$ gal quando a Lua está mais próxima da Terra, e esta mais próxima do Sol.

Estes valores teóricos sofrem variações devido à resposta elástica da crosta terrestre, que aumenta a maré gravimétrica cerca de 15\%. As marés oceânicas somam, além da variação na atração gravitacional devido à sua massa, a carga e descarga oceânicas 
sobre a crosta, produzindo efeitos adicionais que podem alcançar $10 \%$ dos efeitos diretos astronômicos (DUCARME, 2005).

\subsection{Potencial de maré}

Segundo Ducarme (2005), ainda que houvesse um equilíbrio global entre a atração gravitacional e a força centrífuga nos sistemas planetários, as forças de maré ocorreriam dentro de cada planeta como forças residuais, expressando a desigualdade local entre a atração gravitacional exercida pelos outros corpos e a força centrífuga homogênea devido à rotação Kepleriana em torno do centro comum de massa do sistema considerado.

A rotação do planeta em torno do seu próprio eixo produz uma força centrífuga constante sem qualquer contribuição para a força de maré. Esta força $F_{C}^{\prime}$ está associada à rotação em torno do centro de massa comum assim como em cada um dos outros pontos que giram em torno de diferentes centros de rotação instantâneos, considerando uma rotação kepleriana.

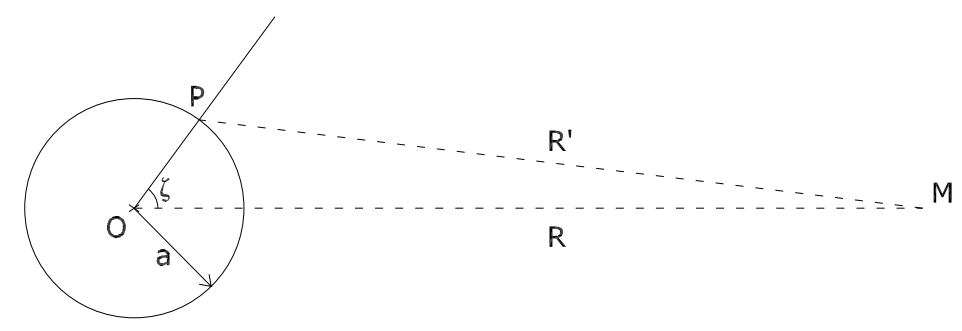

Figura 12: Ponto $P$ em um sistema onde $\zeta$ é a distância zenital ao corpo celeste $M$

Em $P$, na Figura 12 , pela relação $\bar{F}_{G}=-\bar{\Delta} W_{G}$, a atração gravitacional deriva de um potencial: 


$$
W_{G}=\frac{G M}{R^{\prime}}
$$

Expressando $R^{\prime}$ em função de $a, R$ e $\zeta,(3.24)$ se transforma em:

$$
W_{G}=\frac{G M}{R\left(1-2 \frac{a}{R} \cos \zeta+\frac{a^{2}}{R^{2}}\right)^{\frac{1}{2}}}
$$

Como $a \leq R$, pode-se desenvolver o denominador em uma expansão polinomial de Legendre sob a forma:

$$
\begin{aligned}
W_{G} & =\frac{G M}{R} \sum_{j=0}^{\infty}\left(\frac{a}{R}\right)^{j} P_{j}(\cos \zeta) \\
& =W_{0}+W_{1}+W_{2}+\cdots
\end{aligned}
$$

A adição vetorial de duas forças corresponde a uma adição escalar de seus potenciais. Como a força de maré em $P$ é definida por (3.13), tem-se para o potencial de maré $W:$

$$
W=W_{G}+W_{C}
$$

Para definir o potencial centrífugo $W_{C}$, integra-se (3.13) no centro de massa da Terra. Logo:

$$
W_{C}(O)+W_{G}(O)=C
$$

Em (3.28), $C$ é uma constante de integração que pode ser zero. O potencial centrífugo em um ponto $P$, nada mais é do que a soma entre o potencial centrífugo em $O$ e o trabalho realizado pela força centrífuga para mover seu ponto de aplicação de $O$ para $P$, ou seja: 


$$
W_{C}(P)=W_{C}(O)+\int_{O}^{P}\left|\overrightarrow{F_{C}}\right| d \vec{r}
$$

onde, $\left|\overrightarrow{F_{C}}\right|=\frac{G M}{R^{2}}$. Como a força centrífuga é constante em norma e direção, tem-se:

$$
\left|\vec{F}_{C}\right| d \vec{r}=\frac{G M}{R^{2}} \cos \zeta d r
$$

Substituindo (3.30) em (3.29), e realizando a integração, encontra-se:

$$
W_{C}(P)=W_{C}(O)-\frac{G m}{R^{2}} a \cos \zeta
$$

Na soma $W_{G}+W_{C}$, os termos de ordem zero, $W_{0}=W_{G}(0)=-W_{C}(0)$, e de primeira ordem, $W_{1}=\frac{G M}{R}\left(\frac{a}{r}\right) \cos \zeta$, desaparecem. Logo, o potencial de maré é dado por:

$$
\begin{aligned}
W & =\frac{G M}{R} \sum_{j=2}^{\infty}\left(\frac{a}{R}\right)^{j} P_{j}(\cos \zeta) \\
& =W_{2}+W_{3}+\cdots
\end{aligned}
$$

Introduzindo o valor $\bar{a}$ para a distância geocêntrica $a$, e o valor $C$ para a distância $R$, reescreve-se (3.32) para $n=2$ :

$$
W_{2}=2 D\left(\frac{C}{R}\right)^{3}\left(\frac{a}{\bar{a}}\right)^{2}\left(\cos ^{2} \zeta-\frac{1}{3}\right)
$$

onde $D$ é a constante de Doodson e é calculada através da equação:

$$
D=\frac{3}{4} G M \frac{a_{d}^{2}}{C_{d}^{3}}
$$

$C_{d}$ é a distância geocêntrica do corpo pertubador e $a_{d}$ o valor médio do raio da Terra. Para a Lua tem-se $D=2,620629 \mathrm{~m}^{2} s^{-2}$, e para o Sol $D^{\prime}=0,4599 D$. 


\subsection{Representação do potencial de maré}

O desenvolvimento em série do potencial de maré se realiza em duas etapas. Laplace demonstrou que transformando as coordenadas do ponto onde a força de maré é aplicada de um sistema de referência terrestre para o celeste, é possível separar três famílias de ondas: diurnas, semi-diurnas e de longo período. Estas famílias são caracterizadas por uma distribuição geográfica específica sobre a superfície da Terra. Posteriormente, para cada uma destas famílias é realizado um desenvolvimento harmônico, encontrando-se as diferentes componentes de onda do potencial de maré.

\subsubsection{O desenvolvimento de Laplace}

O potencial de maré pode ser escrito, num sistema de referência terrestre, considerando os graus $n=2$ e $n=3$ :

$$
\begin{gathered}
W_{2}=\frac{G M}{2} \frac{a^{2}}{R^{3}}\left(3 \cos ^{2} \zeta-1\right) \\
W_{3}=\frac{G M}{2} \frac{a^{3}}{R^{4}}\left(5 \cos ^{3} \zeta-3 \cos \zeta\right)
\end{gathered}
$$

Considere-se a posição do ponto sobre a Terra em coordenadas geodésicas, latitude $(\phi)$ e longitude $(\lambda)$, e a posição do corpo pertubador em coordenadas equatoriais, ascenção reta $(\alpha)$ e declinação $(\delta)$. No triângulo esférico representado na Figura 13, tem-se a relação:

$$
\cos \zeta=\sin \phi \sin \delta+\cos \phi \cos \delta \cos H
$$

$H$ é o ângulo horário que é dado por:

$$
H=\omega t^{\prime}-\alpha+\lambda
$$




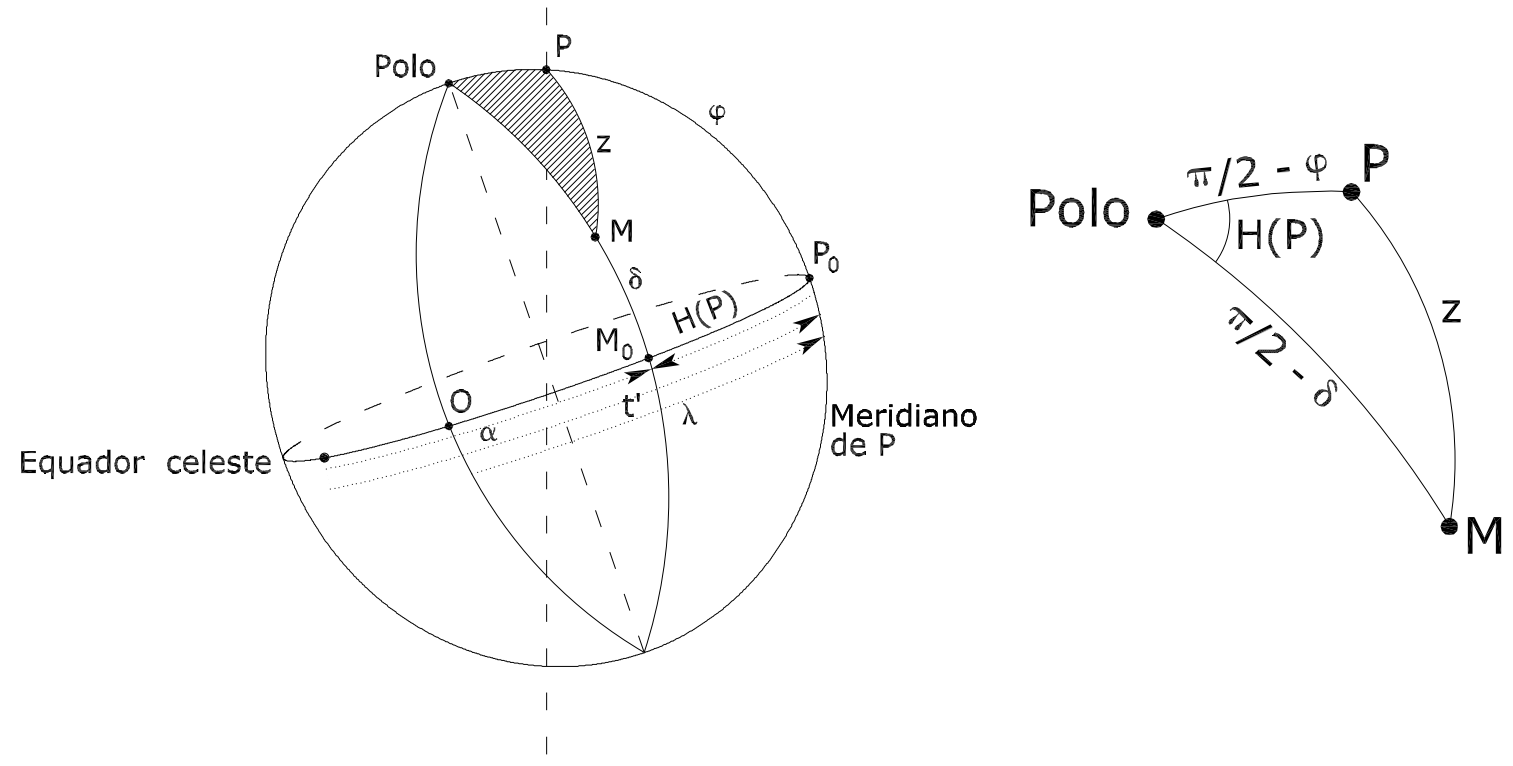

Figura 13: Triângulo esférico para transformação de coordenadas de um sistema terrestre para o celeste ( $\mathrm{Na}$ figura, z representa $\zeta$ )

onde $t^{\prime}$ representa o tempo sideral no meridiano de referência. Elevando ao quadrado a (3.37), encontra-se:

$\cos ^{2} \zeta=\sin ^{2} \phi \sin ^{2} \delta+2 \sin \phi \sin \delta \cos \phi \cos \delta \cos H+\cos ^{2} \phi \cos ^{2} \delta \cos ^{2} H$

Através das relações trigonométricas citadas em (3.40), e de suas substituições em (3.39), reescreve-se (3.35) e obtém-se as três famílias de maré em (3.41):

$$
\begin{aligned}
\cos ^{2} H & =\frac{1}{2}(\cos 2 H+1) \\
\sin \phi \cos \phi & =\frac{1}{2} \sin 2 \phi \\
\sin \delta \cos \delta & =\frac{1}{2} \sin 2 \delta
\end{aligned}
$$




$$
W_{2}=\frac{3}{4} G M \frac{a^{2}}{R^{3}}[\underbrace{\cos ^{2} \phi \cos ^{2} \delta \cos 2 H}_{\text {setorial }}+\underbrace{\sin 2 \phi \sin 2 \delta \cos 2 H}_{\text {tesseral }}+\underbrace{3\left(\sin ^{2} \phi-\frac{1}{3}\right)\left(\sin ^{2} \delta-\frac{1}{3}\right)}_{\text {zonal }}]
$$

A expressão acima possui três argumentos trigonométricos sublinhados que caracterizam as três famílias de ondas de maré denominadas por setorial, tesseral e zonal. Neste caso, define-se por família como o grupo de ondas que possuem características em comum em função da posição do corpo perturbador em relação à Terra.

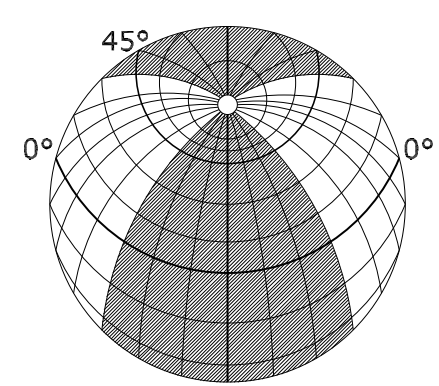

(a)

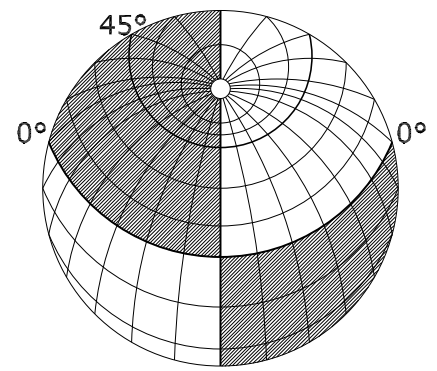

(b)

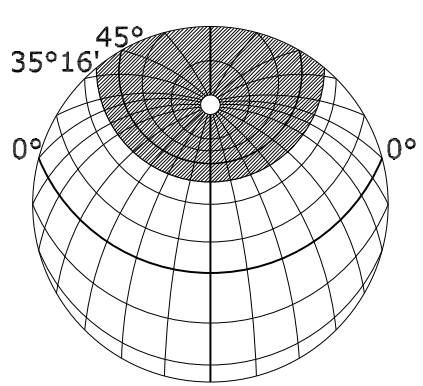

(c)

Figura 14: Interpretação geométrica das três famílias de ondas de maré

A Figura 14 (a) fornecce uma interpretação geométrica da primeira destas famílias, a setorial. Suas linhas nodais são os meridianos a $45^{\circ}$ para cada lado do meridiano do corpo perturbador $(\delta)$. Logo, a superfície se divide em quatro setores onde a função é alternadamente positiva e negativa. As áreas onde o potencial é positivo são as de alta maré, e as de potencial negativo, as de baixa maré. O período destas ondas é semi-diurno, e suas amplitudes tem um máximo no equador quando a declinação do corpo perturbador 
é zero. Já nos pólos, as amplitudes serão nulas.

A interpretação geométrica da segunda família está na Figura 14 (b), a tesseral. Ela tem um paralelo, que é o Equador, e um meridiano, que está à $90^{\circ}$ do meridiano do corpo perturbador. Assim, a superfície é dividida em quatro áreas as quais mudam o sinal em função de $\delta$. O período das ondas é diurno e a amplitude é máxima nas latitudes $45^{\circ} \mathrm{N}$ e $45^{\circ} S$ quando $\delta$ é máximo. A amplitude é sempre zero no equador e nos pólos.

A terceira família, Figura 14 (c), é a zonal. Como linhas nodais, esta função tem os paralelos $35^{\circ} 16^{\prime} N$ e $35^{\circ} 16^{\prime} S$. Seu fundamental período é 14 dias para a Lua e seis meses para o Sol.

Segundo Melchior (1983), a parte constante desta função tem como conseqüência o rebaixamento da superfície equipotencial nos pólos de $28 \mathrm{~cm}$ e a sua elevação no equador em $14 \mathrm{~cm}$. Logo, o efeito permanente desta família é um pequeno aumento do achatamento da Terra.

Segundo Ducarme (2005), considerando em um instante fixo a distribuição geográfica destas três famílias, pode-se ver que correspondem aos três polinômios associados de Legendre para o segundo grau em $\phi$ e $\lambda$. A dependência em longitude está associada com o ângulo horário.

$$
\begin{gathered}
P_{2}^{0}: \frac{1}{2}\left(3 \sin ^{2} \phi-1\right) \rightarrow \text { zonal } \\
P_{2}^{1}: \frac{3}{2} \sin 2 \phi \cos \lambda \rightarrow \text { tesseral } \\
P_{2}^{2}: \frac{3}{2} \cos ^{2} \phi \cos 2 \lambda \rightarrow \text { setorial }
\end{gathered}
$$

\subsubsection{O desenvolvimento harmônico}

Na expressão devido a Laplace relativa ao desenvolvimento do potencial, (3.41), há três quantidades que dependem do tempo: 
- o ângulo horário do corpo pertubador $(\mathrm{H})$;

- a declinação do corpo pertubador $(\delta)$, e;

- a distância para o corpo pertubador $(R)$.

A seguir, considere-se os parâmetros que definem o movimento da Lua e o movimento aparente do Sol. As velocidades correspondentes são expressas em graus por hora $(\% / h)$. Em um sistema de referência terrestre tem-se para o movimento aparente diurno da Lua e do Sol:

- $\dot{t}=15,00000^{\circ} / h$ (período de $24 \mathrm{~h} 00 \mathrm{~min}$ ) para o tempo médio solar $t$;

- $\dot{\tau}=14,49205^{\circ} / h$ (período de $24 \mathrm{~h} 50 \mathrm{~min}$ ) para o tempo médio lunar $\tau$.

O movimento orbital da Lua requer variáveis suplementares. São elas:

- $\dot{s}=0,544902^{\circ} / h$ (período de 27,321 dias), $s$ define a posição da Lua sobre sua órbita e corresponde à variação da declinação da Lua;

- $\dot{p}=0,00464^{\circ} / h$ (período de 8,847 anos) está associado à revolução do perigeo médio lunar;

- $\dot{N}=0,00221^{\circ} / h$ (período de 18,613 anos) corresponde à revolução retrógrada do nodo lunar.

O movimento aparente do Sol é expresso por:

- $\dot{h}=0,04107^{\circ} / h(365,25$ dias $)$ é o período típico de um ano ;

- $\dot{p_{s}}=0,000002^{\circ} / h(20.940$ anos $)$ é o período de rotação do perihelio da órbita terrestre. 
Além disso, os tempos médios solar e lunar $(t$ e $\tau$ ) estão ligados ao tempo sideral $t^{\prime}$ pela relação:

$$
t^{\prime}=\dot{t}+\dot{h}=\dot{\tau}+\dot{s}
$$

Finalmente tem-se seis variáveis independentes, as quais estão em ordem decrescente de velocidade angular: $\tau, s, h, p, N^{\prime}(-N), p_{s}$. O ângulo horário $A H$ corresponde às variáveis $\tau$ para a Lua, e $t(\tau+s)$ para o Sol.

\subsubsection{As ondas semi-diurnas}

Seja a forma geral das funções setoriais das ondas semi-diurnas para a Lua:

$$
W_{2}^{S D}=D\left(\frac{c}{d}\right)^{3} \cos ^{2} \phi \cos ^{2} \delta \cos 2 \dot{\tau} t
$$

A principal perturbação na distância Terra - Lua é a elipticidade da órbita lunar. Considerando que $c$ é o semi-eixo maior da órbita, tem-se:

$$
\begin{aligned}
d & =c(1-e \cos (\dot{s}-\dot{p}) t) \\
\frac{c}{d} & =1+0,0549 \cos (\dot{s}-\dot{p}) t+\cdots
\end{aligned}
$$

onde $e(0,0549)$ é a excentricidade da órbita.

A posição da Lua sobre sua órbita é definida pela variável $s$ e é definida como longitude média da Lua. Haverá a passagem pelo perigeu quando $s=p$, e a passagem pelo apogeu quando $s=p+180^{\circ}$. A variável $s-p$ representa, desta forma, a diferença entre a posição da Lua e a sua passagem pelo perigeu. Como uma primeira aproximação tem-se: 


$$
\left(\frac{c}{d}\right)^{3}=1+0,1647 \cos (\dot{s}-\dot{p}) t
$$

Considerando a inclinação média da órbita lunar sobre o equador $\left(\epsilon=23^{\circ} 27^{\prime}\right)$, tem-se o seguinte relação:

$$
\sin \delta=\sin \epsilon \sin s
$$

Substituindo a relação trigonométrica $\cos ^{2} \delta=1-\sin ^{2} \delta$ em (3.47) e desenvolvendo, tem-se:

$$
\begin{aligned}
\cos ^{2} \delta & =1-\sin ^{2} \epsilon \sin ^{2} s \\
\cos ^{2} \delta & =\left(1-\frac{1}{2} \sin ^{2} \epsilon\right)+\frac{1}{2} \sin ^{2} \epsilon \cos 2 \dot{s} t \\
\cos ^{2} \delta & =0,9208+0,0792 \cos 2 \dot{s} t
\end{aligned}
$$

Substituindo (3.48) em (3.44), tem-se a expressão geral:

$$
\left.W_{2}^{S D}=D \cos ^{2} \phi[0,9208 \cos 2 \dot{\tau} t+0,1516 \cos (\dot{s}-\dot{p}) t \cos 2 \dot{\tau} t+0,0792 \cos 2 \dot{s} t) \cos 2 \dot{\tau} t\right]
$$

O termo principal, $0,9208 D \cos ^{2} \phi \cos 2 \dot{\tau} t$, representa a onda $M_{2}$ e possui um período de 12h25min. Transformando esta expressão em funções de produtos de co-seno pela relação trigonométrica $2 \cos a \cos b=\cos (a+b)+\cos (a-b)$, obtem-se pares de ondas simétricas em relação à $M_{2}$, sendo cada uma correspondendo a uma perturbação da órbita lunar. A forma elíptica da órbita produz:

- $0,0758 D \cos ^{2} \phi \cos (2 \dot{\tau}+(\dot{s}-\dot{p})) t \rightarrow$ onda $L_{2}$ (período de $\left.12 h 11 \mathrm{~min}\right)$;

- $0,0758 D \cos ^{2} \phi \cos (2 \dot{\tau}-(\dot{s}-\dot{p})) t \rightarrow$ onda $N_{2}$ (período de $\left.12 h 39 \mathrm{~min}\right)$. 
Encontra-se, de forma similar, as ondas declinacionais:

- $0,0396 D \cos ^{2} \phi \cos (2 \dot{\tau}+2 \dot{s}) t \rightarrow$ onda $K_{2}^{m}$ (período de $\left.11 h 58 m i n\right)$;

- $0,0396 D \cos ^{2} \phi \cos (2 \dot{\tau}-2 \dot{s}) t \rightarrow$ onda sem nomenclatura (período de $12 h 55 \mathrm{~min}$ ).

De modo análogo, tem-se para o Sol:

- Onda principal $\left\{S_{2}(\right.$ perodode $12 h 00 \mathrm{~min}) \rightarrow$ argumento $2 \dot{t}$

- Ondas elípticas $\left\{\begin{array}{l}R_{2}(\text { perodode } 12 h 01 \mathrm{~min}) \rightarrow \text { argumento } 2 \dot{t}-\left(\dot{h}-\dot{p}_{1}\right) \\ T_{2}(\text { perodode } 11 \text { h59min }) \rightarrow \text { argumento } 2 \dot{t}+\left(\dot{h}-\dot{p}_{s}\right)\end{array}\right.$

- Ondas declinacionais $\left\{\begin{array}{l}K_{2}^{S}(\text { perodode } 11 \text { h58min }) \rightarrow \text { argumento } 2(\dot{t}+\dot{h}) \\ \text { onda sem nomenclatura }(\text { perodode } 12 h 02 \text { min }) \rightarrow \text { argumento } 2(\dot{t}-\dot{h})\end{array}\right.$

\subsubsection{As ondas diurnas}

Considere-se agora a forma geral das funções tesserais das ondas diurnas para a Lua:

$$
W_{2}^{D}=D\left(\frac{c}{d}\right)^{3} \sin 2 \phi \sin 2 \delta \cos A H
$$

O termo $\left(\frac{c}{d}\right)^{3}$ é o mesmo anterior. Pela relação trigonométrica $\sin 2 \delta=2 \sin \delta \cos \delta$ tem-se o desenvolvimento:

$$
\begin{aligned}
\sin 2 \delta & =2 \sin \delta \sqrt{1-\sin ^{2} \delta} \\
2 \sin \delta & =(1-\sin \delta+\cdots)
\end{aligned}
$$

e obtém-se uma aproximação de primeira ordem: 


$$
\sin 2 \delta 2 \sin \epsilon \sin s=0,796 \sin \dot{s} t
$$

Desta forma, substituindo (3.51) em (3.50), encontra-se:

$$
W_{2}^{D}=D \sin 2 \phi(1+0,1647 \cos (\dot{s}-\dot{p})) 0,796 \sin \dot{s} t \cos \dot{\tau} t
$$

Em função do valor médio de $\sin 2 \delta$ ser zero, não há nenhuma onda principal correspondente ao período lunar fundamental (24h50min). As principais ondas declinacionais são:

- $K_{1}^{m}$ (período de $\left.23 \mathrm{~h} 56 \mathrm{~min}\right)$ - argumento $\dot{\tau}+\dot{s}$;

- $O_{1}$ (período de 25h49min) - argumento $\dot{\tau}-\dot{s}$.

e, as principais ondas elípticas:

- $Q_{1}$ (período de $\left.26 \mathrm{~h} 52 \mathrm{~min}\right)$ - argumento $\dot{\tau}-\dot{s}-(\dot{s}-\dot{p})$ (elíptica a partir de $\left.O_{1}\right)$;

- $J_{1}$ (período de $\left.23 \mathrm{~h} 06 \mathrm{~min}\right)$ - argumento $\dot{\tau}+\dot{s}+(\dot{s}-\dot{p})$ (elíptica a partir de $K_{1}^{m}$ ).

Para o Sol, deduz-se de forma similar as principais ondas declinacionais:

- $K_{1}^{s}$ (período de $\left.23 \mathrm{~h} 56 \mathrm{~min}\right)$ - argumento $\dot{\tau}+\dot{h}$;

- $P_{1}$ (período de $\left.24 \mathrm{~h} 04 \mathrm{~min}\right)$ - argumento $\dot{\tau}-\dot{h}$.

e, as elípticas:

- $\pi_{1}$ (período de $\left.24 \mathrm{~h} 08 \mathrm{~min}\right)$ - argumento $\dot{\tau}-\dot{h}-\left(\dot{h}-\dot{p}_{s}\right)$ (elíptica a partir de $\left.P_{1}\right)$;

- $\psi_{1}$ (período de $\left.23 \mathrm{~h} 53 \mathrm{~min}\right)$ - argumento $\dot{\tau}+\dot{h}+\left(\dot{h}-\dot{p}_{s}\right)$ (elíptica a partir de $\left.K_{1}^{s}\right)$. 
Da relação de ondas acima, vê-se que $K_{1}$, com um período sideral $t^{\prime}$, é uma onda lunisolar devido à relação:

$$
t^{\prime}=\tau+s=t+h
$$

Quando a Lua está no equador, $K_{1}^{m}$ e $O_{1}$ se anulam. E, da mesma forma, $K_{1}^{s}$ e $P_{1}$, quando o Sol está no equador. É através destas interferências que as ondas diurnas desaparecem quando a declinação dos corpos perturbadores tendem a zero $(\sin \delta=0)$.

\subsubsection{As ondas de longo período}

O potencial que gera a família das ondas zonais não depende do ângulo horário $H$ e conseqüentemente, as principais ondas de longo período são de origem declinacionais e elípticas. Para a Lua, as duas principais ondas são:

- $M_{f}$ (período de 13,66 dias) declinacional, argumento $2 \dot{s}$;

- $M_{m}$ (período de 27,55 dias) elíptica de $M_{f}$, argumento $(\dot{s}-\dot{p})$.

e para o Sol:

- $S s a$ (período de 182,6 dias) declinacional, argumento $2 \dot{h}$;

- $S a$ (período de 365,25 dias) elíptica de $S s a$, argumento $\left(\dot{h}-\dot{p}_{s}\right)$

\subsubsection{Sistema de classificação para as ondas de maré}

A denominação das ondas de maré foi determinada por George Darwin a fim de proporcionar uma forma prática de memorizá-las. De fato, vê-se que as letras escolhidas estão dispostas simetricamente ao longo do alfabeto em relação às letras $\mathbf{M}$ (do inglês Moon, Lua) e $\mathbf{S}$ (do inglês Sun, Sol). 
Como exemplo tem-se as ondas $K_{1}^{m}$ e $O_{1}$. No alfabeto, têm-se a seqüência $\mathbf{K}$, L, M, N, O. Como visto anteriormente, trata-se das duas ondas declinacionais principais cujas definições diferem pela soma ou subtração do parâmetro $\dot{s}$ ao tempo médio lunar $(\dot{\tau})$.

Doodson (1922) introduziu uma notação que tornou possível a classificação automática de todas as ondas de maré deduzidas teoricamente na ordem crescente de suas velocidades.

O parâmetro utilizado, o qual ele denominou número de argumento, é deduzido a partir de uma expressão matemática que envolve o próprio argumento. Este é escrito como uma função das seis variáveis independentes definidas em 3.5.2:

$$
a \dot{\tau}+b \dot{s}+c \dot{h}+d \dot{p}+e \dot{N}^{\prime}+f \dot{p}_{s}
$$

O número do argumento ou número de Doodson é obtido pela combinação de seis algarismos consecutivos como se segue:

$$
a,(b+5),(c+5),(d+5),(e+5),(f+5)
$$

De acordo com 3.54, os valores tomados para $a$ variam de 0 a 9 enquanto para os demais de -4 a 4 onde o sinal é levado em conta nesta expressão.

Os primeiros três algarismos estão associados às variáveis que representam as maiores velocidades. Logo, são separados dos três últimos por um ponto. Segue alguns exemplos na Tabela 2 .

\begin{tabular}{c|l|c} 
Onda & Argumento & Número do argumento (i) \\
\hline$M_{2}$ & $2 \dot{\tau}$ & 255.555 \\
\hline$S_{2}$ & $2 \dot{\tau}-2 \dot{h}+2 \dot{s}$ & 273.555 \\
\hline$N_{2}$ & $2 \dot{\tau}-\dot{s}+\dot{p}$ & 245.655 \\
\hline$Q_{1}$ & $\dot{\tau}-2 \dot{s}+\dot{p}$ & 135.655
\end{tabular}

Tabela 2: Exemplos de determinação do número de Doodson 
Os três últimos algarismos do número do argumento representam os efeitos de uma variação cujo período é longo e sua distinção só é possível a partir da análise de um extenso período contínuo de observações. Já os três primeiros são denominados de número componente. Trata-se de um número que diferencia quais dentre as ondas de maré podem ser caracterizadas a partir de um período mínimo de observações.

Se o número componente for diferente de cinco no terceiro algarismo, a onda correspondente só é identificada com boa precisão a partir de um ano de observações contínuas. Os dois primeiros algarismos representam o número de grupo. A partir de um mês de observações é possível diferenciar os grupos. E, com alguns dias de observação, pode-se diferenciar as ondas diurnas das semi-diurnas que são diferenciadas pelos algarismos 1 e 2 no primeiro dígito do número constituinte.

A Tab. 3 fornece o número do argumento para algumas ondas além das mencionadas neste texto. Como os índices são classificados em ordem crescente, as ondas estão dispostas na tabela de acordo com o aumento de suas velocidades.

\subsection{Cálculo da magnitude do fenômeno de maré}

Mensurar as diversas componentes derivadas da ação da força de maré em um determinado local não é uma tarefa tão simples. Exige instrumentos distintos pois além da variação gravimétrica, a crosta, assim como a massa oceânica, sofrem deslocamentos e geram outros diante de sua movimentação. Estes por sua vez, não ocorrem em uma só direção.

Seja um sistema de eixos ortogonais entre si (Figura 15). A origem coincide com um ponto onde a componente da força de maré é aplicada. O eixo z tem a direção da vertical deste ponto, orientado para o exterior. Os componentes da força de maré ao longo das três principais direções são ilustrados na Figura 15, e dados pelas equações a seguir: 


\begin{tabular}{|c|c|c|c|c|c|}
\hline Nome & $\mathbf{i}$ & Argumento & $\mathbf{f}^{a}$ & Ampl. ${ }^{b}$ & Origem \\
\hline \multicolumn{6}{|c|}{ Componentes de longo período } \\
\hline$M_{0}$ & 055.555 & 0 & $0^{\circ}$ & +50458 & L constante de achatamento \\
\hline$S_{0}$ & 055.555 & 0 & $0^{\circ}$ & +23411 & S constante de achatamento \\
\hline$S_{a}$ & 056.554 & $h-p_{S}$ & $0,041067^{\circ}$ & +1176 & S onda elíptica \\
\hline$S s_{a}$ & 057.555 & $2 h$ & $0,082137^{\circ}$ & +7287 & S onda declinacional \\
\hline$M_{m}$ & 065.455 & $s-p$ & $0,544375^{\circ}$ & +8254 & L onda elíptica \\
\hline$M_{f}$ & 075.555 & $2 s$ & $1,098033^{\circ}$ & +15642 & L onda declinacional \\
\hline \multicolumn{6}{|c|}{ Componentes diurnas } \\
\hline$Q_{1}$ & 135.655 & $(\tau-s)-(s-p)$ & $13,398661^{\circ}$ & +7216 & L onda elíptica de $O_{1}$ \\
\hline$O_{1}$ & 145.555 & $\tau-s$ & $13,943036^{\circ}$ & +37689 & L principal onda lunar \\
\hline$M_{1}$ & 155.655 & $(\tau+s)-(s-p)$ & $14,496694^{\circ}$ & -2964 & L onda elíptica de ${ }^{m} K_{1}$ \\
\hline$\pi_{1}$ & 162.556 & $(t-h)-\left(h-p_{s}\right)$ & $14,917865^{\circ}$ & +1029 & S onda elíptica de $P_{1}$ \\
\hline$P_{1}$ & 163.555 & $t-h$ & $14,958931^{\circ}$ & +17554 & S principal onda solar \\
\hline$S_{1}$ & 164.556 & $(t+h)-\left(h-p_{s}\right)$ & $15,000002^{\circ}$ & -423 & S onda elíptica de ${ }^{s} K_{1}$ \\
\hline${ }^{m} K_{1}$ & 165.555 & $\tau+s=t^{\prime}$ & $15,041069^{\circ}$ & -36233 & L onda declinacional \\
\hline${ }^{s} K_{1}$ & 165.555 & $t+h=t^{\prime}$ & $15,041069^{\circ}$ & -16817 & S onda declinacional \\
\hline$\psi_{1}$ & 166.554 & $(t+h)+\left(h-p_{s}\right)$ & $15,082135^{\circ}$ & -423 & S onda elíptica de ${ }^{s} K_{1}$ \\
\hline$\phi_{1}$ & 167.555 & $t+3 h$ & $15,123206^{\circ}$ & -756 & S onda eclinacional \\
\hline$J_{1}$ & 175.455 & $(\tau+s)+(s-p)$ & $15,585443^{\circ}$ & -2964 & L onda elíptica de ${ }^{m} K_{1}$ \\
\hline$O O_{1}$ & 166.554 & $\tau+3 s$ & $16,139102^{\circ}$ & -1623 & L onda declinacional \\
\hline \multicolumn{6}{|c|}{ Componentes semi-diurnas } \\
\hline $2 N_{2}$ & 235.755 & $2 \tau-2(s-p)$ & $27,895355^{\circ}$ & +2301 & L onda elíptica de $M_{2}$ \\
\hline$\mu_{2}$ & 237.555 & $2 \tau-2(s-h)$ & $27,968208^{\circ}$ & +2777 & L onda de variação \\
\hline$N_{2}$ & 245.655 & $2 \tau-(s-p)$ & $28,439730^{\circ}$ & +17387 & L maior onda elíptica de $M_{2}$ \\
\hline$\nu_{2}$ & 247.455 & $2 \tau-(s-2 h+p)$ & $28,512583^{\circ}$ & +3303 & L "evection wave" \\
\hline$M_{2}$ & 255.555 & $2 \tau$ & $28,984104^{\circ}$ & +90812 & L onda principal \\
\hline$\lambda_{2}$ & 263.655 & $2 \tau+(s-2 h+p)$ & $29,455625^{\circ}$ & -670 & L "evection wave" \\
\hline$L_{2}$ & 265.455 & $2 \tau+(s-p)$ & $29,528479^{\circ}$ & -2567 & L menor onda elíptica de $M_{2}$ \\
\hline$T_{2}$ & 272.556 & $2 t-\left(h-p_{s}\right)$ & $29,958933^{\circ}$ & +2479 & S maior onda elíptica de $S_{2}$ \\
\hline$S_{2}$ & 273.555 & $2 t$ & $30,000000^{\circ}$ & +42286 & S onda principal \\
\hline$R_{2}$ & 274.554 & $2 t+\left(h-p_{s}\right)$ & $30,041067^{\circ}$ & -354 & S menor onda elíptica de $S_{2}$ \\
\hline${ }^{m} K_{2}$ & 275.555 & $2(\tau+s)=2 t^{\prime}$ & $30,082137^{\circ}$ & +7858 & L onda declinacional \\
\hline${ }^{s} K_{2}$ & 275.555 & $2(t+h)=2 t^{\prime}$ & $30,082137^{\circ}$ & +3648 & S onda declinacional \\
\hline \multicolumn{6}{|c|}{ Componentes ter-diurnas } \\
\hline$M_{3}$ & 355.555 & $3 \tau$ & $43,476156^{\circ}$ & -1188 & L onda principal \\
\hline
\end{tabular}

Tabela 3: Principais ondas de maré (Fonte: Melchior (1983))

${ }^{a}$ Freqüência em graus/hora.

${ }^{b}$ Amplitude em $\boldsymbol{\mu g a l}$.

$$
\begin{aligned}
& F_{Z}=-\frac{\delta W}{\delta a} \\
& F_{X}=-\frac{\delta W}{a \delta \phi} \\
& F_{Y}=-\frac{\delta W}{a \cos \phi \delta \lambda}
\end{aligned}
$$




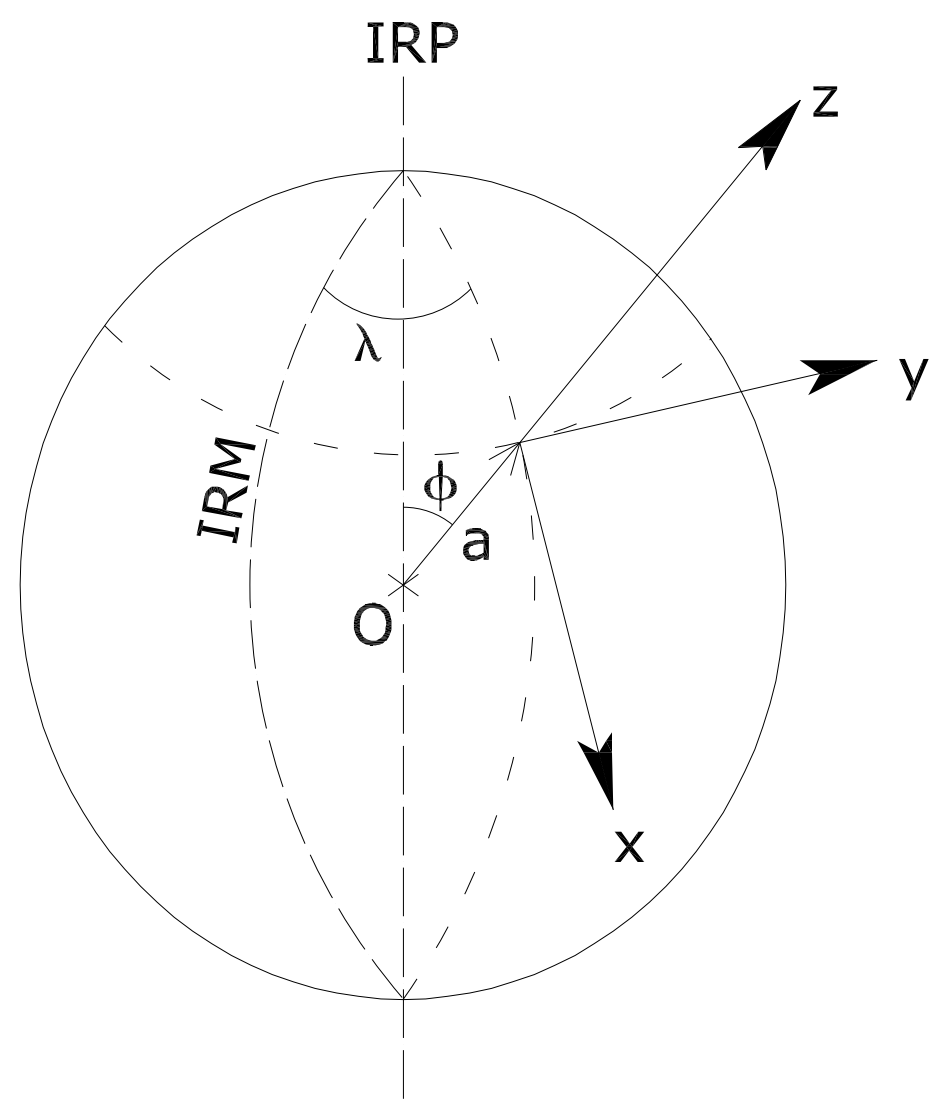

Figura 15: Sistema de eixos cartesianos

Para cada uma destas equações, existem três argumentos trigonométricos de acordo com a família de ondas representados na Tabela 4 .

\begin{tabular}{c|c|c|c} 
Função & $\boldsymbol{F}_{\boldsymbol{Z}}$ & $\boldsymbol{F}_{\boldsymbol{X}}$ & $\boldsymbol{F}_{\boldsymbol{Y}}$ \\
\hline zonal & $3\left(\sin ^{2} \phi-\frac{1}{3}\right)\left(\sin ^{2} \delta-\frac{1}{3}\right)$ & $-3 \sin 2 \phi\left(\sin ^{2} \delta-\frac{1}{3}\right)$ & - \\
tesseral & $\sin 2 \phi \sin 2 \delta \cos A H$ & $-2 \cos 2 \phi \sin 2 \delta \cos A H$ & $2 \sin \phi \sin 2 \delta \sin A H$ \\
setorial & $\cos ^{2} \phi \cos ^{2} \delta \cos 2 A H$ & $\sin 2 \phi \cos ^{2} \delta \cos 2 A H$ & $\cos \phi \cos ^{2} \delta \sin 2 A H$
\end{tabular}

Tabela 4: Argumentos trigonométricos das três famílias de maré (Fonte: Ducarme $(2005))$

Uma superfície equipotencial é aquela na qual qualquer deslocamento não envolve trabalho. Suponha uma superfície qualquer cuja equação está representada a seguir:

$$
V=h_{1}
$$

$h_{1}$ é a altura geopotencial à superfície de referência. Tal superfície, pode ser o geóide, 
cuja equação deve ser:

$$
V=0
$$

A aceleração da gravidade é dada por:

$$
g=-\frac{\delta V}{\delta r}
$$

onde $r$ é o raio em metros ao longo da vertical do ponto considerado. Segundo Melchior (1983), com a aplicação da força de maré, a superfície equipotencial é deformada, e o ponto $P(r)$ é transportado para $P(r+\xi)$, onde o potencial da Terra é dado, segundo um desenvolvimento de Taylor para $n=1$ :

$$
V(r+\xi)=V(r)+\xi \frac{\delta V(r)}{\delta r}
$$

Desta forma, a equação da superfície equipotencial de altura $h_{1}$ se torna:

$$
V+\xi \frac{\delta V}{\delta r}+W=h_{1}
$$

Substituindo (3.56) e (3.58) em (3.60) encontra-se a expressão que representa a maré do geóide:

$$
\xi=\frac{W}{g}
$$

Desta forma, conclui-se que o trabalho realizado no transporte de uma unidade de massa de um nível inicial para um nível perturbado equivale ao produto $\xi g$, que deve ser igual à variação de potencial $W$.

A partir de (3.33) é possível estimar a ordem de grandeza dos diferentes fenômenos de maré. Iniciemos pela maré do geóide. Atribuindo para a constante $\frac{D}{g}$ o valor de 
0,2676 m, enquanto o termo trigonométrico de (3.33) varia de $\frac{4}{3}$ a $-\frac{2}{3}$, o deslocamento devido à maré lunar alcança $53,52 \mathrm{~cm}$, e a contribuição solar é de 24,61 cm. O total, em ocasiões especiais, alcança 78,13 cm. A Tabela 5 mostra, além destes deslocamentos, as variações na gravidade e na inclinação da vertical, cujas demonstrações foram omitidas neste trabalho.

\begin{tabular}{l|c|c|c} 
Fator de escala & Lua & Sol & Total \\
\hline Marés do geóide $\left(\xi=\frac{D}{g}\right)$ & $54 \mathrm{~cm}$ & $25 \mathrm{~cm}$ & $79 \mathrm{~cm}$ \\
Marés gravimétricas $\left(\Delta g=-\frac{2 D}{a}\right)$ & $165 \mu \mathrm{gal}$ & $76 \mu \mathrm{gal}$ & $241 \mu \mathrm{gal}$ \\
Marés clinométricas $\left(n=\frac{2 D}{a g}\right)$ & $170 \mathrm{nrad}$ & $80 \mathrm{nrad}$ & $250 \mathrm{nrad}$
\end{tabular}

Tabela 5: Amplitudes máximas para uma Terra rígida (Fonte: Ducarme (2005))

\subsection{Deformações elásticas da Terra devido aos efeitos da força de maré}

Até a seção anterior a Terra foi considerada um corpo rígido e indeformável. Porém o nosso planeta é um corpo elástico, ou seja, sujeito a deformações. Estas, por sua vez, dependem não só das propriedades elásticas do corpo, como também da intensidade das forças e do tempo que elas permanecem aplicadas.

Segundo Gemael (1986), o potencial de maré num ponto $P$, no caso da Terra sólida (sem oceanos) e elástica, é composta de três parcelas:

$$
W=W^{\prime}+W^{\prime \prime}+W^{\prime \prime \prime}
$$

onde $W^{\prime}$ representa o potencial de maré da Terra sólida e indeformável, segundo (3.35), no caso de $n=2$. $W^{\prime \prime}$ é a variação do potencial decorrente da redistribuição de massas determinada pela deformação da Terra elástica em resposta às perturbações dos corpos celestes. $W^{\prime \prime \prime}$ é a variação do potencial devido ao deslocamento do ponto $P$. As duas últimas correspondem ao efeito indireto da força de maré.

A resposta da Terra à força de maré, sob a forma de deformações do corpo ter- 
restre e das equipotenciais, está representado na Figura 16. S é a superfície equipotencial $\left(W_{G}\right)$ da Terra rígida não perturbada. O potencial de maré $W^{\prime}$ gera uma nova superfície $E^{\prime}\left(W_{G}+W^{\prime}\right)$, separada $u_{R}$ da anterior. O planeta, considerado elástico, tende a deformarse atingindo a forma de equilíbrio ajustando-se à superfície equipotencial $S_{1}$. O ponto $P$ desloca-se para $P_{1}$ apresentando uma deformação radial $u$. Como efeitos indiretos, a deformação da Terra não rígida implica em uma redistribuição de massas e, conseqüentemente, em uma variação de potencial em $P$. O deslocamento de $P$ para uma nova posição determina mais uma variação de potencial, $W^{\prime \prime \prime}$, resultando uma nova equipotencial $E_{1}$.

Tomando-se como hipótese que a deformação elástica é diretamente proporcional à força aplicada, em 1909 Love introduziu dois novos parâmetros em elasticidade esférica, h e k, que recebem o nome de números de Love. Em 1912, Shida introduziu um terceiro número 1. Estes três parâmetros são simplesmente fatores de proporcionalidade, portanto, adimensionais.

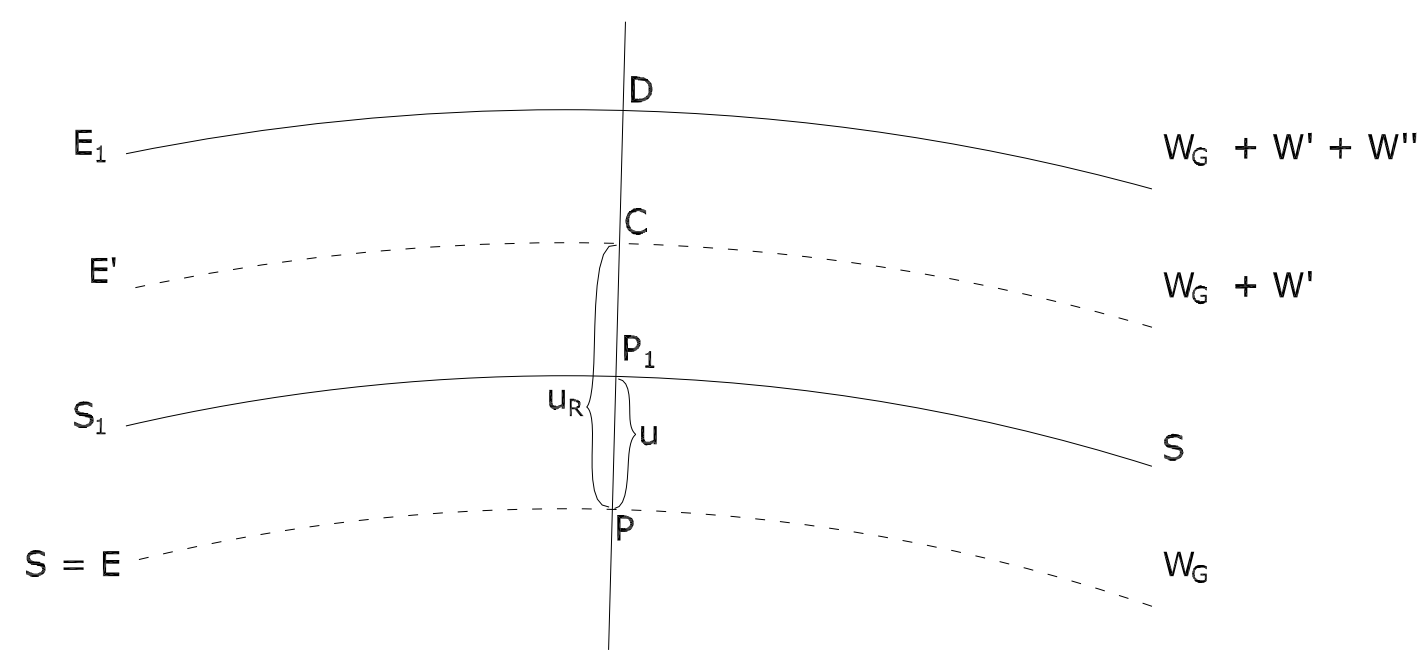

Figura 16: Resposta da Terra sólida e elática à força de maré

Na Figura 16, vê-se que pela ação do potencial $W^{\prime}$, a equipotencial $E$ passa para 
$E_{1}$ sofrendo uma deformação $u_{R}$, ou seja:

$$
u_{R}=\frac{W^{\prime}}{g}
$$

Como visto na mesma figura, a Terra elástica sofre uma deformação $u$. O número de Love $\mathbf{h}$ relaciona as duas deformações, $u_{R}$ e $u$, caracterizando o deslocamento radial:

$$
h=\frac{u}{u_{R}}
$$

Também pode-se dizer que:

$$
u=\frac{W^{\prime \prime \prime}}{g}
$$

Substituindo (3.63) e (3.65) em (3.64), tem-se:

$$
h=\frac{W^{\prime \prime \prime}}{W^{\prime}}
$$

O número de Love $\mathbf{k}$ relaciona o potencial de maré $W^{\prime}$ e o potencial de deformação $W^{\prime \prime}$, caracterizando, assim, a mudança de potencial devido às redistribuições de massa:

$$
k=\frac{W^{\prime \prime}}{W^{\prime}}
$$

O número de Shida 1 caracteriza os deslocamentos horizontais nas direções lesteoeste (v) e norte-sul (u). São expressos da seguinte forma, respectivamente:

$$
\begin{gathered}
u=\frac{l}{g} \frac{\delta W_{2}}{\delta \varphi} \\
v=\frac{l}{g \cos \varphi} \frac{\delta W_{2}}{\delta \lambda}
\end{gathered}
$$


A Tabela 5 exibe valores de amplitudes para uma Terra rígida. Ao considerar a sua elasticidade introduzindo os números de Love e Shida tem-se uma nova tabela com os valores máximos de amplitude para uma Terra elástica, Tabela 6 . 


\begin{tabular}{l|c|c|c|c} 
Fator de escala & Lua & Sol & Total & Amplificação \\
\hline Marés do geóide $\left(\zeta=(1+k) \frac{D}{g}\right)$ & $70 \mathrm{~cm}$ & $32 \mathrm{~cm}$ & $102 \mathrm{~cm}$ & 1,30 \\
Marés gravimétricas $\left(\Delta g=-\left(1+h-\frac{3}{2} k\right) \frac{2 D}{a}\right)$ & $191 \mu \mathrm{gal}$ & $88 \mu \mathrm{gal}$ & $280 \mu \mathrm{gal}$ & 1,16 \\
Marés clinométricas $\left(n=(1+k-h) \frac{2 D}{a g}\right)$ & $117 \mathrm{nrad}$ & $55 \mathrm{nrad}$ & $172 \mathrm{nrad}$ & 0,69 \\
Deslocamento radial $\left(u_{r}=h \frac{D}{g}\right)$ & $32 \mathrm{~cm}$ & $15 \mathrm{~cm}$ & $47 \mathrm{~cm}$ & 0,60 \\
Deslocamento tangencial $\left(u_{\theta}=l \frac{2 D}{g}\right)$ & $9 \mathrm{~cm}$ & $5 \mathrm{~cm}$ & $13 \mathrm{~cm}$ & 0,08
\end{tabular}

Tabela 6: Amplitudes máxima para uma Terra elástica (Fonte: Ducarme (2005)) 


\section{Processamento e análise dos dados de nível do mar}

\subsection{Introdução}

As oscilações do nível do mar, função da força geradora de maré, se aproximam de um fenômeno periódico, o qual, teoricamente, é composto por um número infinito de ondas senoidais e cossenoidais. Cada uma dessas ondas, em um determinado ponto da superfície terrestre, pode ser caracterizada pela sua amplitude e por sua fase. Entende-se por amplitude de uma onda a diferença entre as alturas máxima e mínima provocadas pela ação da força de maré. Em oceanografia, as fases estão referidas a Greenwich.

Cada um destes parâmetros pode ser obtido a partir de modelos globais de maré oceânica em função das coordenadas geográficas da estação. Atualmente, existem diversos modelos com diferentes resoluções e coberturas. Outra forma de obtê-los consiste na análise da série temporal de medições do nível do mar numa estação específica. Estas medições são realizadas pelos marégrafos.

Neste trabalho, foram utilizados os dados da base de Cananéia, citada anteriormente na Seção 2.5, obtidos junto ao IOUSP. O processamento destes dados foi realizado pelo programa VAV (VENEDIKOV; ARNOSO; VIEIRA, 2003), inicialmente desenvolvido para análise de séries temporais de marés terrestres através do método dos mínimos quadrados. Em uma versão mais recente, suas ferramentas foram ampliadas permitindo a análise das observações referentes às marés oceânicas. 


\subsection{Pré-processamento das observações}

A estação maregráfica de Cananéia possui a maior série temporal de dados do nível do mar no Brasil. Desde 26/02/1954 a variação do nível do mar é mensurada pelo mesmo marégrafo AOTT. Neste trabalho, o período analisado corresponde do início da série a 31/12/2004. Durante este intervalo, ocorreram interrupções devido a problemas operacionais as quais corresponderam a 1.368 horas num total de 445.727 horas, ou seja, 0,3\% de todo o período. Os dados brutos registrados pelo marégrafo passam por um processo de digitalização e conversão para dados horários. A título de exemplo, a Figura 17 mostra os dados horários do nível do mar no ano de 1976.

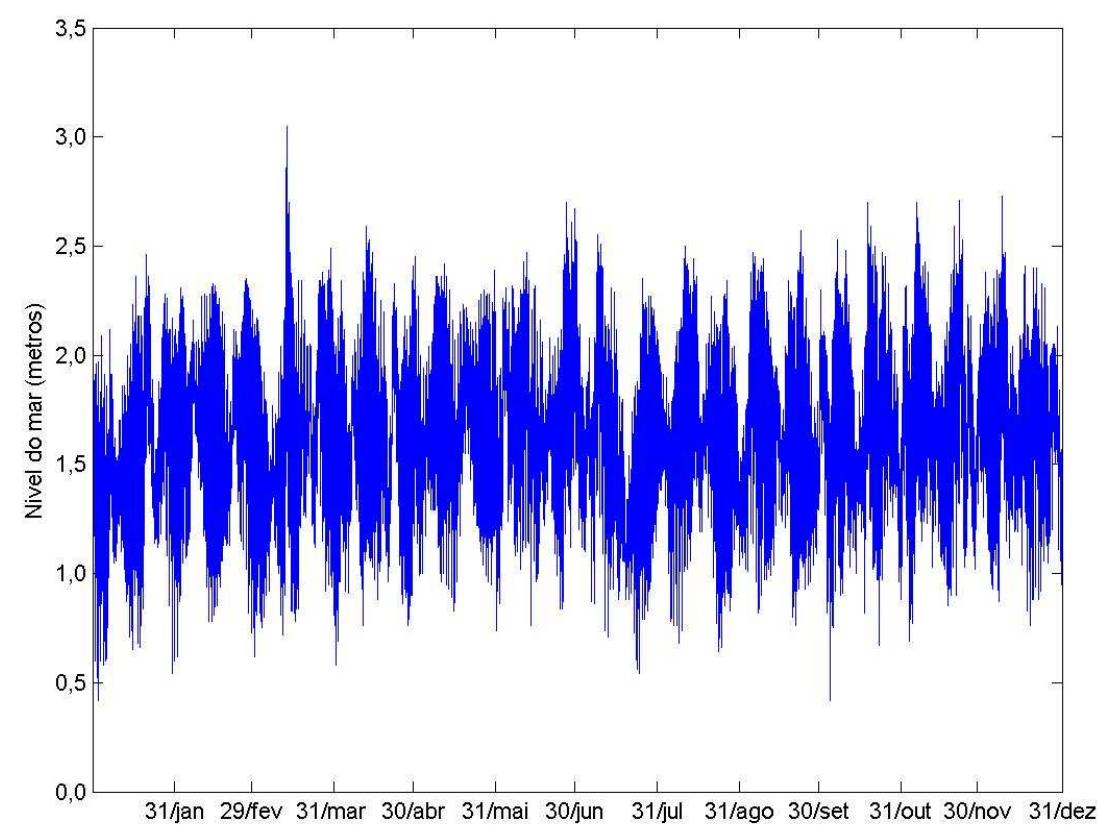

Figura 17: Nível do mar registrado no marégrafo de Cananéia durante o ano de 1976

Através da análise visual dos registros do nível do mar (Figura 17), constata-se que há diversos pontos ou intervalos com valores discrepantes. Eles podem representar algum fenômeno isolado mas podem ser prejudiciais às análises em questão. Para detectá-los foram encontrados os resíduos para as principais ondas diurnas e semi-diurnas. Utilizando um nível de confiança de 99,9\%, ou $3 \sigma$, considerando a distribuição $t$ de Student, encontrou-se um valor limite para as ondas diurnas (Figura 18) e para as semi-diurnas 
(Figura 19).

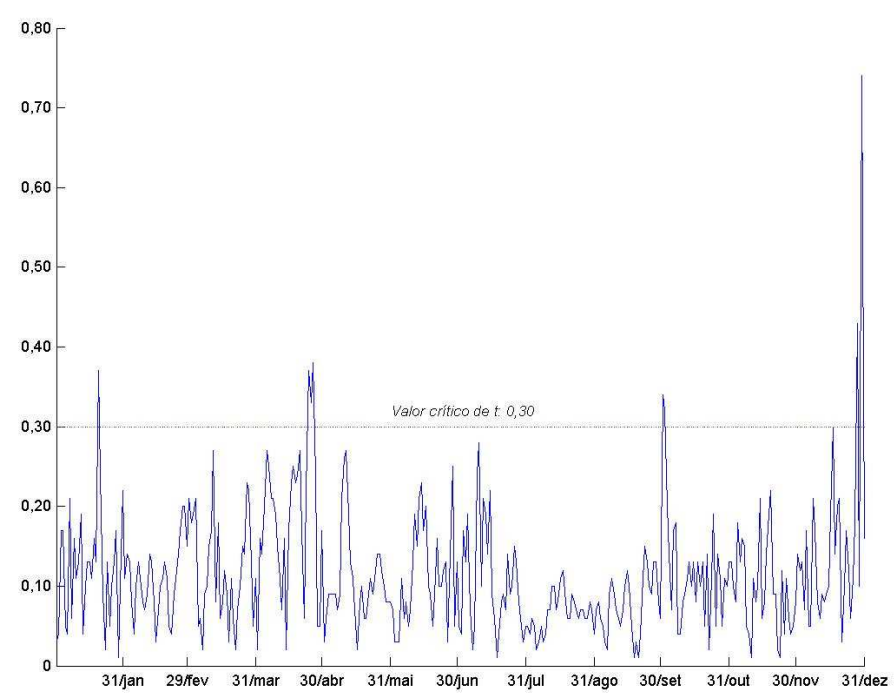

Figura 18: Resíduos das ondas diurnas principais, em metros, durante o ano de 1976

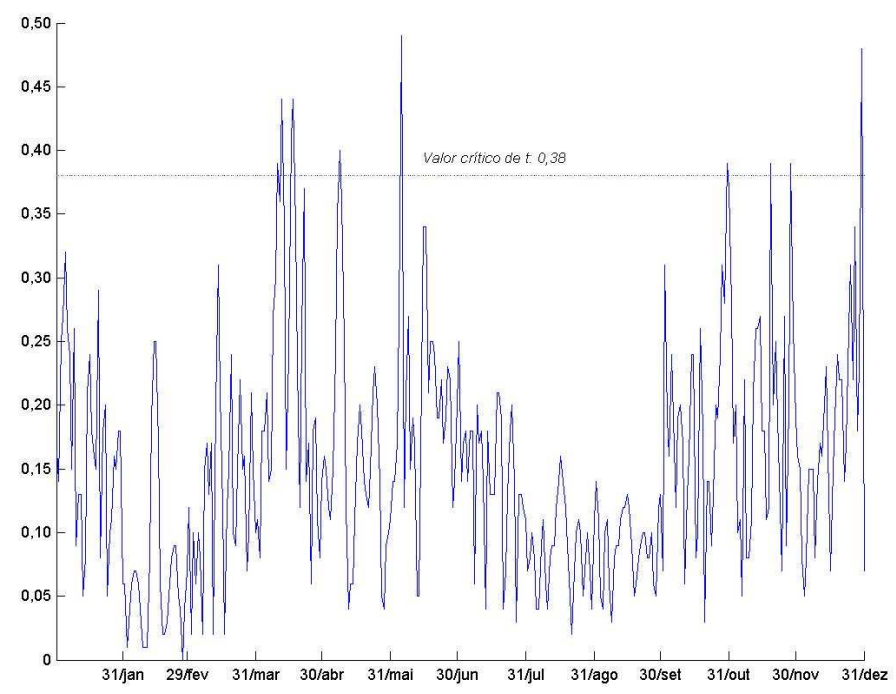

Figura 19: Resíduos das ondas semi-diurnas principais, em metros, durante o ano de 1976

Para elevar a qualidade da análise, os intervalos que apresentaram resíduos superiores ao valor crítico de $t$ calculado para a amostra foram removidos. Este procedimento automático de remoção foi usado nesta situação diante do volume de dados, pois eliminar cada um dos eventos anômalos seria uma tarefa longa. Desta forma, os dados foram preparados para a análise. Este é o objetivo do pré-processamento. Embora os dados 
brutos do marégrafo tenham sido digitalizados e convertidos para dados horários, o que significa que já houve um processo de filtragem, este procedimento é de grande importância e deve ser realizado. No entanto, isto não garante maior precisão nos resultados finais pois a remoção de grandes intervalos pode prejudicar a análise. A maneira de encontrar este equilíbrio, ou seja, saber o quanto a remoção de dados é benéfica para a análise em questão, é a observância do valor do Akaike Information Criterion (AIC), ou Critério de Informação de Akaike (VENEDIKOV; ARNOSO; VIEIRA, 2003), fornecido pelo programa. Segundo Posada e Buckley (2004), o AIC é um estimador que representa a quantidade de informação perdida quando se usa um modelo $g$ para se aproximar de um modelo $f$. Quanto menor o valor fornecido pelo AIC, mais apropriado é o modelo para a análise dos dados. Na série de dados do nível do mar de Cananéia, após cada remoção, um valor de AIC foi obtido. Quando o valor seguinte foi superior ao anterior, interrompeu-se o procedimento e adotou-se a última série obtida como a melhor representação do modelo de variação do nível do mar.

Após a remoção destes intervalos tem-se novas séries com novos valores críticos de $t$, menores que os anteriores, representados nas Figuras 20 e 21. O valor será menor pois os intervalos que contribuíram com um valor residual maior, num total de 4,9\%, foram eliminados. Para toda a série foi realizado o mesmo procedimento, eliminando-se $3,2 \%$ dos dados.

\subsection{Comparação entre modelos de maré oceânica}

Os modelos de maré oceânica são utilizados, principalmente, para a previsão das tábuas de maré. Além disso, também são usados para o cálculo teórico do efeito de carga oceânica e da maré polar. Outro exemplo de sua aplicação é que, em qualquer análise de dados de nível do mar, uma forma de encontrar os resíduos de uma série é remover do sinal de maré coletado um modelo teórico.

Um modelo de maré oceânica fornece os parâmetros, amplitude e fase, para as 


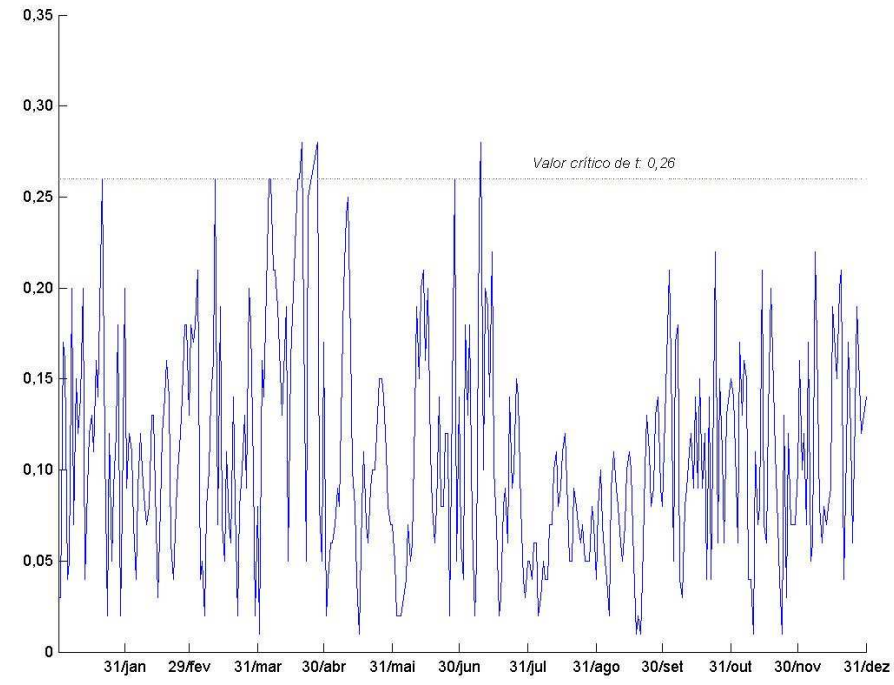

Figura 20: Resíduos das ondas diurnas principais durante o ano de 1976, após a remoção de alguns intervalos

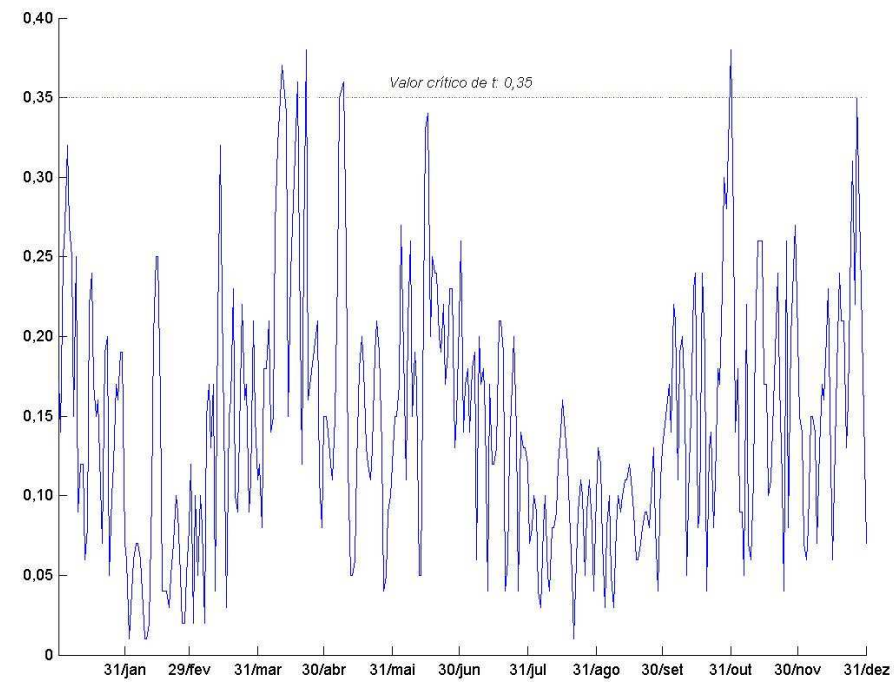

Figura 21: Resíduos das ondas semi-diurnas principais durante o ano de 1976, após a remoção de alguns intervalos

principais ondas diurnas (O1, Q1, P1 e K1) e semi-diurnas (N2, M2, S2 e K2) em função da localização geográfica. Somente alguns modelos recentes dispõem das componentes para ondas de longo período (Mf), como o GOT99.2 (RAY, 1999).

Estes modelos podem ser desenvolvidos a partir de equações hidrodinâmicas, com a introdução de dados altimétricos, sejam de marégrafos (SCHWIDERSKI, 1980), ou 
de satélites (PROVOST et al., 1998), ou de ambos (MAZZEGA; MERGE; FRANCIS, 1994). Há modelos sem a introdução de algum tipo de observação (PROVOST et al., 1994) enquanto há outros em que foram utilizados somente dados maregráficos e de satélites, como no modelo gerado a partir dos dados do satélite Geosat (CARTWRIGHT; RAY, 1990). Os modelos utilizados neste trabalho estão na Tabela 7. O modelo de Schwiderski (1980) é o mais antigo dentre eles e muito utilizado até hoje sendo sua acurácia suficiente para muitas aplicações geofísicas (ZAHRAN; JENTZSCH; SEEBER, 2005).

\begin{tabular}{|c|c|c|}
\hline Modelo & Resolução & Cobertura \\
\hline Schwiderski & $1,0^{\circ} \times 1,0^{\circ}$ & $90^{\circ} \mathrm{N}-78^{\circ} \mathrm{S}$ \\
\hline ORI96 & $0,5^{\circ} \times 0,5^{\circ}$ & $89,75^{\circ} \mathrm{N}-77,75^{\circ} \mathrm{S}$ \\
\hline NAO99 & $0,5^{\circ} \times 0,5^{\circ}$ & $89,75^{\circ} \mathrm{N}-89,75^{\circ} \mathrm{S}$ \\
\hline GOT00 & $0,5^{\circ} \times 0,5^{\circ}$ & $90^{\circ} \mathrm{N}-90^{\circ} \mathrm{S}$ \\
\hline FES95 & $0,5^{\circ} \times 0,5^{\circ}$ & $90^{\circ} \mathrm{N}-85^{\circ} \mathrm{S}$ \\
\hline FES99 & $0,25^{\circ} \times 0,25^{\circ}$ & $90^{\circ} \mathrm{N}-85^{\circ} \mathrm{S}$ \\
\hline FES02 & $0,25^{\circ} \times 0,25^{\circ}$ & $90^{\circ} \mathrm{N}-85^{\circ} \mathrm{S}$ \\
\hline CSR3.0 & $0,5^{\circ} \times 0,5^{\circ}$ & $90^{\circ} \mathrm{N}-78^{\circ} \mathrm{S}$ \\
\hline CSR4.0 & $0,5^{\circ} \times 0,5^{\circ}$ & $90^{\circ} \mathrm{N}-90^{\circ} \mathrm{S}$ \\
\hline TPX0.6 & $0,25^{\circ} \times 0,25^{\circ}$ & $90,125^{\circ} \mathrm{N}-90,125^{\circ} \mathrm{S}$ \\
\hline
\end{tabular}

Tabela 7: Modelos de maré oceânica utilizados neste trabalho, suas respectivas resoluções e coberturas

Aplicou-se o programa VAV sobre os dados maregráficos, tanto para os préprocessados quanto para os que não o foram, obtendo-se os valores de amplitude e de fase para cada uma das principais ondas diurnas e semi-diurnas (Tabela 8).

\begin{tabular}{|c|c|c|c|c|c|c|c|c|}
\hline \multirow{2}{*}{ Ondas } & \multicolumn{4}{|c|}{ Análise 1 } & \multicolumn{4}{c|}{ Análise 2 } \\
\cline { 2 - 9 } & $\mathrm{A}^{a}$ & $\delta(A)$ & $\kappa^{b}$ & $\delta(\kappa)$ & $\mathrm{A}$ & $\delta(A)$ & $\kappa$ & $\delta(\kappa)$ \\
\hline $\mathrm{Q} 1$ & 3,16 & 0,15 & 98,2 & 2,8 & 3,10 & 0,00 & 98,4 & 0,0 \\
\hline $\mathrm{O} 1$ & 11,25 & 0,15 & 128,4 & 0,8 & 11,47 & 0,00 & 128,7 & 0,0 \\
\hline $\mathrm{P} 1$ & 2,88 & 0,16 & 198,6 & 3,3 & 2,97 & 0,00 & 196,8 & 0,1 \\
\hline $\mathrm{K} 1$ & 6,41 & 0,15 & 195,7 & 1,4 & 6,45 & 0,00 & 196,3 & 0,0 \\
\hline $\mathrm{N} 2$ & 5,59 & 0,22 & 259,3 & 2,3 & 5,74 & 0,00 & 258,7 & 0,0 \\
\hline $\mathrm{M} 2$ & 36,66 & 0,22 & 186,8 & 0,3 & 37,16 & 0,00 & 186,9 & 0,0 \\
\hline $\mathrm{S} 2$ & 23,78 & 0,21 & 194,0 & 0,5 & 23,99 & 0,00 & 194,2 & 0,0 \\
\hline $\mathrm{K} 2$ & 7,30 & 0,19 & 183,8 & 1,5 & 7,55 & 0,00 & 184,5 & 0,0 \\
\hline
\end{tabular}

Tabela 8: Componentes calculadas de maré oceânica para a estação de Cananéia

\footnotetext{
${ }^{a}$ Amplitude (cm).

${ }^{b} \mathrm{Fase}\left({ }^{\circ}\right)$.
} 
A análise 1 foi realizada com os dados que não foram pré-processados, e a análise 2, com os que o foram. Vê-se mais uma vez, comparando os desvios $\delta$ de cada uma das componentes, a importância do pré-processamento para a obtenção de resultados mais precisos.

A Tabela 9 contém as componentes, amplitude e fase, obtidas a partir dos modelos citados na Tabela 7, além dos valores obtidos para a estação de Cananéia, análise 2 da Tabela 8 .

\begin{tabular}{|l|c|c|c|c|c|c|c|c|c|}
\hline Ondas & & Q1 & O1 & P1 & K1 & N2 & M2 & S2 & K2 \\
\hline Valor & $\mathrm{A}^{a}$ & 3,10 & 11,47 & 2,97 & 6,45 & 5,74 & 37,16 & 23,99 & 7,55 \\
calculado & $\kappa^{b}$ & 98,4 & 128,7 & 196,8 & 196,3 & 258,7 & 186,9 & 194,2 & 184,5 \\
\hline Schwiderski & $\mathrm{A}$ & 3,20 & 9,00 & 1,90 & 5,00 & 4,00 & 35,00 & 17,00 & 4,30 \\
& $\kappa$ & 94,0 & 117,0 & 174,0 & 180,0 & 223,0 & 172,0 & 154,0 & 153,0 \\
\hline ORI96 & $\mathrm{A}$ & 4,10 & 12,91 & 1,14 & 4,84 & 8,47 & 34,91 & 20,58 & 5,44 \\
& $\kappa$ & 90,0 & 87,3 & 142,1 & 161,9 & 210,5 & 164,9 & 155,3 & 159,6 \\
\hline NAO99 & $\mathrm{A}$ & 2,85 & 11,00 & 2,13 & 3,44 & 9,08 & 33,25 & 24,21 & 6,96 \\
& $\kappa$ & 78,2 & 91,6 & 220,9 & 165,6 & 206,1 & 163,5 & 155,6 & 151,7 \\
\hline GOT00 & $\mathrm{A}$ & 2,65 & 9,94 & 1,68 & 4,95 & 7,67 & 34,45 & 24,25 & 7,12 \\
& $\kappa$ & 96,0 & 124,4 & 180,7 & 191,6 & 214,1 & 162,6 & 168,6 & 167,0 \\
\hline FES95 & $\mathrm{A}$ & 2,64 & 11,88 & 2,38 & 6,09 & 8,25 & 37,28 & 33,11 & 6,92 \\
& $\kappa$ & 96,0 & 121,6 & 172,6 & 185,1 & 215,2 & 202,4 & 199,7 & 172,9 \\
\hline FES99 & $\mathrm{A}$ & 2,85 & 11,29 & 0,91 & 7,02 & 4,97 & 34,95 & 25,57 & 8,26 \\
& $\kappa$ & 90,7 & 118,7 & 190,1 & 180,4 & 223,1 & 163,4 & 163,1 & 168,5 \\
\hline FES02 & $\mathrm{A}$ & 2,96 & 11,62 & 2,53 & 6,72 & 8,56 & 36,43 & 27,13 & 8,16 \\
& $\kappa$ & 92,5 & 118,2 & 179,3 & 188,4 & 222,4 & 165,6 & 166,4 & 169,3 \\
\hline CSR3.0 & $\mathrm{A}$ & 3,19 & 11,40 & 2,42 & 6,60 & 6,56 & 39,45 & 22,64 & 6,08 \\
& $\kappa$ & 96,7 & 120,0 & 172,5 & 176,4 & 213,4 & 167,3 & 165,7 & 168,8 \\
\hline CSR4.0 & $\mathrm{A}$ & 2,96 & 11,06 & 2,30 & 6,12 & 6,06 & 38,21 & 22,63 & 6,11 \\
& $\kappa$ & 95,5 & 121,0 & 172,5 & 177,1 & 210,6 & 163,5 & 165,8 & 169,2 \\
\hline TPX0.6 & $\mathrm{A}$ & 3,43 & 11,94 & 1,92 & 6,60 & 5,38 & 38,32 & 28,33 & 5,25 \\
& $\kappa$ & 103,01 & 116,26 & 171,88 & 187,74 & 226,08 & 155,36 & 168,66 & 169,83 \\
\hline
\end{tabular}

Tabela 9: Comparativo para as componentes principais de maré oceânica para a estação de Cananéia entre os valores calculados e os obtidos a partir de modelos globais

\footnotetext{
${ }^{a}$ Amplitude $(\mathrm{cm})$.

${ }^{b} \operatorname{Fase}\left({ }^{\circ}\right)$.
}

Comparar estes modelos com os valores obtidos para a estação e decidir qual deles se adapta melhor à região de Cananéia é uma tarefa que não deve ser realizada observando valores e gráficos apenas. As Figuras 22 e 23 demonstram tal dificuldade. Além do mais, 
como um sinal de maré é composto por suas duas pricipais componentes, amplitude e fase, esta comparação deve ser realizada observando-as em conjunto, como um vetor.

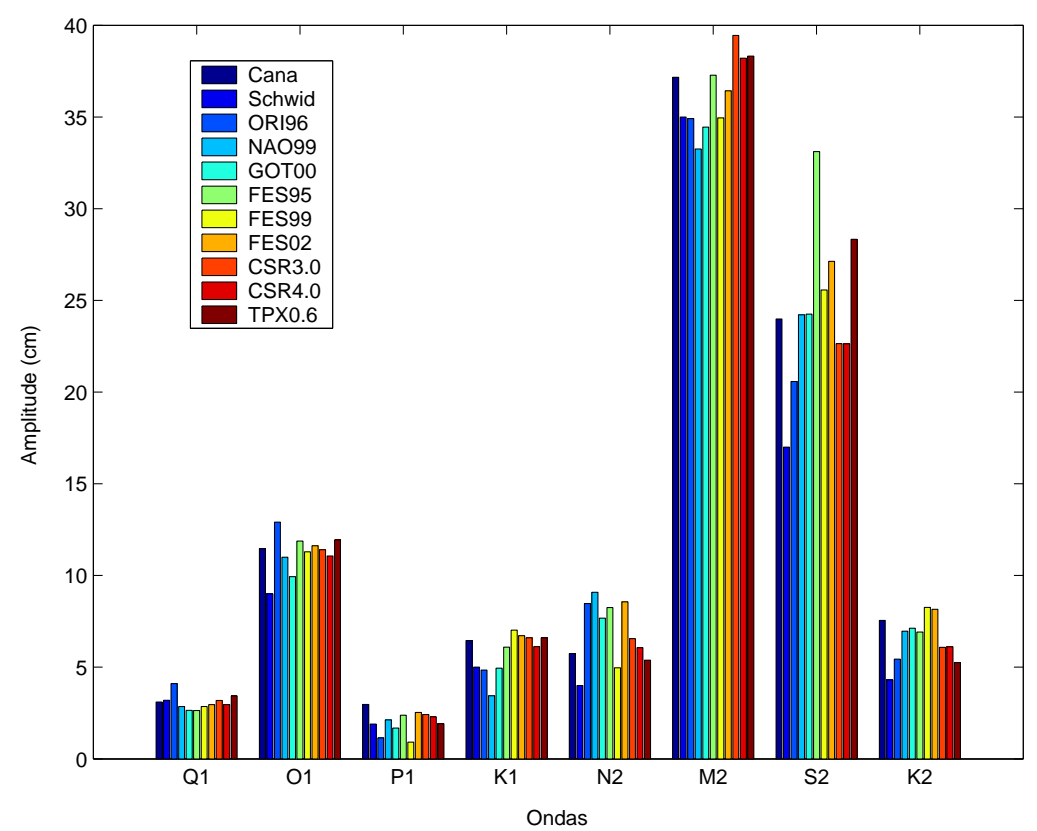

Figura 22: Comparação das amplitudes das ondas diurnas e semi-diurnas entre os dados de Cananéia e alguns modelos de maré oceânica

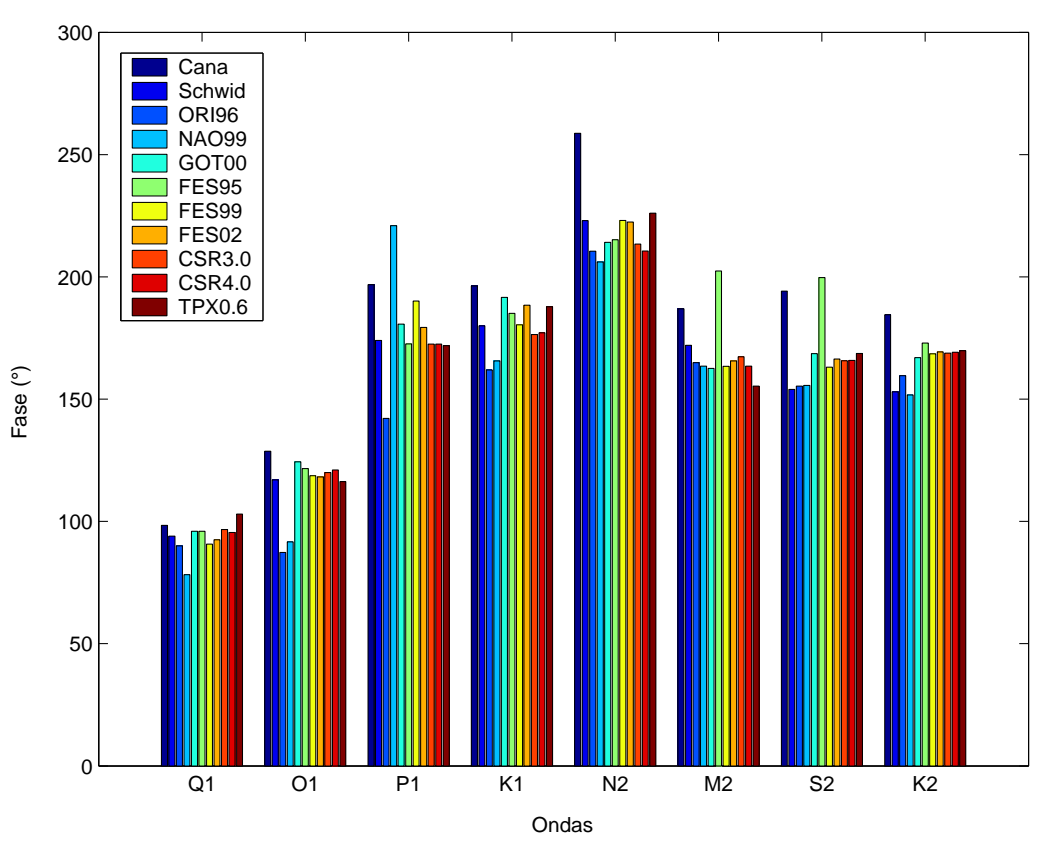

Figura 23: Comparação das fases das ondas diurnas e semi-diurnas entre os dados de Cananéia e alguns modelos de maré oceânica

Para tal, Andersen, Woodworth e Flather (1995) utilizaram em seu trabalho o Root Mean Square difference (RMS), ou diferença média quadrática. Neste trabalho, 
usou-se a diferença entre o vetor calculado, aquele obtido a partir da análise das observações maregráficas, e o interpolado, obtido a partir de um modelo, para cada uma das ondas. A Figura 24 apresenta graficamente esta diferença. Quanto menor o valor, mais apropriado será o modelo.

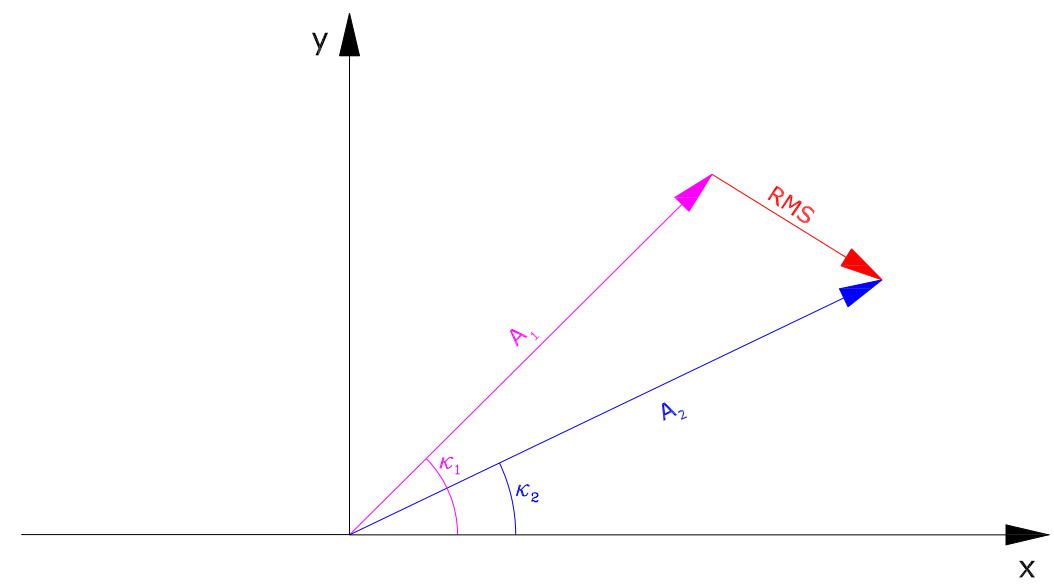

Figura 24: Desvio médio quadrático, obtido a partir da diferença entre o vetor calculado e o interpolado

Para uma determinada onda, esta diferença é calculada da seguinte forma:

$$
R M S=\sqrt{\frac{1}{N} \sum_{N}\left[\frac{1}{2}\left(A_{1} \cos \kappa_{1}-A_{2} \cos \kappa_{2}\right)^{2}+\left(A_{1} \sin \kappa_{1}-A_{2} \sin \kappa_{2}\right)^{2}\right]}
$$

Na equação (4.1), $A_{1}$ e $\kappa_{1}$ são, respectivamente, a amplitude e fase da onda obtidos através de um modelo, e $A_{2}$ e $\kappa_{2}$ são as componentes obtidas a partir da análise. $N$ é o número de comparações, neste caso, 1. Pode-se realizar este cálculo para um conjunto de ondas, como por exemplo, para aquelas que possuem os maiores valores de amplitude, $M 2, S 2, K 1, O 1$. Neste caso, aplica-se a seguinte variação da equação 4.1:

$$
R M S=\sqrt{\frac{1}{N} \sum_{N}\left[\frac{1}{2} \sum_{M 2, S 2, K 1, O 1}\left(A_{1} \cos \kappa_{1}-A_{2} \cos \kappa_{2}\right)^{2}+\left(A_{1} \sin \kappa_{1}-A_{2} \sin \kappa_{2}\right)^{2}\right]}
$$


Utilizando os dados da Tabela 9 e aplicando a equação acima para as ondas diurnas, para as semi-diurnas e para as quatro de maior intensidade, obtém-se os valores RMS (Tabela 10) que indicaram que o modelo mais apropriado para a estação de Cananéia é o FES95 (PROVOST; BENNETT; CARTWRIGHT, 1995).

\begin{tabular}{|c|c|c|c|}
\hline Modelo & Ondas diurnas & Ondas semi-diurnas & M1, O1, K2, S2 \\
\hline Schwiderski & 2,93 & 13,40 & 13,20 \\
\hline ORI96 & 6,97 & 15,42 & 16,03 \\
\hline NAO99 & 5,90 & 16,31 & 16,42 \\
\hline GOT00 & 1,96 & 13,76 & 13,30 \\
\hline FES95 & 1,69 & 10,58 & 9,88 \\
\hline FES99 & 2,48 & 14,34 & 14,26 \\
\hline FES02 & 1,79 & 13,66 & 13,25 \\
\hline CSR3.0 & 2,20 & 12,94 & 12,58 \\
\hline CSR4.0 & 2,08 & 14,03 & 13,68 \\
\hline TPX0.6 & 2,23 & 17,16 & 17,05 \\
\hline
\end{tabular}

Tabela 10: Valores de diferença RMS entre os modelos de maré oceânica e o valor calculado para Cananéia

Nas três situações, o valor da diferença RMS para o modelo FES95 foi o menor. O FES95 combinou soluções de equações hidrodinâmicas ao primeiro ano de dados da missão Topex/Poseidon. Com base nesta conclusão, para a remoção do efeito de carga oceânica a partir dos dados gravimétricos (Capítulo 5), este modelo foi utilizado.

\subsection{Variação relativa do NMM}

A variação relativa do NMM, que não leva em consideração a variação da crosta, foi encontrada utilizando o mesmo programa VAV. Em Ducarme et al. (2005), a mesma análise foi realizada levando em consideração a remoção de diversos outros efeitos. Neste capítulo, a partir de uma regressão linear simples encontrou-se o valor de variação ascendente de $21 \mathrm{~cm}$ em 50 anos, ou seja, 4,2 mm/ano. Este valor está próximo ao determinado por Mesquita, Harari e França (1995) que foi de 4,1 mm/ano. Já o valor de de 4, $6 \mathrm{~mm} /$ ano foi encontrado por Ducarme et al. (2005) que detectou uma descontinuidade na reta que representa a ascenção do NMM da ordem de $4 \mathrm{~cm}$ em Abril de 1975. Todas as determinações indicam um aumento do NMM. A Figura 25 exibe a ascenção do NMM 
ao longo dos 50 anos de coleta em Cananéia determinada neste trabalho. Em vermelho tem-se os pontos com os valores horários do nível do mar e em verde a tendência de aumento do nível médio.

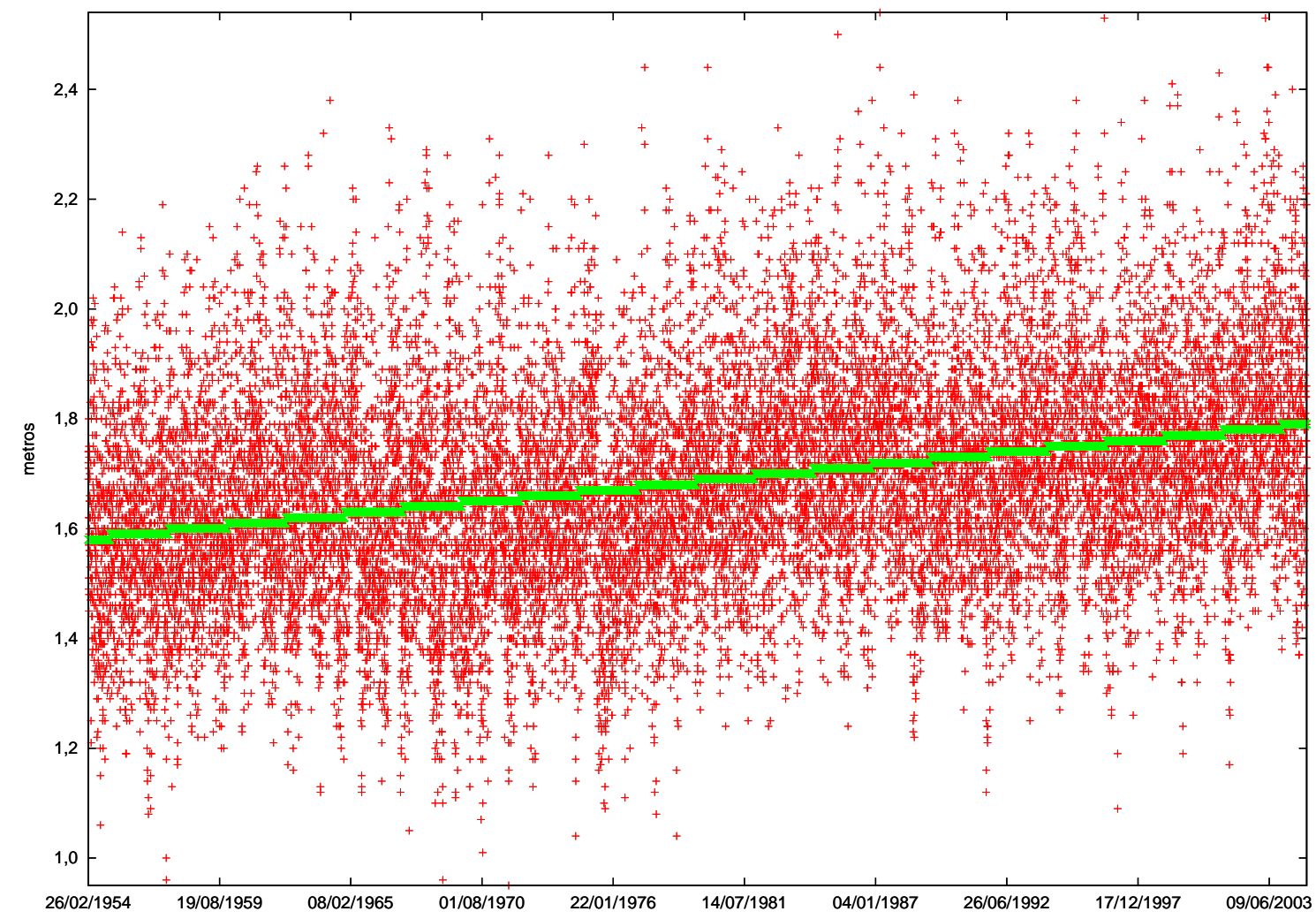

Figura 25: Ascenção do NMM ao longo dos 50 anos de coleta em Cananéia 


\section{Resultados derivados na estação Cananéia}

\subsection{O gravímetro astatizado e o seu comportamento instrumental}

De acordo com Freitas (1993), a maré terrestre, segundo respectivamente as componentes vertical, horizontal e a inclinação produzida na superfície, subdivide-se em maré gravimétrica, extensométrica e clinométrica.

Neste trabalho, o dispositivo utilizado para a observação das marés gravimétricas é um sensor, o gravímetro Geodynamics 783, ou simplesmente GEO783. Trata-se de um gravímetro astatizado cujo esquema de funcionamento é ilustrada na Figura 26.

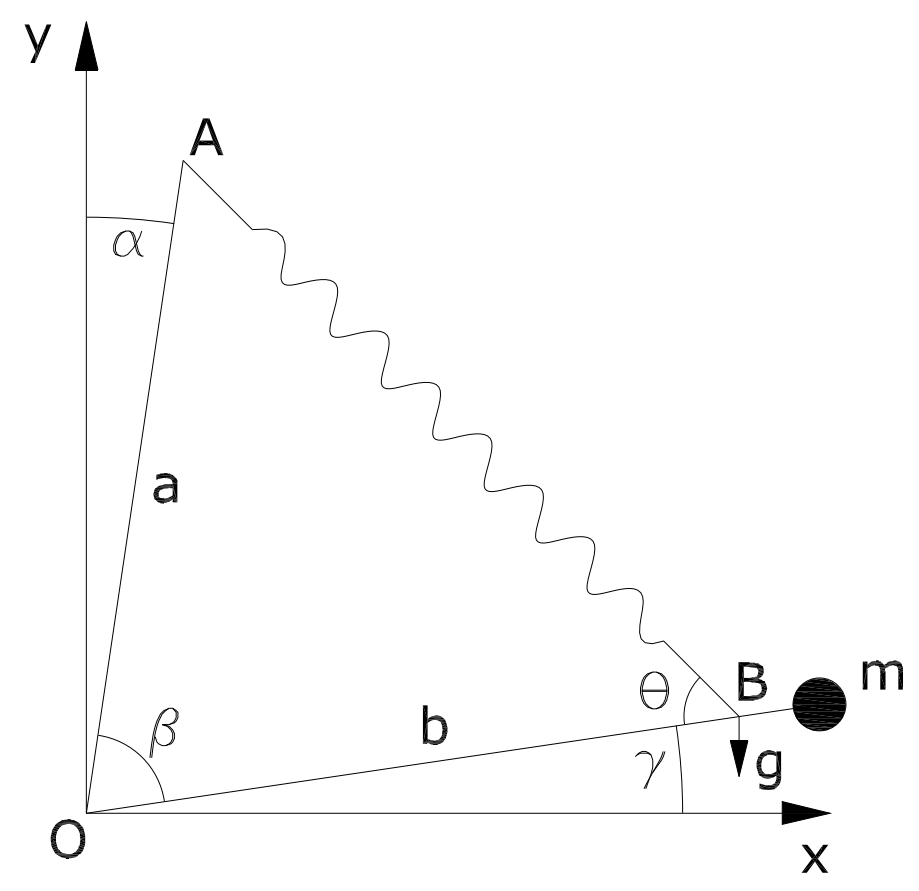

Figura 26: Geometria de um gravímetro astatizado 
Os eixos $x$ e $y$, ortogonais entre si, formam um plano de referência. O beam ${ }^{1}$, ou feixe do instrumento, que é constituído por uma haste com um peso de massa $m$ em sua extremidade, oscila em torno do eixo perpendicular ao plano de referência em $O$. O ponto $B$ representa o seu centro de gravidade. Uma mola une o ponto $A$ ao $B$. Geralmente, os aparelhos possuem o comprimento $\overline{O A}=a$ equivalente a $\overline{O B}=b$, ou seja, $a=b$. De acordo com a Figura 26, tem-se as seguintes relações angulares:

$$
\begin{cases}\alpha+\beta+\gamma=\frac{\pi}{2} & (\mathrm{a}) \\ \beta=\pi-2 \Theta & \text { (b) }\end{cases}
$$

A mola possui um comprimento inicial $H_{0}$. Quando uma força $F$ é aplicada à mesma, o seu comprimento se torna $H$, ou seja:

$$
F=k\left(H-H_{0}\right)
$$

k é a constante de elasticidade da mola e varia conforme o seu material ou sua geometria.

Dois torques governam o equilíbrio estático do feixe. O primeiro em função da gravidade e o segundo, da mola. Para a gravidade tem-se a seguinte expressão, onde $j$ representa o desvio angular do plano $O A B$ em relação à vertical:

$$
\begin{aligned}
M_{g}(g, \alpha, \beta, j) & =m g b \cos \gamma \cos j \\
& =m g b \operatorname{sen}(\alpha+\beta) \cos j
\end{aligned}
$$

Para a mola tem-se:

$$
M_{m}(k, \theta)=k x b \operatorname{sen} \theta
$$

\footnotetext{
${ }^{1}$ Palavra da língua inglesa, também usada em nossa língua, se refere ao conjunto haste-peso que oscila no gravímetro.
} 
Para que haja um equilíbrio, o somatório dos torques deve ser nulo, ou seja:

$$
M_{g}(g, \alpha, \beta, j)=M_{m}(k, \theta)
$$

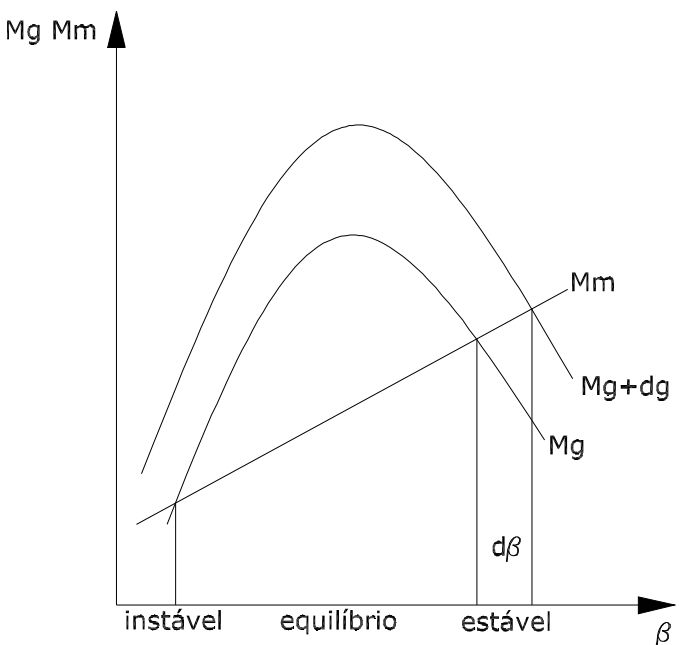

(A)

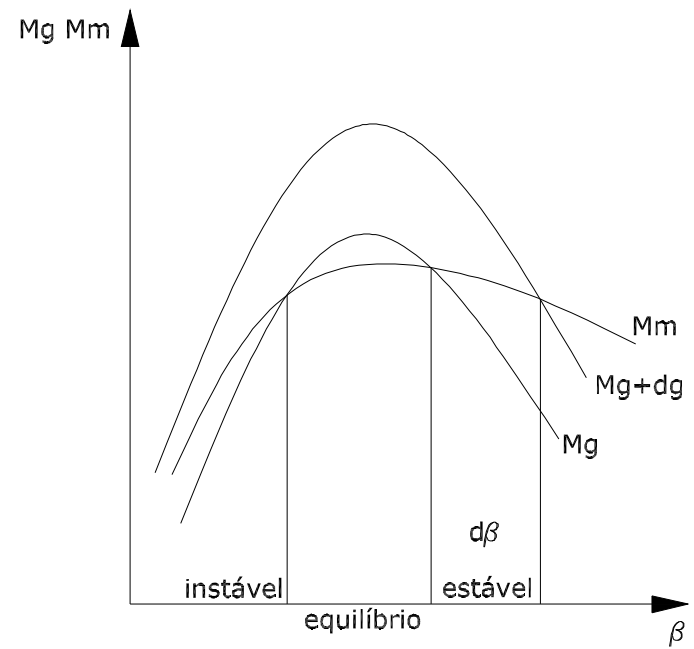

(B)

Figura 27: Características de torque para um sistema linear e para um sistema astatizado (Fonte: Torge (1989))

A Figura 27 representa duas posições, A e B. De acordo com Torge (1989) em A estão representadas as características de torque para um sistema linear onde uma mudança de gravidade $d g$ altera $M_{g}(g+d g, \beta)$ e o equilíbrio ocorre para um ângulo $\beta+d \beta$ tornando o sistema estável neste intervalo. Em B estão representadas as características de torque para um gravímetro astatizado onde, com a aproximação dos valores dos dois torques, a variação da diferença entre eles em relação ao ângulo $\beta$ cairá e, conseqüentemente, a sensibilidade aumentará tornando o sistema estável.

Para avaliar a resposta instrumental às mudanças de seus parâmetros, primeiramente diferencia-se parcialmente em relação a cada uma de suas variáveis a equação de equilíbrio entre os torques (5.5) encontrando a equação (5.6): 


$$
\begin{aligned}
& \frac{\delta M_{g}}{\delta g} d g+\frac{\delta M_{g}}{\delta \beta} d \beta+\frac{\delta M_{g}}{\delta \alpha} d \alpha+\frac{\delta M_{g}}{\delta j} d j=\frac{\delta M_{m}}{\delta k} d k+\frac{\delta M_{m}}{\delta \beta} d \beta \\
& \left(\frac{\delta M_{m}}{\delta \beta}-\frac{\delta M_{g}}{\delta \beta}\right) d \beta=\frac{\delta M_{g}}{\delta g} d g-\frac{\delta M_{m}}{\delta k} d k+\frac{\delta M_{g}}{\delta \alpha} d \alpha+\frac{\delta M_{g}}{\delta j} d j
\end{aligned}
$$

Do conceito matemático de diferenciação tem-se:

$$
\frac{\delta M_{g}}{\delta g} d g=\frac{M_{g}}{g} d g
$$

e,

$$
\begin{aligned}
\frac{\delta M_{m}}{\delta k} d k & =\frac{M_{m}}{k} d k \\
& =\frac{M_{g}}{k} d k \quad \text {,considerando o equilíbrio entre os torques }
\end{aligned}
$$

Diferenciando parcialmente em relação a $\alpha$ e a $j$ tem-se respectivamente:

$$
\begin{gathered}
\frac{\delta M_{g}}{\delta \alpha} d \alpha=M_{g} \operatorname{cotg}(\alpha+\beta) d \alpha \\
\frac{\delta M_{g}}{\delta j} d j=-M_{g} \operatorname{tg}(j) d j
\end{gathered}
$$

Substituindo as expressões acima, (5.6) é escrita na forma:

$$
d \beta=\frac{M_{g}}{\frac{\delta M_{m}}{\delta \beta}-\frac{\delta M_{g}}{\delta \beta}}\left(\frac{d g}{g}-\frac{d k}{k}+\operatorname{cotg}(\alpha+\beta) d \alpha-\operatorname{tg}(j) d j\right)
$$

Para avaliar somente a variação em $g$, eliminam-se os termos $\frac{d k}{k}, \cot g(\alpha+\beta) d \alpha$ e $t g(j) d j$ de (5.7). Logo: 


$$
\begin{aligned}
d \beta & =\frac{M_{g}}{\frac{\delta M_{m}}{\delta \beta}-\frac{\delta M_{g}}{\delta \beta}} \frac{d g}{g} \\
d \beta & =A \frac{d g}{g}
\end{aligned}
$$

Segundo Ducarme (2005), A representa o coeficiente de amplificação do instrumento, ou seja, o coeficiente que rege a sua sensibilidade. Na Figura 27, o denominador de $A$ equivale à diferença entre as tangentes das curvas $M_{g}$ e $M_{m}$. Quando o instrumento é ajustado mecanicamente de modo que as duas tangentes se aproximem, tem-se um grande aumento em A e, conseqüentemente, na sua sensibilidade.

O erro causado pelo parâmetro $j$, também chamado de erro na transversal, é dado por:

$$
d \beta=-A t g(j) d j
$$

Substituindo (5.8) na equação acima, tem-se:

$$
\frac{d g}{g}=-t g(j) d j
$$

O erro $\Delta g$ para um desvio em $j$ é encontrado ao integrar (5.10). Logo:

$$
\begin{aligned}
\Delta g & =-\int_{0}^{i} g t g(j) d j \\
& =g l o g \cos j \\
& \simeq-g \frac{j^{2}}{2}
\end{aligned}
$$

Quando o desvio é nulo, ou seja, quando o plano $O A B$ da Figura 26 está na vertical, não haverá erro para a medição em $g$ em função de $j$. À medida que $j$ aumenta, 
o erro também aumenta quadraticamente.

O erro em $g$ causado pelo desvio na direção paralela ao beam, ou seja, longitudinalmente, é descrito por:

$$
d \beta=\operatorname{Acotg}(\alpha+\beta) d \alpha
$$

Derivando a expresão 5.1(a), encontra-se:

$$
d \alpha=-d \beta-d \gamma
$$

Substituindo a expressão acima na equação (5.8) e a expressão 5.1(b) em (5.12), tem-se:

$$
\begin{aligned}
\frac{d g}{g} & =\frac{-t g \gamma}{1+A t g \gamma} \\
& \simeq-\gamma(1-A \gamma)
\end{aligned}
$$

O erro $\Delta g$, a partir do erro em $\gamma$, é encontrado ao integrar a equação (5.13):

$$
\begin{aligned}
\Delta g & =\frac{1}{1+A^{2}}[\ln (\cos \gamma+A \operatorname{sen} \gamma)-A \gamma] \\
& \simeq \frac{-\gamma^{2}}{2}+\frac{A \gamma^{3}}{3}
\end{aligned}
$$

Este erro é eliminado quando o feixe encontra-se na horizontal e segue, aproximadamente, uma parábola em torno desta posição.

A partir do comportamento destes erros vê-se que a sensibilidade de um gravímetro astatizado varia facilmente em função da posição incorreta de sua linha de leitura.

Na prática, estes erros são minimizados através do método da construção da pa- 
rábola para cada um dos níveis do gravímetro. Este possui dois níveis, o longitudinal, paralelo à direção do feixe, e o transversal, perpendicular ao primeiro. Geralmente, o nível tem seis linhas divisórias, três à esquerda, e três à direita (Figura 28). Primeiramente, toma-se o nível longitudinal e, com o giro nos parafusos calantes correspondentes, faz-se com que uma das bordas da bolha do nível ocupe posições pré-determinadas pelo operador. Na Figura 28, por exemplo, a borda esquerda ocuparia as posições de 1 a 5 , e retornaria à primeira posição. Em cada uma destas posições deve-se anotar o valor mensurado pelo instrumento e o horário da observação. Ao final, a diferença entre as observações da posição no início e no final do processo é distribuída nas demais. Esta diferença corresponde à variação gravimétrica durante o período de observações. Após compensados, estes valores são inseridos em um gráfico em função da posição. O formato do gráfico é semelhante a uma parábola. O ponto de convergência desta parábola corrensponde à posição de maior sensibilidade do instrumento. Com o nível longitudinal nesta posição, o mesmo procedimento deve ser feito na transversal. Após determinar a posição da bolha no nível transversal, repete-se novamente no longitudinal para conferência. Segundo Melchior (1983), este procedimento deve ser realizado mensalmente em um gravímetro astatizado.

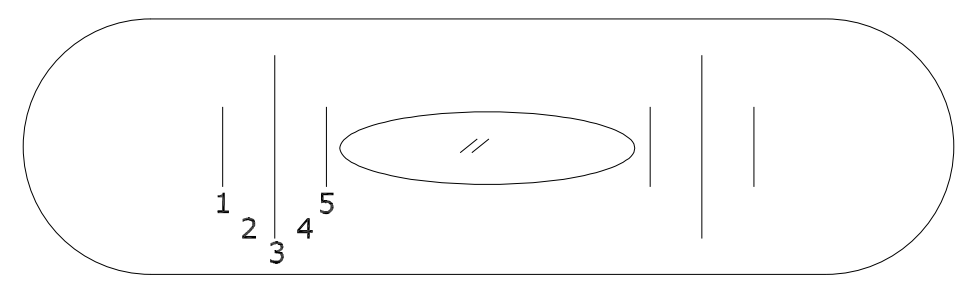

Figura 28: Exemplo de um nível em um gravímetro e das posições usadas para determinação da parábola 


\subsection{Pré-processamento dos dados gravimétricos}

A série de dados gravimétricos a ser analisada compreende os meses de Fevereiro a Julho do ano de 2006 e foi registrada na estação de Cananéia pelo sensor GEO783.

Os dados gravimétricos devem ser preparados antes de sua análise. Da forma como eles são registrados no sistema de aquisição de dados, são denominados dados brutos e contém outros anômalos. Estas anomalias podem surgir, por exemplo, com a entrada de uma pessoa no cômodo onde se encontra o aparelho, ou ainda, com interferências na eletrônica do mesmo, fazendo-se necessário removê-las. A Figura 29 ilustra uma série de três dias de registro onde se observa alguns picos de interferência de origem desconhecida. Já a Figura 30 ilustra a mesma série após a correção. Esta fase do pré-processamento foi realizada com o software Tsoft (VAUTERIN, 2005).

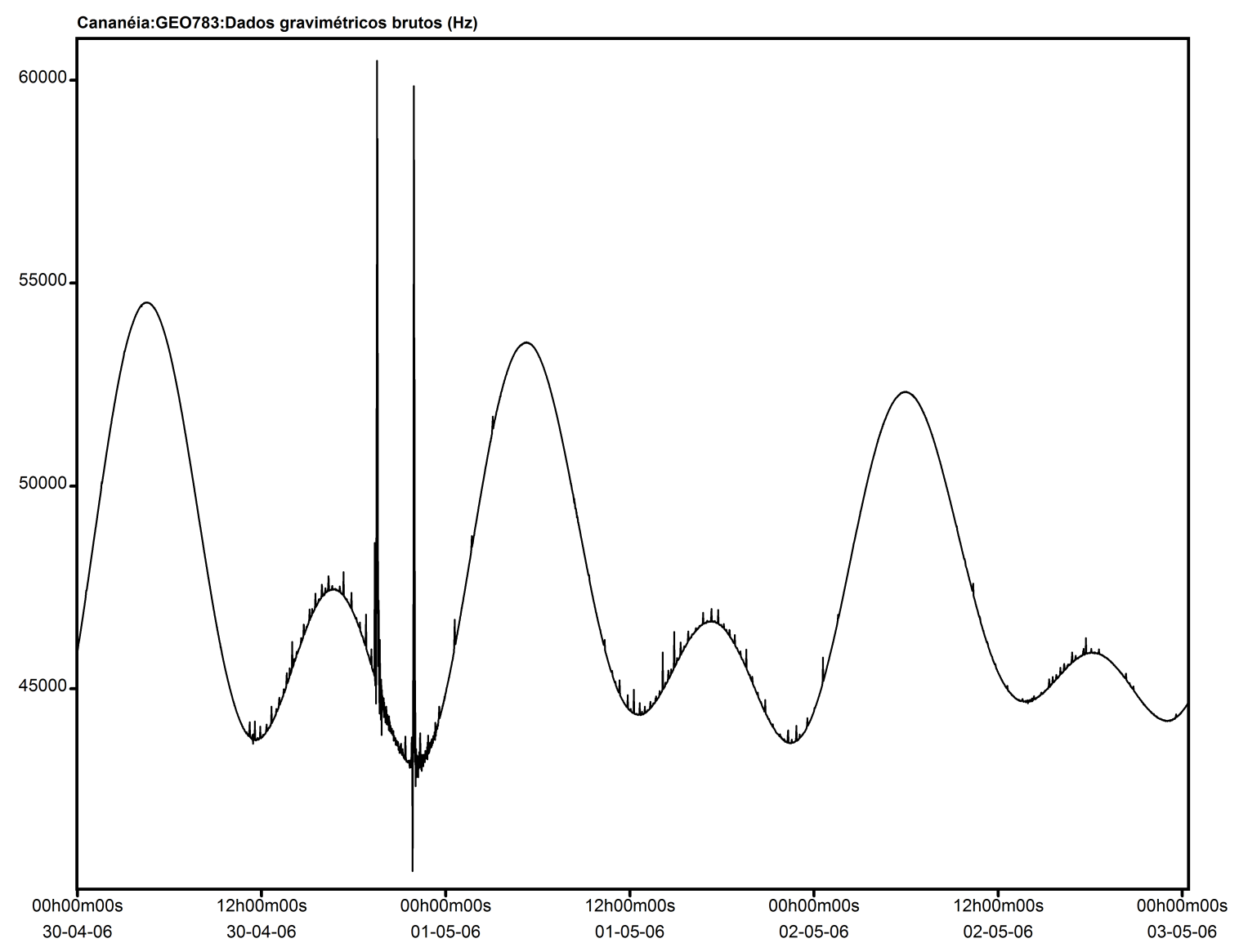

Figura 29: Registros gravimétricos brutos 


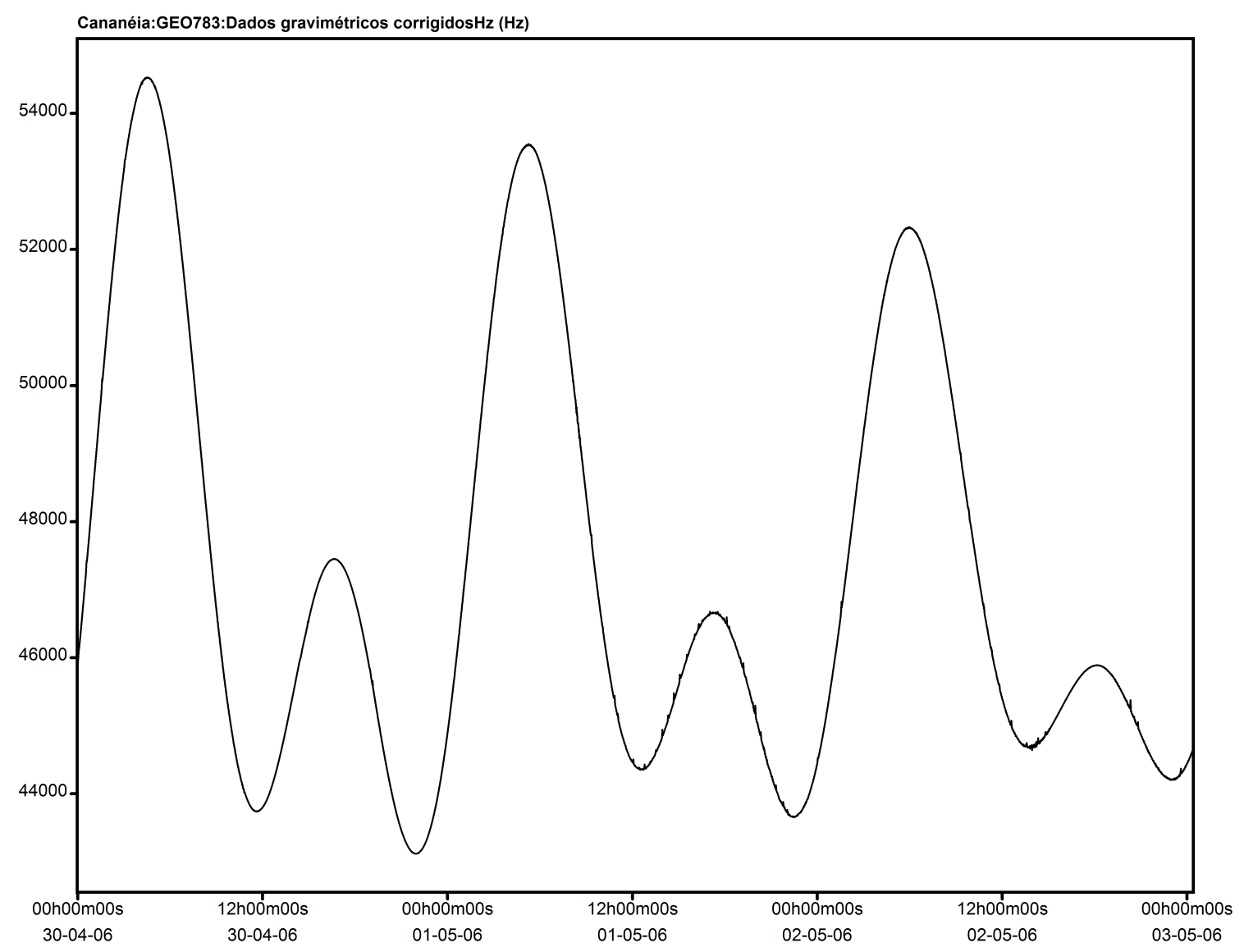

Figura 30: Registros gravimétricos após correções

O sistema digital de aquisição de dados, $\mu D A S$, está configurado para registrar em Hertz o sinal de saída do gravímetro a cada minuto. Os dados armazenados são transferidos para um computador e devem ser convertidos para a unidade correta. Esta conversão só é possível através de um procedimento denominado calibração.

A calibração consiste em aplicar ao sistema uma variação de tensão correspondente a um valor de variação de gravidade, ambas conhecidas. O valor de calibração

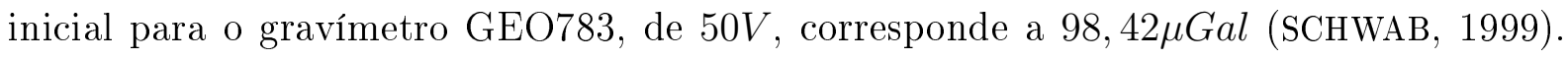
Quando da realização da calibração, imediatamente antes e após a sua ativação, as diferenças de tensão na saída do gravímetro devem ser mensuradas para se obter a verdadeira tensão que foi aplicada ao equipamento. Por se tratar de uma força eletrostática, tem-se a relação: 


$$
\frac{98,42}{50^{2}}=\frac{g}{U^{2}}
$$

$U$ é a tensão em Volt aplicada ao sistema em um determinado período, e $g$ a variação de gravidade correspondente em $\mu \mathrm{Gal}$. Geralmente o valor da tensão aplicada não costuma variar, mas é importante o seu acompanhamento em toda a operação de calibração. Além do mais, a calibração se torna necessária para o acompanhamento da sensibilidade do instrumento. Em Cananéia, durante o período de coleta de dados, o valor de tensão foi de 50,27V, o que corresponde à 99, 486 $\mu \mathrm{Gal}$.

Segundo (MELCHIOR, 1983), como a sensibiliade do sistema varia com o tempo e de forma não-linear, é apropriado repetir as operações de calibração semanalmente tendo o cuidado de não pertubar a curva de maré. Uma forma é escolher períodos de mínima perturbação e também períodos quando a curva de maré é a mais suave, ou seja, em fases de quadratura da Lua e do Sol. Graficamente é possível reconhecer a calibração através da deformação que ela causa na curva. A Figura 31 ilustra uma calibração realizada num período de quadratura.

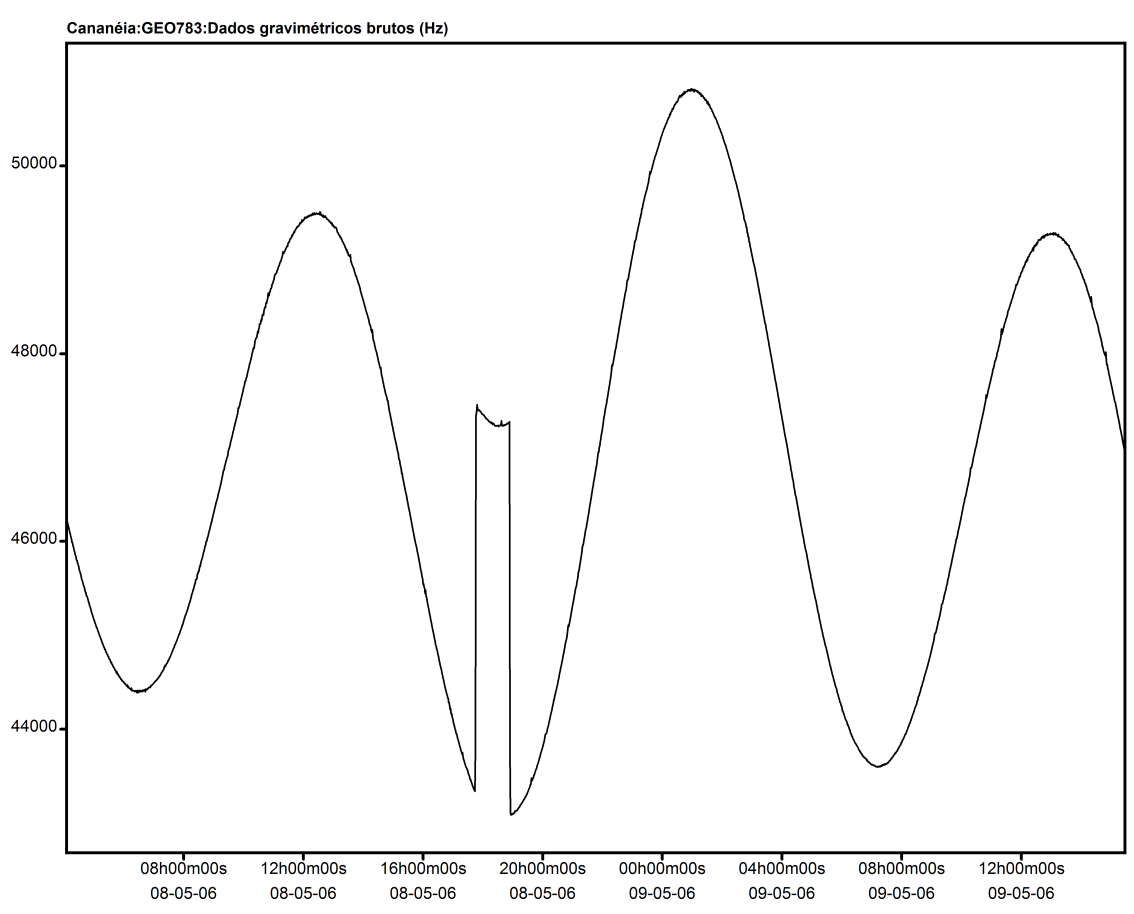

Figura 31: Calibração aplicada ao instrumentro num período de quadratura 
O cálculo de uma calibração é realizado igualmente pelo Tsoft. O mesmo obtém, na unidade em que é mensurada a variação gravimétrica, a variação decorrente da aplicação de tensão no aparelho. Para isto o usuário deve escolher os quatro pontos notáveis de uma calibração (Figura 32). O primeiro ponto é o que antecede a ascenção da curva e está representado na figura no canto inferior esquerdo com o número 0. Quando da aplicação da tensão o gravímetro tende a se estabilizar após alguns minutos. O usuário deve ter a sensibilidade de notar quando esta estabilização ocorre para determinar o ponto seguinte, que na figura é o ponto superior esquerdo com o número 1. O ponto imediatamente antes da queda da curva, no canto superior direito da figura ao lado do número 1, é o terceiro ponto. E o último, assim como o segundo caso, é anotado quando da estabilização da curva após a sua queda e está na canto inferior direito da figura ao lado do número 0.

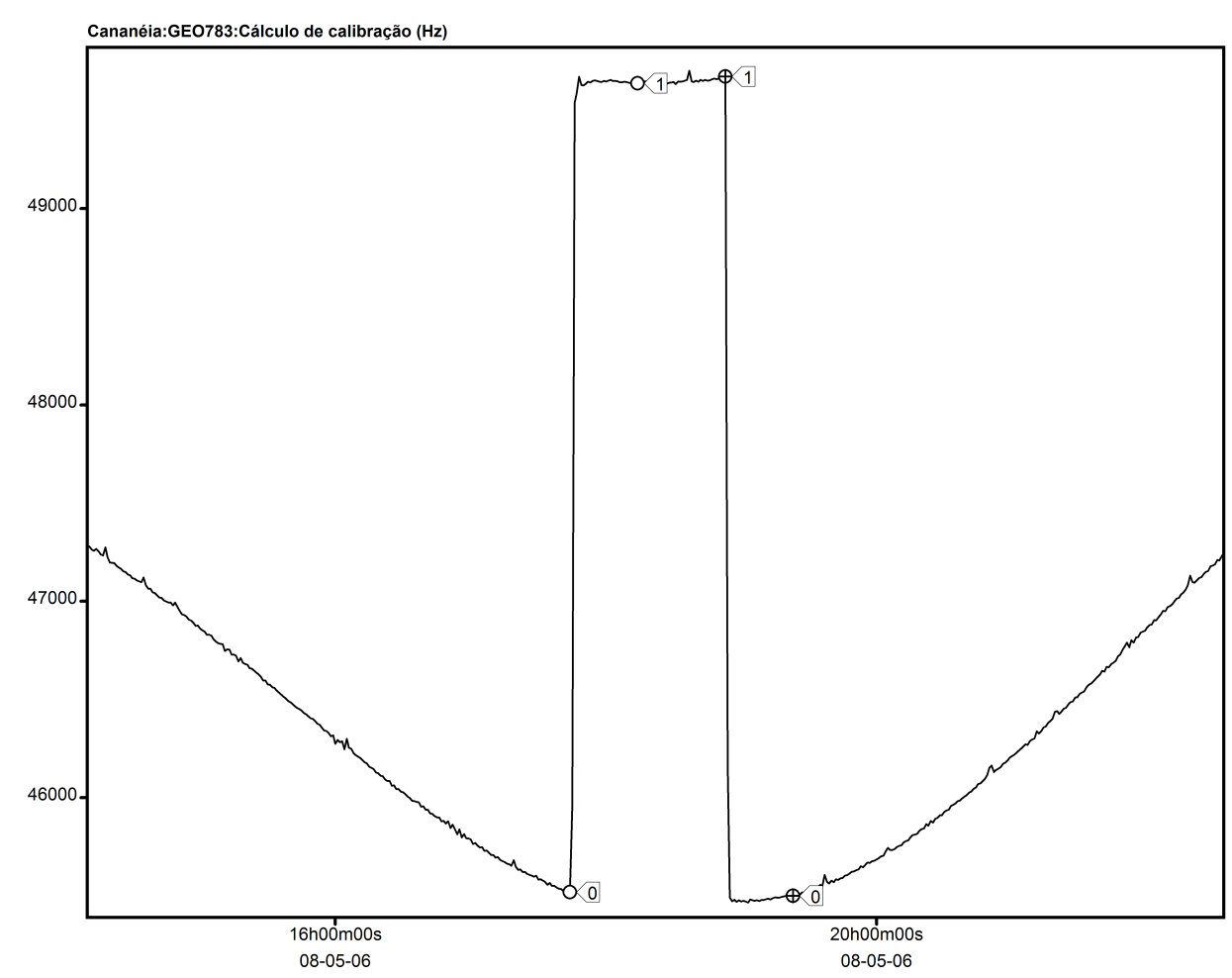

Figura 32: Quatros pontos notáveis para o cálculo da calibração

Ao calcular todas as calibrações de uma série é necessário verificar se os valores estão próximos entre si. O motivo é simples. De posse de todos os valores com seus respectivos horários e datas, um conjunto de programas em linguagem Fortran é aplicada aos dados, às próprias calibrações, e ao valor encontrado a partir de (5.15) correspon- 
dente à tensão. Resumidamente, o processo realizado por tais programas é o de calcular uma média para as calibrações e, em função do valor de tensão, converter toda a série de registros para uma unidade gravimétrica, no caso o $\mu$ Gal. Porém, se os valores de calibração divergirem significativamente entre si, ao aplicar um único valor para toda a série o resultado final também estaria divergente. A fim de se evitar tal erro, faz-se necessário avaliar os valores das calibrações para, eventualmente, dividir a série em períodos. Desta forma se aplicariam diferentes valores aos blocos e, conseqüentemente, a série estaria com seus valores mais próximos do real. Mais uma vez vê-se que a calibração é um importante procedimento a ser realizado. Embora Melchior (1983) tenha citado que tal operação deve ser realizada semanalmente, diante da atual experiência em Cananéia, o ideal é que o operador seja instruído a efetuar a calibração duas vezes por semana. A Tabela 11 apresenta as datas das realizações das calibrações durante o período de coleta e os valores calculados para as mesmas e a Figura 33 apresenta os valores graficamente.

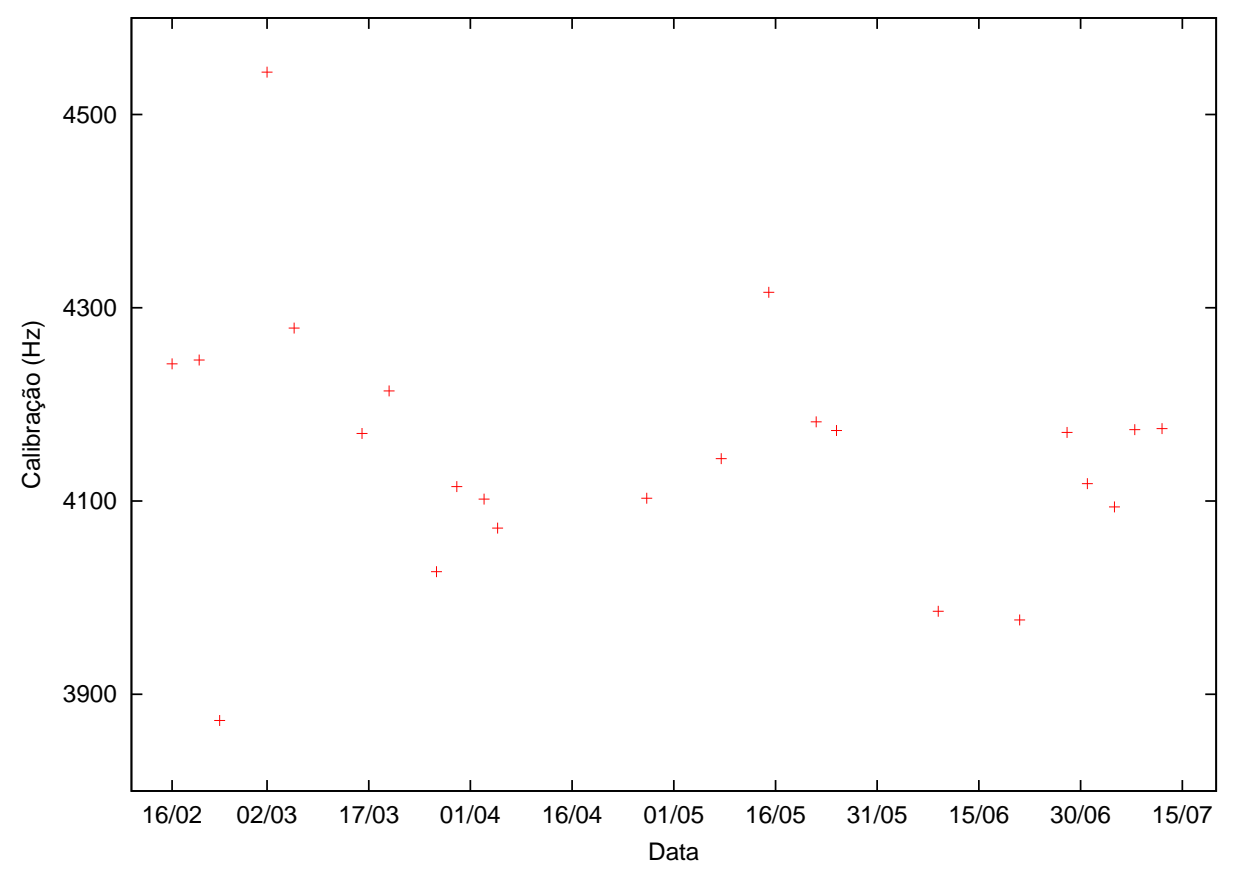

Figura 33: Valores das calibrações

O primeiro ponto a se observar diante do gráfico é a diferença entre o maior e o menor dentre os valores calculados para as calibrações que excede $16 \%$ da média que é de $4151 \mathrm{~Hz}$. Ou seja, os valores estão dispersos em relação ao seu valor médio o que é 


\begin{tabular}{|c|c|c|}
\hline Data (ano/mês/dia) & Hora & Valor calculado para a calibração $\mathbf{~ H z ) ~}$ \\
\hline $2006 / 02 / 16$ & $14: 00$ & 4242 \\
\hline $2006 / 02 / 20$ & $14: 00$ & 4226 \\
\hline $2006 / 02 / 23$ & $14: 00$ & 3873 \\
\hline $2006 / 03 / 02$ & $13: 00$ & 4544 \\
\hline $2006 / 03 / 06$ & $13: 00$ & 4279 \\
\hline $2006 / 03 / 16$ & $18: 00$ & 4170 \\
\hline $2006 / 03 / 20$ & $18: 00$ & 4214 \\
\hline $2006 / 03 / 27$ & $18: 00$ & 4027 \\
\hline $2006 / 03 / 30$ & $18: 00$ & 4115 \\
\hline $2006 / 04 / 03$ & $18: 00$ & 4102 \\
\hline $2006 / 04 / 05$ & $18: 00$ & 4072 \\
\hline $2006 / 04 / 27$ & $18: 00$ & 4103 \\
\hline $2006 / 05 / 08$ & $18: 00$ & 4144 \\
\hline $2006 / 05 / 15$ & $18: 00$ & 4316 \\
\hline $2006 / 05 / 22$ & $18: 00$ & 4182 \\
\hline $2006 / 05 / 25$ & $18: 00$ & 4173 \\
\hline $2006 / 06 / 09$ & $13: 00$ & 3986 \\
\hline $2006 / 06 / 19$ & $18: 00$ & 3977 \\
\hline $2006 / 06 / 26$ & $18: 00$ & 4171 \\
\hline $2006 / 06 / 29$ & $18: 00$ & 4118 \\
\hline $2006 / 07 / 03$ & $18: 00$ & 4094 \\
\hline $2006 / 07 / 06$ & $18: 00$ & 4174 \\
\hline $2006 / 07 / 10$ & $18: 00$ & 4175 \\
\hline
\end{tabular}

Tabela 11: Valores calculados para as calibrações efetuadas na estação de Cananéia

um indício de que a sensibilidade variou neste período. Logo, há a necessidade da divisão deste período em outros menores para o cálculo dos parâmetros de conversão.

No entanto, observa-se que os intervalos entre uma calibração e outra não foram constantes. Diante deste quadro, é provável que uma eventual mudança de sensibilidade do instrumento não possa vir a ser detectada. Além disso, caso a série seja dividida, outra possibilidade é a de que um ou mais blocos tenham apenas um único valor de calibração de acordo com a divisão. Tomar poucos ou apenas um único valor de calibração para converter um trecho da série pode resultar em maus resultados quando analisados posteriormente.

Diante deste quadro, vê-se quão importante é a calibração para o acompanhamento da sensibilidade do gravímetro e o quanto sua ausência prejudica o pré-processamento dos dados gravimétricos e a análise dos mesmos. 


\subsection{Processamento das observações gravimétricas}

Após a definição dos períodos e dos valores de calibração a série de registros gravimétricos foi convertida em valores horários e transformada de freqüência (Hertz) em aceleração de gravidade $(\mu g a l)$, para análise em outro aplicativo, o Eterna (WENZEL, 1994). A Figura 34 ilustra um trecho desta série após a conversão.

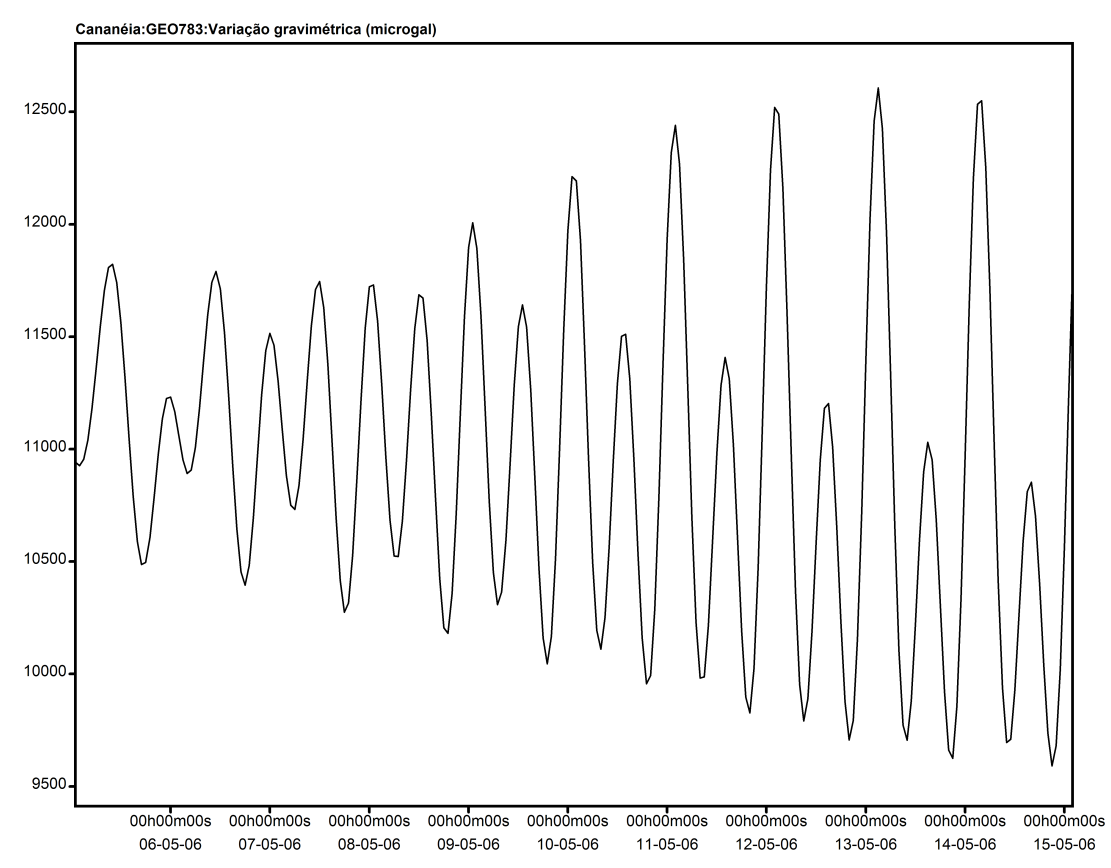

Figura 34: Dados gravimétricos após a conversão de Hertz em $\mu g a l$

Através do Eterna é possível determinar os fatores de amplitude e de fase para determinadas ondas resultantes do efeito das marés terrestres. O fator de amplitude é a relação entre a amplitude mensurada e a obtida a partir do modelo inelástico de WahrDehant segundo as coordenadas geográficas do local. A Tabela 12 mostra os resultados obtidos a partir da análise dos dados gravimétricos da estação de Cananéia, sendo que a amplitude teórica é a obtida a partir do modelo inelástico rígido para um planeta sem oceanos. $A_{t}$ representa a amplitude teórica, $F A$ o fator de amplitude sendo $\sigma_{F A}$ o seu respectivo desvio, $F$ a fase juntamente com o seu desvio $\sigma_{F}$. Para obter a amplitude de determinada onda basta multiplicar $A_{t}$ por $F A$ correspondentemente. As fases estão referidas à hora local. 


\begin{tabular}{|c|c|c|c|c|c|}
\hline Onda & $\boldsymbol{A}_{\boldsymbol{t}}(\boldsymbol{\mu g a l})$ & $\mathbf{F A}$ & $\boldsymbol{\sigma}_{\boldsymbol{F}} \boldsymbol{A}$ & $\mathbf{F ~}\left(^{\circ}\right)$ & $\boldsymbol{\sigma}_{\boldsymbol{F}}$ \\
\hline Q1 & 4,55341 & 1,16856 & 0,01392 & $-1,9054$ & 0,6827 \\
\hline O1 & 23,78228 & 1,17207 & 0,00250 & $-1,9308$ & 0,1216 \\
\hline M1 & 1,87039 & 1,17037 & 0,02556 & $-3,7833$ & 1,2542 \\
\hline PSK1 & 33,44728 & 1,12537 & 0,00174 & $-1,0101$ & 0,0884 \\
\hline J1 & 1,87033 & 1,10490 & 0,03520 & 2,4803 & 1,8160 \\
\hline OO1 & 1,02327 & 1,06564 & 0,03652 & 2,7966 & 1,9685 \\
\hline 2N2 & 1,88408 & 1,12254 & 0,02373 & 1,4866 & 1,2091 \\
\hline N2 & 11,79795 & 1,17231 & 0,00393 & 2,3394 & 0,1922 \\
\hline M2 & 61,62097 & 1,15243 & 0,00071 & 2,5080 & 0,0354 \\
\hline L2 & 1,74173 & 1,18110 & 0,04441 & 5,0604 & 2,1561 \\
\hline SK2 & 28,66932 & 1,13669 & 0,00149 & 2,9472 & 0,0753 \\
\hline M3 & 1,09639 & 1,22994 & 0,02128 & $-1,8705$ & 0,9918 \\
\hline M4 & 0,01807 & 5,31841 & 0,69746 & 37,1405 & 7,5084 \\
\hline
\end{tabular}

Tabela 12: Resultados obtidos na estação de Cananéia

Os desvios obtidos, tanto para os fatores de amplitude quanto para as fases, foram satisfatórios diante do período de observações. Considerando M2, a principal onda semi-diurna, utilizando os valores da Tabela 12, multiplicando-se a sua $A_{t}$ pelo seu $F A$ encontra-se uma amplitude de 71,01385 \pm 0,04376 $\mu \mathrm{gal}$, ou seja, uma desvio de 44ngal. Para a fase tem-se $2,5080 \pm 0,0354^{\circ}$. Para O1, a amplitude foi de 27,87450 $\pm 0,05946 \mu \mathrm{gal}$ enquanto para a fase o valor encontrado foi de $-1,9308 \pm 0,1216^{\circ}$. Para as demais ondas o comportamento dos desvios foram semelhantes demonstrando que o equipamento trabalhou em uma região de operação adequada e que a variação de sensibilidade foi bem monitorada. As precisões ainda podem ser melhoradas com o aumento da série temporal e com a correção dos efeitos atmosféricos. Logo, diante dos valores obtidos, tem-se um modelo de maré terrestre para a estação de Cananéia. Este modelo consiste nos valores encontrados de fator de amplitude e fase para um determinado grupo de ondas que se encontram na Tabela 12.

A partir das observações gravimétricas corrigidas, removeram-se os efeitos gravimétricos de maré terrestre definidos pelo atual modelo determinado através de um ajustamento pelo método dos mínimos quadrados, encontrando o sinal resultante (Figura 35). Este sinal contém os efeitos de carga oceânica dentre outros. Para removê-los foi necessário calculá-los anteriormente. 
No Capítulo 4 viu-se que o modelo de maré oceânica que mais se adapta à região de Cananéia é o FES95 (PROvost; BennetT; CARTwright, 1995). Portanto, a partir deste modelo, obtiveram-se os valores gravimétricos devido ao efeito de carga oceânica, amplitude e fase, para Cananéia. Para tal, foi utilizado o aplicativo em Fortran LOAD97, que faz parte do pacote Eterna (WENZEL, 1994). Os resultados obtidos estão na Tabela 13. Outra forma de obter os efeitos de carga oceânica foi a partir das componentes de maré oceânica obtidas a partir das observações maregráficas (Tabela 8 do Capítulo 4). Utilizando o mesmo aplicativo, outros valores gravimétricos foram obtidos (Tabela 14).

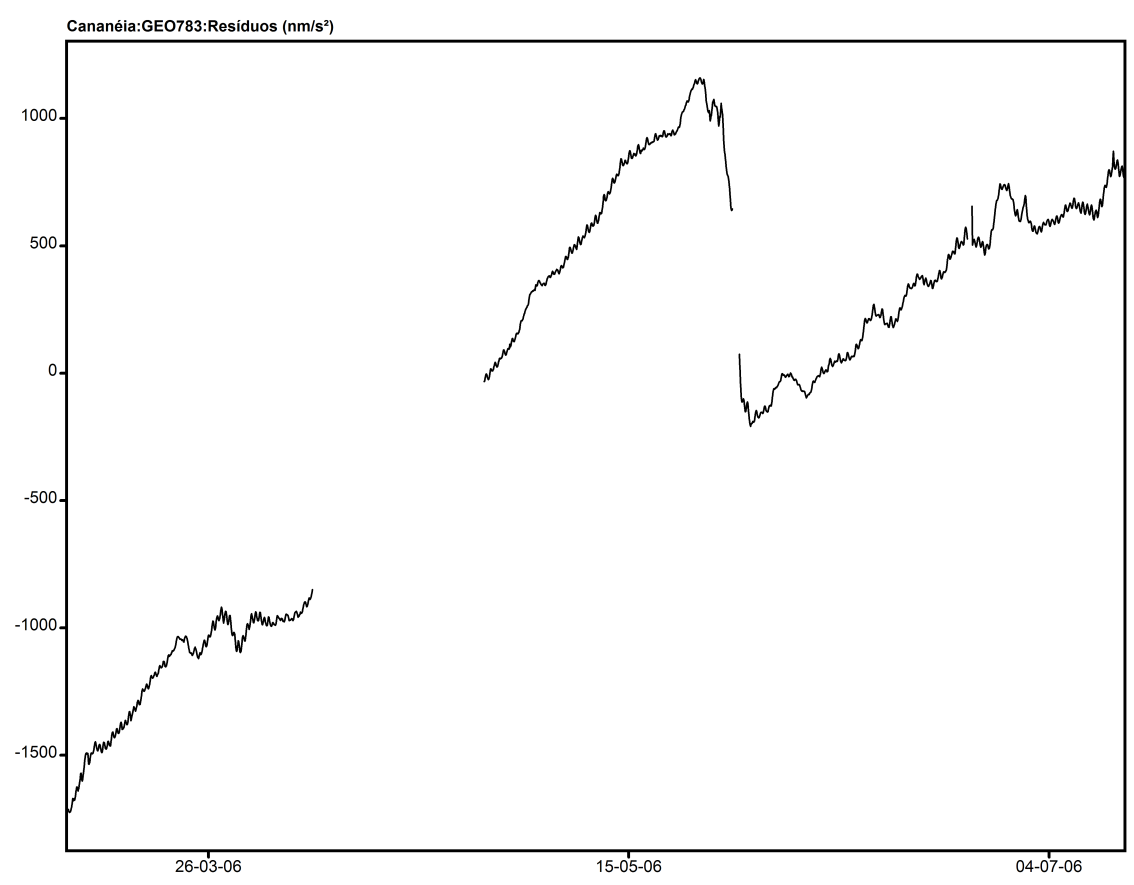

Figura 35: Registros encontrados após a remoção do novo modelo definido

\begin{tabular}{|c|c|c|}
\hline Onda & Amplitude $(\boldsymbol{\mu g a l})$ & Fase $\left(^{\circ}\right)$ \\
\hline Q1 & 0,22333 & 143,8009 \\
\hline O1 & 0,83399 & 125,2221 \\
\hline P1 & 0,13138 & 103,7439 \\
\hline K1 & 0,28671 & 102,8586 \\
\hline N2 & 0,61263 & 5,8735 \\
\hline M2 & 2,71678 & 17,9535 \\
\hline S2 & 1,32847 & 20,0439 \\
\hline K2 & 0,31650 & 26,8152 \\
\hline
\end{tabular}

Tabela 13: Valores de carga oceânica obtidas a partir do modelo FES95 


\begin{tabular}{|c|c|c|}
\hline Onda & Amplitude $(\boldsymbol{\mu g a l})$ & Fase $\left(^{\circ}\right)$ \\
\hline Q1 & 0,22430 & 143,6705 \\
\hline O1 & 0,83184 & 125,0339 \\
\hline P1 & 0,12981 & 102,6664 \\
\hline K1 & 0,28448 & 102,4706 \\
\hline N2 & 0,60443 & 4,9051 \\
\hline M2 & 2,71044 & 18,4254 \\
\hline S2 & 1,30657 & 20,1404 \\
\hline K2 & 0,31914 & 26,3534 \\
\hline
\end{tabular}

Tabela 14: Valores de carga oceânica obtidas a partir das observações maregráficas

Após a remoção do efeito de carga oceânica, através de um ajustamento pelo métodos dos mínimos quadrados, um novo sinal foi encontrado. Numa primeira situação, os valores de carga oceânica utilizados foram os obtidos a partir do modelo FES95. A Figura 36 ilustra a diferença antes, gráfico superior, e após esta remoção, gráfico inferior. Em seguida a mesma operação foi realizada, porém com a utilização do modelo de carga oceânica obtido a partir das observações maregráficas da própria estação (Figura 37).

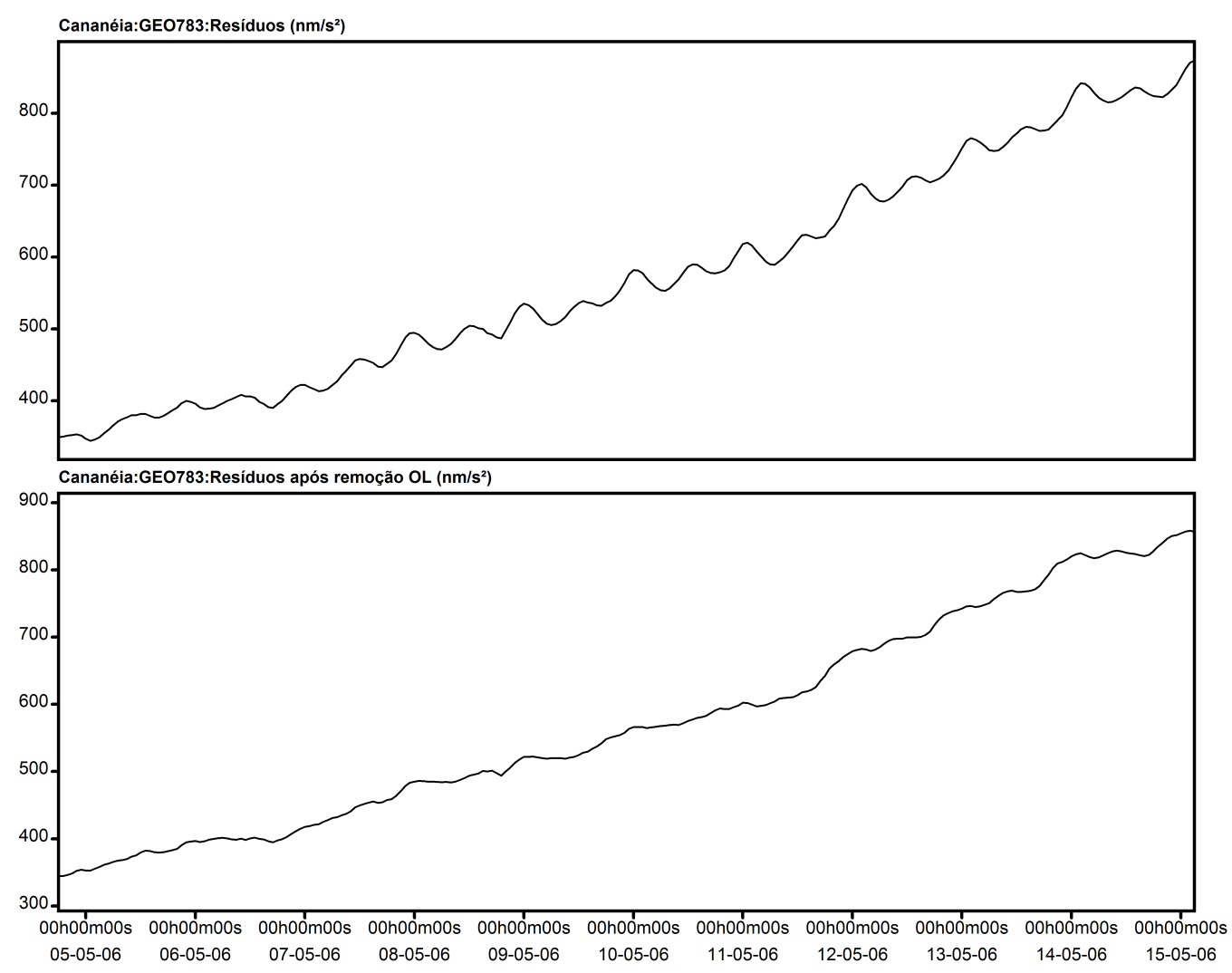

Figura 36: Registros antes e após a remoção do efeito de carga oceânica utilizando dados do modelo FES95 

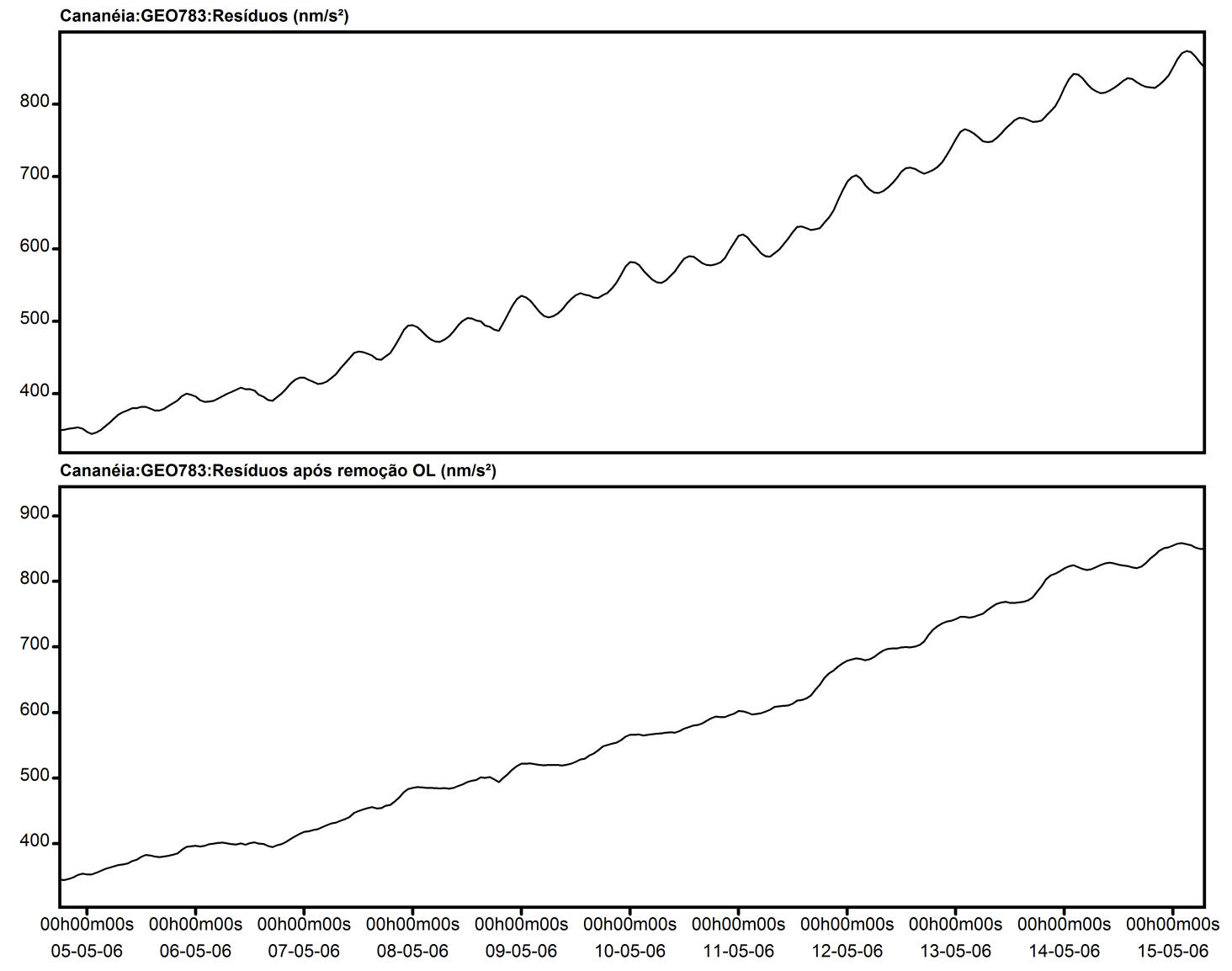

Figura 37: Registros antes e após a remoção do efeito de carga oceânica utilizando as observações da própria estação

Os gráficos são semelhantes e para verificar a diferença entre eles determinou-se o espectro a partir da transformada de Fourier (FFT) para o sinal resultante encontrado após a remoção do efeito de marés terrestres, para a carga oceânica calculada a partir do modelo FES95 e para os novos sinais obtidos após a remoção deste efeito. Os maiores valores de concentração de freqüência estão nas regiões diurna (freqüência próxima a um ciclo por dia) e semi-diurna (freqüência próxima a dois ciclos por dia).

O gráfico com a sobreposição dos três resultados citados acima para a região de freqüência diurna encontra-se na Figura 38 e possui a sequinte simbologia: a linha tracejada representa o espectro dos sinais anteriores, a linha cheia a carga oceânica e a área sombreada o novo sinal encontrado. A Figura 39 traz a mesma análise para a região de freqüência semi-diurna. 


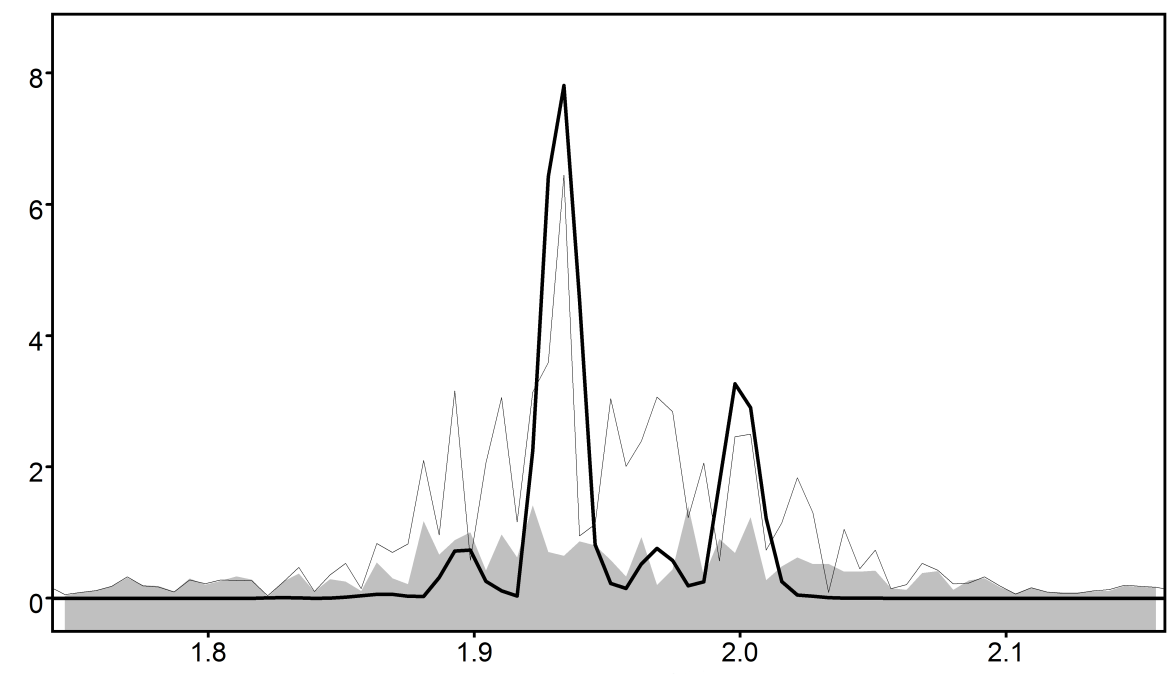

Figura 38: Espectro para os resíduos e carga oceânica calculada a partir do modelo FES95 na região de freqüência semi-diurna

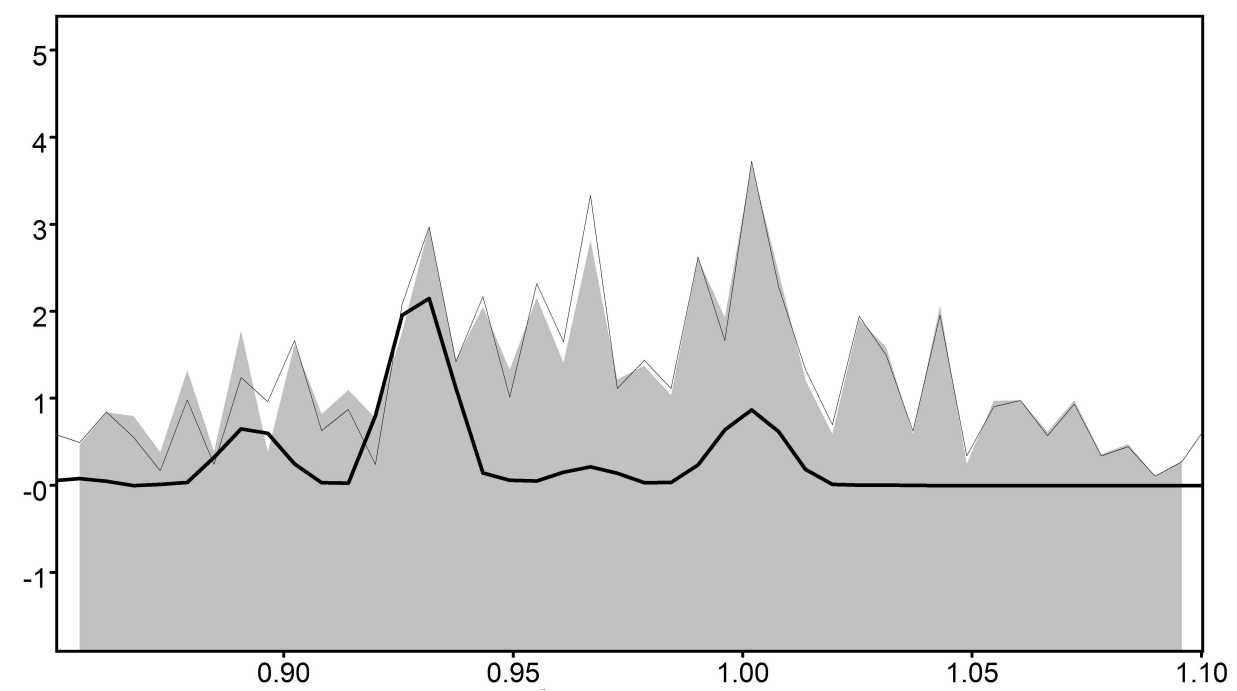

Figura 39: Espectro para os resíduos e carga oceânica calculada a partir do modelo FES95 na região de freqüência diurna

Observando os gráficos, vê-se que para a região de freqüência semi-diurna o efeito de carga oceânica foi removido em grande parte. Já para a região de freqüência diurna, isto não ocorreu na mesma intensidade. Dentre os fatores que podem justificar estes resultados um deles é a diferença da amplitude do efeito de carga oceânica, onde para as ondas semi-diurnas $M 2$ e $S 2$ o efeito é maior e a remoção fica mais clara quando visualizada em um gráfico. 
De forma semelhante, porém com os valores de carga oceânica obtidos a partir dos dados maregráficos, o mesmo procedimento foi realizado. As Figuras 40 e 41 apresentam estes gráficos.

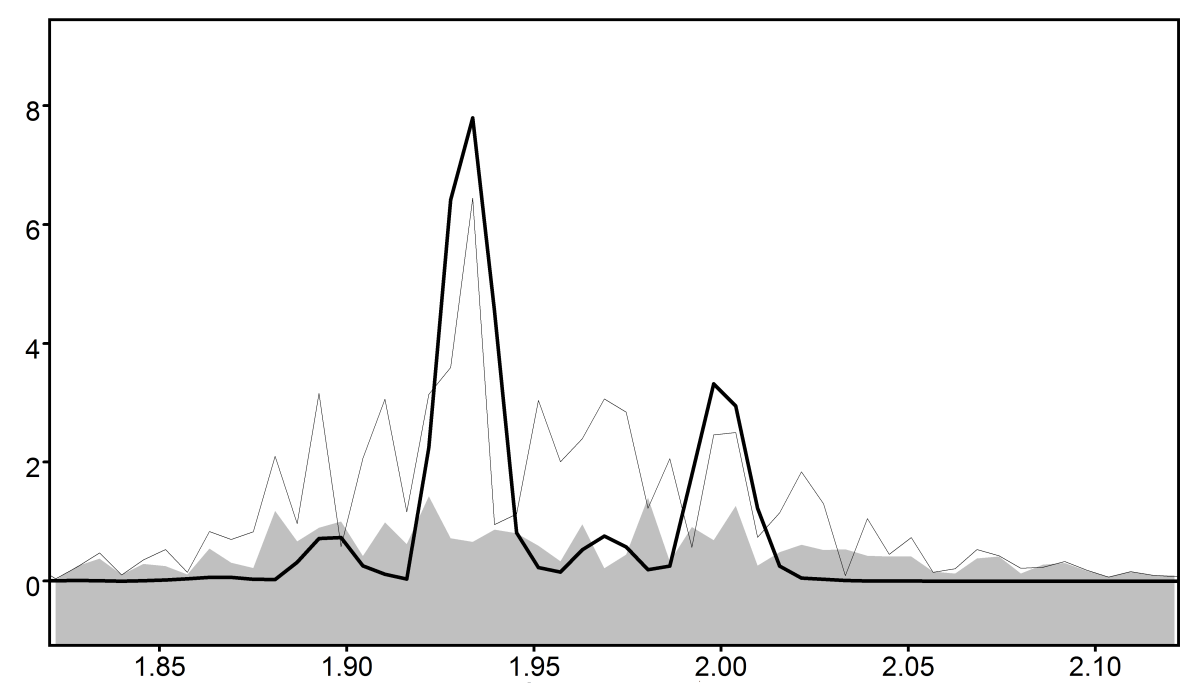

Figura 40: Espectro para os resíduos e carga oceânica calculada a partir das observações maregráficas na região de freqüência semi-diurna

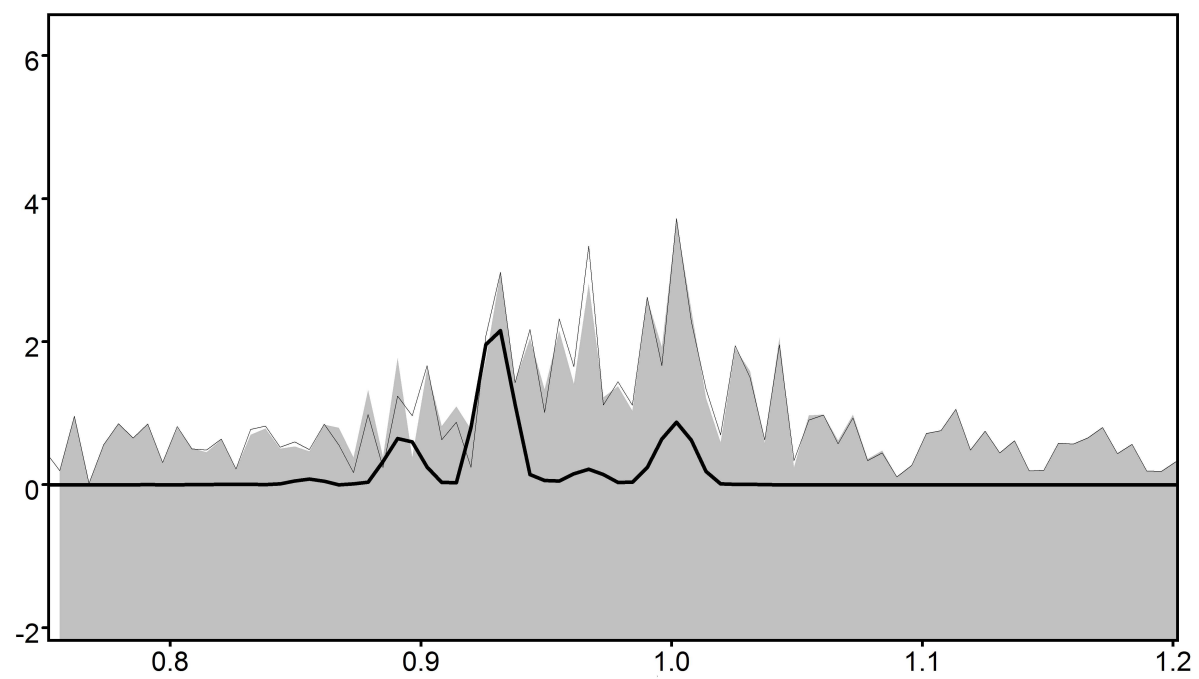

Figura 41: Espectro para os resíduos e carga oceânica calculada a partir das observações maregráficas na região de freqüência diurna

Os resultados determinados são semelhantes aos encontrados quando removeuse o efeito de carga oceânica utilizando o modelo FES95. Para encontrar a diferença entre os dois resultados calculou-se o valor das áreas das regiões sombreadas nos gráficos. 
A diferença ocorreu a partir da terceira casa decimal tanto para os sinais na região de freqüência diurna quanto para os da semi-diurna demonstrando que para a remoção dos efeitos de carga oceânica o modelo FES95 é apropriado.

Dentre outros efeitos, o novo sinal resultante contém, além do efeito de carga atmosférica, que não foi removido neste trabalho, uma deriva instrumental que não foi determinada o que impede o cálculo de uma tendência de movimentação para a crosta. Além disso, no final do mês de junho de 2006 o equipamento saiu da região de operação gerando uma discontinuidade nas observações (Figura 35). Posteriormente, embora o equipamento tenha sido ajustado para uma região adequada de funcionamento, não foi realizada nenhuma correção gráfica.

Conclui-se que para obter uma tendência gravimétrica e, posteriormente, uma associação ao movimento da crosta, é necessário que o monitoramento deste sensor seja realizado com maior freqüência principalmente quanto à determinação de sua região de operação através do método da construção da parábola. Quanto à sua deriva instrumental, uma alternativa seria associar a variação gravimétrica registrada durante a série a medições absolutas e, desta forma, reduzir aquele efeito.

\subsection{Resultados obtidos com o uso do GPS}

No Capítulo 4 a variação do NMM encontrada foi obtida com a análise dos dados maregráficos o que representa uma variação relativa. Na seção anterior concluiu-se que a partir das observações gravimétricas não foi possível avaliar o movimento da crosta. Visando este objetivo para um determinado período de observações e, conseqüentemente, a determinação da variação absoluta do NMM, foram analisados os dados coletados pelo receptor GPS da base ativa de Cananéia.

O processamento das observações GPS foi realizado a partir de um sistema automático fornecido pela agência CSRS através da internet (http://www.geod.nrcan. gc.ca/ppp_e.php). O tipo de processamento utilizado é o PPP e os resultados estão 
referenciados ao International Terrestrial Reference Frame (ITRF). As observações compreendem o período de 01/01/2004 à 26/12/2006. Obteve-se para cada dia um resultado para a altitude geométrica juntamente com o seu desvio padrão. A Figura 42 apresenta os valores de altitude geométrica para a estação de Cananéia durante o ano de 2004. Os desvios obtidos para cada um dos resultados encontrados foi em média de 11 milímetros. As Figura 43 e Figura 44 apresentam os valores para os anos de 2005 e 2006 onde os desvios se comportaram de forma semelhante.

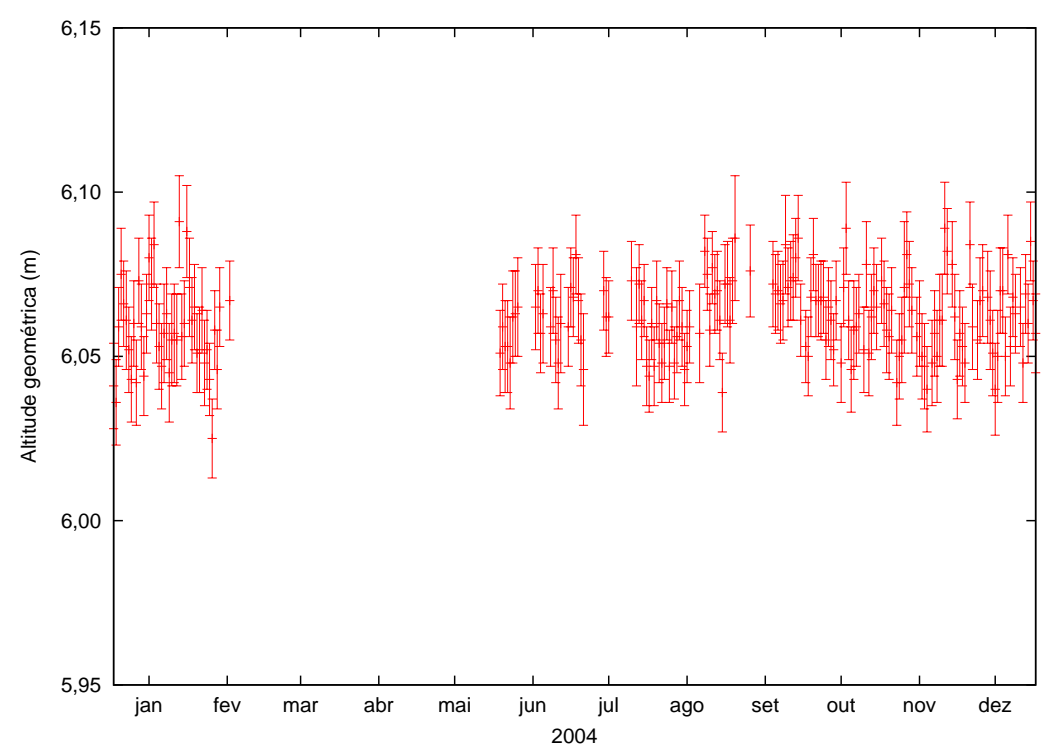

Figura 42: Altitude geométrica da estação Cananéia para 2004

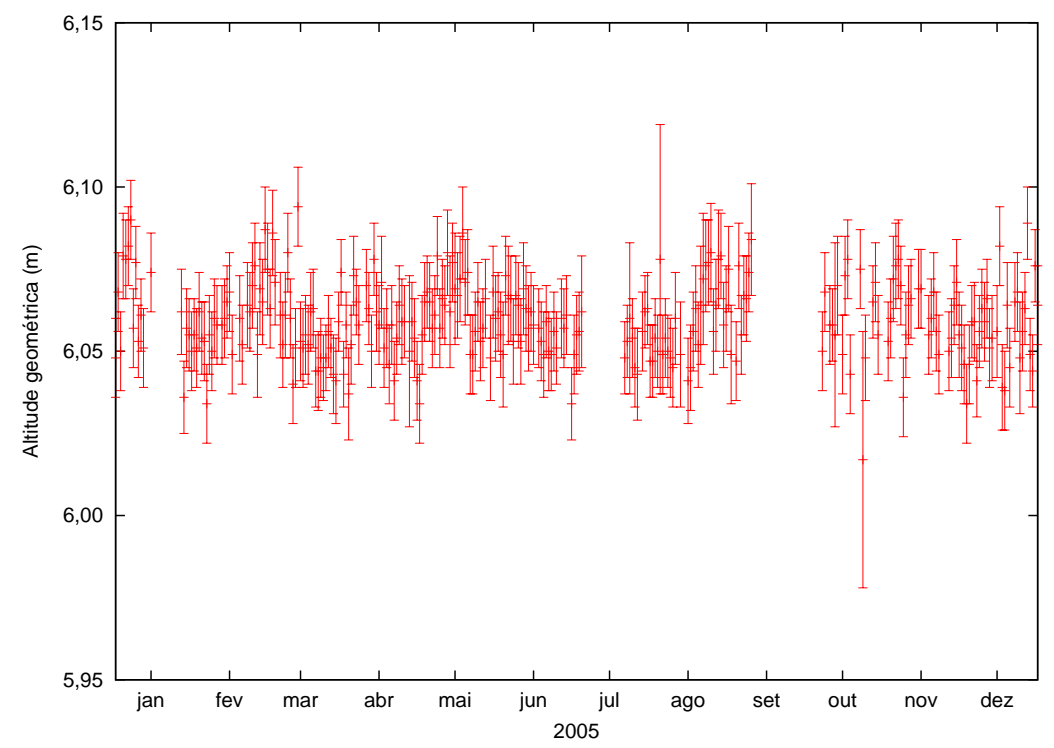

Figura 43: Altitude geométrica da estação Cananéia para 2005 


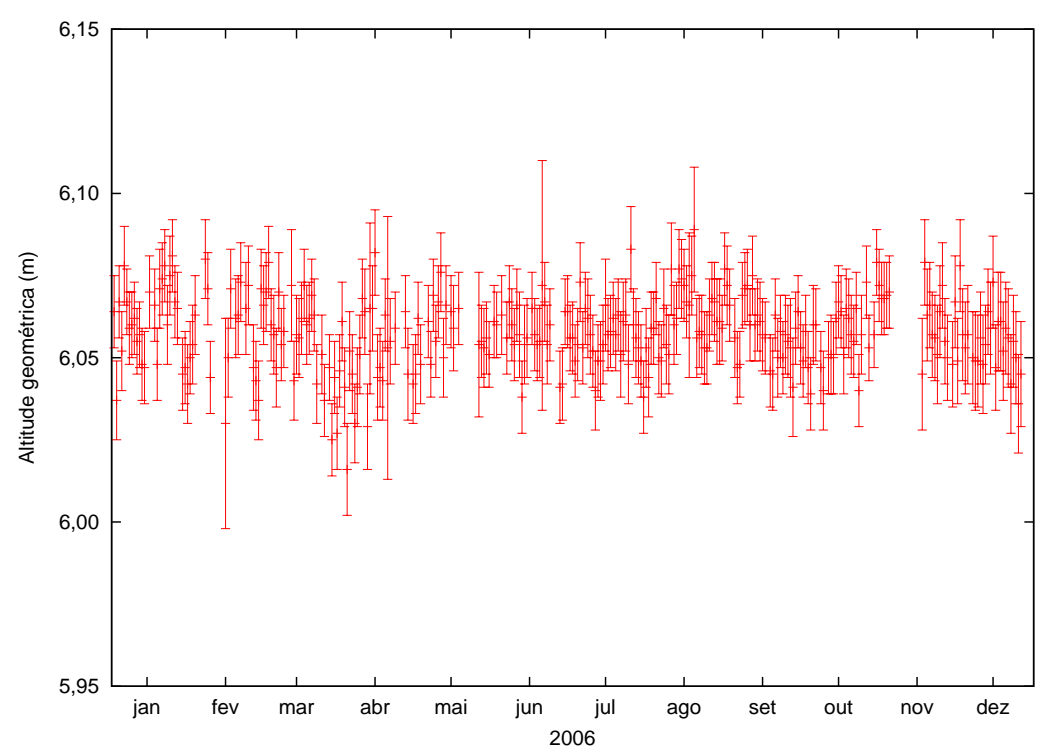

Figura 44: Altitude geométrica da estação Cananéia para 2006

Através de uma regressão linear simples aplicada para todos os resultados (Figura 45) encontrou-se uma tendência de declínio de 1,59 \pm 0,50 mm/ano. Este valor confirmou apenas a tendência de que a crosta está se rebaixando encontrada em Mesquita et al. (2005) que foi de 3,8 $\pm 1,1 \mathrm{~mm} /$ ano. No entanto, para a determinação destes resultados foram realizadas técnicas diferentes de processamento e o período de observações não foi coincidente. Em Mesquita et al. (2005) o processamento utilizado foi o relativo onde foram tomadas como referência coordenadas de algumas estações do International GNSS Service (IGS) e o período de observações foi de janeiro de 2003 a julho de 2005. Diante destes números, onde o erro em relação ao valor encontrado é relativamente grande, cerca de 30\%, não é possível avaliar o movimento da crosta. Pode-se dizer apenas que há uma tendência de rebaixamento mas ainda é necessário que um período maior de observações seja processado e que se busque aumentar a precisão dos resultados. Com isso, poderse-á definir um valor que associado ao aumento relativo do NMM defina a sua variação absoluta. 


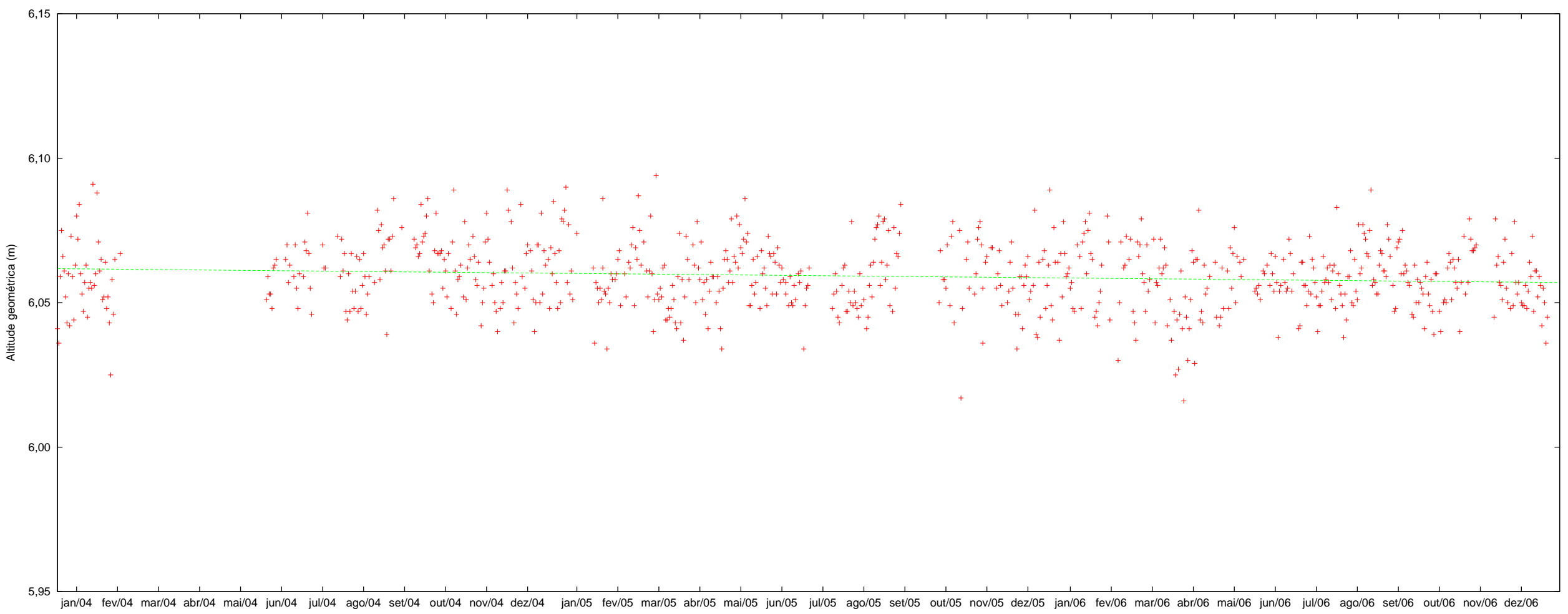

Figura 45: Comportamento da altitude geométrica em Cananéia entre os anos de 2004 a 2006 


\section{Conclusões e recomendações}

Diante dos resultados apresentados neste trabalho algumas conclusões e recomendações podem ser apresentadas. O objetivo inicial, que era de avaliar o movimento absoluto do NMM na estação de Cananéia, não foi atingido com segurança. No entanto, cabe ressaltar as contribuições obtidas a partir dos resultados maregráficos (Capítulo 4) e do processamento das observações GPS (Capítulo 5).

Primeiramente, verificou-se que não foi possível determinar a variação absoluta para o NMM em Cananéia. Embora a tendência observada para o nível do mar seja um fato incontestável diante de várias determinações realizadas como em Mesquita, Harari e França (1995) e também neste trabalho, há necessidade de processar um período maior de observações GPS a fim de confirmar as tendências encontradas para a movimentação da crosta. Além disso, outros tipos de processamento e outros softwares devem ser utilizados a fim de que os resultados sejam comparados. Quanto ao uso do gravímetro, um período de observações com um equipamento do tipo supercondutor contribuiria para o monitoramento da crosta, uma vez que este não apresenta deriva.

Um fator importante é a sobreposição dos períodos de observações neste trabalho, tanto para o marégrafo quanto para o GPS. Elas só foram coincidentes durante o ano de 2004. Isto sugere o processamento das observações GPS nos anos de 2003 e 2007, assim como a continuação das análises para o nível do mar até o presente momento. Desta forma, será possível estudar a variação absoluta durante um período maior onde haja coincidência nas observações. Além disso, outras estações GPS de monitoramento contínuo, próximas a Cananéia, deveriam ter os seus dados processados a fim de avaliar o movimento da 
crosta em uma área de abrangência maior e não somente em uma única estação.

Com os dados gravimétricos não foi possível determinar, ou até mesmo confirmar, a tendência de movimentação da crosta terrestre em função da impossibilidade de correção da deriva instrumental. No entanto, foi de grande importância e aprendizado o seu uso neste trabalho. A partir de suas observações, foi possível determinar um modelo de maré terrestre para a estação de Cananéia além do cálculo do efeito gravimétrico de carga oceânica e sua comparação com os resultados obtidos a partir de um modelo teórico. Certamente que um período maior de observações associado ao cuidado de manter o instrumento na mesma região de operação levará a resultados mais precisos com relação ao modelo de maré terrestre, à determinação dos efeitos de carga oceânica, e à determinação de uma possível tendência. Outro fator que deve ser observado nas próximas análises é o comportamento da carga atmosférica e a sua correção junto às observações gravimétricas.

Diante do que foi exposto neste trabalho, recomenda-se o prosseguimento das análises tanto para as observações maregráficas quanto GPS na estação de Cananéia. Além disso, o mesmo estudo deve ser realizado na estação do IOUSP em Ubatuba a qual possui estrutura semelhante. 


\section{Referências}

ANDERSEN, O. B.; WOODWORTH, P. L.; FLATHER, R. A. Intercomparison of recent ocean tide models. Journal of Geophysical Research, v. 100, p. 25261-25282, 1995.

CARTWRIGHT, D. E.; RAY, R. D. Oceanic tides from geosat altimetry. Journal of Research Geophysical, v. 99, p. 3069-3090, 1990.

DOUGLAS, B. C.; KEARNEY, M. S.; LEATHERMAN, S. P. Sea Level Rise: History and Consequences. [S.1.]: Academic Press, 2001.

DUCARME, B. Introduction to the theory of tides. Notas de aula. 2005.

DUCARME, B. et al. New analysis of tidal and non tidal signals in a 50 years tide gauge record at cananéia (SP - brazil) with the VAV tidal analysis program. In: IAPSO 2005. [S.l.: s.n.], 2005.

EANES, R. J.; BETTADPUR, S. The CSR3.0 Global Ocean Tide Model. CSR-TM-95-06. [S.l.], 1995.

EGBERT, G. D.; EROFEEVA, S. Y. Efficient inverse modeling of barotropic ocean tides. Journal of Oceanic and Atmospheric Technology, v. 19(2), p. 761-797, 2002.

FREITAS, S. R. C. de. Marés Gravimétricas: Implicações Para a Placa Sul-Americana. Tese (Doutorado) - Instituto Astronômico e Geofísico da Universidade de São Paulo, 1993.

GEMAEL, C. Marés Terrestres: Aplicações Geodésicas. 1986. Curso de pós-graduação em ciências geodésicas.

IPCC. Bilan 2001 des changements climatiques: Les éléments scientifiques. In: . [S.l.]: Intergovernmental Panel on Climate Changes, 2001. Rapport du Groupe de travail I du GIEC.

KANIUTH, K.; VETTER, S. Vertical velocities of european coastal sites derived from continuous GPS observations. GPS Solutions, v. 9, p. 32-40, 2005.

KANTHA, L. H. Barometric tides in the global oceans from a nonlinear tidal model assimilating altimetric tides. part 1: Model description and results. Journal of Geophysic, v. 100 , p. $25283-25308,1995$.

KHAN, S. A.; SCHERNECK, H.-G. The m2 ocean tide loading wave in alaska: Vertical and horizontal displacements, modelled and observed. Journal of Geodesy, v. 77, p. 117$127,2003$. 
MATSUMOTO, K.; TAKANEZAWA, T.; OOE, M. Ocean tide models developed by assimilating TOPEX/POSEIDON altimeter data into hydrodynamical model: A global model and a regional model around japan. Journal of Oceanography, v. 56, p. 567-581, 2000.

MAZZEGA, P.; MERGE, M.; FRANCIS, O. TOPEX/POSEIDON tides: The OMP2 atlas (abstract). Eos Trans. AGU, 75(44), Fall Meet., p. 61, 1994.

MELCHIOR, P. The Tides of the Planet Earth. [S.1.]: Pergamon Press, 1983.

MESQUITA, A. R.; FRANÇA, C. A. S. Sumário de Marés Oceânicas, Notas de Aula Preparadas Para O Curso de Observacion Y Analysis Del Nivel Del Mar. 1996.

MESQUITA, A. R. de et al. Analysis of the mean sea level from a 50 years tide gauge record and GPS observations at cananéia. In: IAPSO. [S.l.], 2005.

MESQUITA, A. R. de; HARARI, J.; FRANÇA, C. A. de S. Interannual variability of tides and sea level at cananéia, brazil, from 1955 to 1990. Publção esp. Inst. oceanogr., S Paulo, p. 11-20, 1995.

MORETTIN, P. A. Ondas e Ondaletas: Da Análise de Fourier À Análise de Ondaletas. [S.1.]: EDUSP, 1999.

PIRAZZOLI, P. A. Sea-Level Changes: The Last 20.000 Years. [S.1.]: John Wiley \& Sons, 1996.

POSADA, D.; BUCKLEY, T. R. Model selection and model averaging in phylogenetics: Advantages of akaike information criterion and bayesian approaches over likelihood ratio tests. Systematic Biology, v. 5, p. 793-808, 2004.

PROvost, C. L.; BEnNETT, F.; CARTWRIGHT, D. E. Ocean tides for and from Topes/Poseidon. Science, v. 267, p. 639-642, 1995.

PROVOST, C. L. et al. Spectroscopy of the world ocean tides from a finite-element hydrodynamic model. Journal of Geophysical Research, v. 99, p. 24777-24797, 1994.

PROVOST, C. L. et al. A hydrodynamic ocean tide model improved by assimilating a satellite altimeter-derived data set. Journal of Geophysical Research, v. 103, p. 5513-5529, 1998.

RAY, R. D. A Global Ocean Tide Model from TOPEX/Poseidon Altimeter: GOT99.2. [S.l.], 1999.

SCHWAB, S. H. S. Marés Gravimétricas, Influências Ambientais e Calibração Instrumental: Estudos Na Estação Curitiba. Tese (Doutorado) — Universidade Federal do Paraná, 1999.

SCHWIDERSKI, E. W. Ocean tides, II, a hydrodynamic interpolation model. Marine Geodesy, v. 3, p. 219-255, 1980.

TORGE, W. Gravimetry. [S.1.]: Walter de Gruyter, 1989.

TORGE, W. Geodesy. 3rd. ed. [S.1.]: Walter de Gruyter, 2001. 
TRABAnCO, J. L. A. Conceitos e Técnicas Modernas de Monitoramento Da Crosta Terrestre e Sua Vinculação Com O Estudo Do Nivel Médio Do Mar - Uma Análise Das Estações Maregráficas de Cananéia e Ubatuba. Tese (Doutorado) - Escola Politécnica da Universidade de São Paulo, 2003.

URSCHE, C. et al. Validating ocean tide loading models using GPS. Journal of geodesy, v. 78, p. $616-625,2005$.

VAUTERIN, M. V. C. . P. Tsoft: Graphical and interactive software for the analysis of time series and earth tides. Computers \& Geosciences, p. 31(5) 631-640, 2005.

VENEDIKOV, A. P.; ARNOSO, J.; VIEIRA, R. VAV: A program for tidal data processing. Computers 85 Geosciences, v. 29, p. 487-502, 2003.

WEBER, R. et al. GPS / GLONASS and Tidal Effects. [S.1.], 1997.

WENZEL, H.-G. The nanogal software: Earth tide data processing package ETERNA. Bulletin d'Information des Marées Terrestres, v. 99, p. 9425-9439, 1994.

ZAHRAN, K. H.; JENTZSCH, G.; SEEBER, G. World wide synthetic tide parameters for gravity, vertical and horizontal displacements. Journal of Geodesy, v. 79, p. 293-299, 2005 . 